Illinois State University

ISU ReD: Research and eData

Theses and Dissertations

$10-1-2013$

\title{
The effects of manipulating problem completion rates on assignment choice and preference consistency
}

Kiley Bliss

Illinois State University, kbliss114@yahoo.com

Follow this and additional works at: https://ir.library.illinoisstate.edu/etd

Part of the Psychology Commons

\section{Recommended Citation}

Bliss, Kiley, "The effects of manipulating problem completion rates on assignment choice and preference consistency" (2013). Theses and Dissertations. 37.

https://ir.library.illinoisstate.edu/etd/37

This Dissertation is brought to you for free and open access by ISU ReD: Research and eData. It has been accepted for inclusion in Theses and Dissertations by an authorized administrator of ISU ReD: Research and eData. For more information, please contact ISUReD@ilstu.edu. 


\title{
THE EFFECTS OF MANIPULATING PROBLEM COMPLETION \\ RATES ON ASSIGNMENT CHOICE AND \\ PREFERENCE CONSISTENCY
}

\author{
Kiley J. Bliss
}

146 Pages

December 2013

A procedure known as mathematics interspersing provides students with additional opportunities (i.e., brief math problems) to complete math problems within an assignment by embedding brief additional problems among longer target problems. Previous research (e.g., Cates \& Dalenberg, 2005) found that the more problems completed on an assignment with interspersing, the higher the likelihood the student chooses that assignment relative to an assignment without interspersing. Some students, however, choose assignments without interspersing.

The purpose of this investigation was to focus on students who do not choose assignments (i.e., non-choosers) with interspersing relative to assignments without interspersing and replicate and extend previous research (e.g., Cates \& Dalenberg, 2005) by manipulating relative problem completion rates at various fixed ratios (FR) (i.e., 0:1 [no interspersing relative to every longer problem], 1:3 [short problem following every three longer problems], and 2:1 [two short problems prior to every longer problem]). Further, students were given a choice between assignments with and without interspersing to determine choice consistency and whether a richer schedule of 
interspersing (i.e., 2:1) could influence students to choose assignment with interspersing. Participant information regarding reinforcement histories for completing mathematics assignments was also gathered.

Results showed that participants, overall, chose and completed more problems on assignments with interspersing relative to those without interspersing. Choice remained consistent for choosers, but the richest interspersing ratio caused non-choosers to choose assignments with interspersing. Non-choosers completed more total problems on assignments with interspersing for both the 1:3 and 2:1 assignment pairs. Relative problem completion rates increased for choosers and non-choosers as interspersing ratios increased. Regarding past reinforcement history, participants reported receiving positive reinforcement most often after completing math assignments in the past. The discussion focuses on potential explanations and interpretations of results, and current limitations, future research endeavors, and applied functions of interspersing are also discussed. 
THE EFFECTS OF MANIPULATING PROBLEM COMPLETION

\section{RATES ON ASSIGNMENT CHOICE AND}

PREFERENCE CONSISTENCY

KILEY J. BLISS

A Dissertation Submitted in Partial

Fulfillment of the Requirements

for the Degree of

DOCTOR OF PHILOSOPHY

Department of Psychology

ILLINOIS STATE UNIVERSITY

2013 
Copyright 2013 Kiley J. Bliss 


\section{THE EFFECTS OF MANIPULATING PROBLEM COMPLETION \\ RATES ON ASSIGNMENT CHOICE AND \\ PREFERENCE CONSISTENCY}

KILEY J. BLISS

COMMITTEE MEMBERS:

Gary L. Cates, Chair

Thomas S. Critchfield

Valeri A. Farmer-Dougan

Christopher H. Skinner 


\section{ACKNOWLEDGMENTS}

I would like to thank Dr. Gary Cates for his support and guidance as the chair for this dissertation and as my advisor throughout my tenure in Illinois State University's School Psychology program. Dr. Cates has helped cultivate my research and clinical interests and taught me important skills for practicing as a professional psychologist and academician. I have developed a lot since I first began in this program and Dr. Cates has been an integral part of that development.

I would also like to thank Kerry Pecho, Jessica Fisher, and Brooke Harris for their hard work and reliability throughout the IRB, data collection, and analyses portions of this project. Working from Atlanta, GA, I literally could not have completed this project in the timely manner I have without their help. They clearly are dedicated, dependable, and intelligent people who have bright professional futures ahead of them.

Lastly, I would like to thank the faculty members who supported me as part of my committee: Dr. Thomas Critchfield, Dr. Valeri Farmer-Dougan, and Dr. Christopher Skinner. I have worked with Dr. Critchfield and Dr. Farmer-Dougan in alternative capacities and have been honored to have their support throughout this process. Dr. Skinner, I appreciate your availability and feedback and your previous research and expertise in the area of mathematics interspersing shaped the design of this project.

K.J.B. 


\section{CONTENTS}

Page

ACKNOWLEDGMENTS $\quad$ i

CONTENTS

TABLES

FIGURES vi

CHAPTER

I. INTRODUCTION 1

Research Questions and Hypotheses 3

II. GENERAL LITERATURE REVIEW 8

Choice 9

Matching Law 13

Mathematics Interspersing $\quad 20$

$\begin{array}{lll}\text { III. STUDY } & 41\end{array}$

Purpose 41

Method 45

Participants $\quad 45$

Materials 46

Procedure 48 Design, Dependent Variables,
and Data Analysis

Hypotheses $\quad 53$

$\begin{array}{ll}\text { Results } & 55\end{array}$

Choice and Preference $\quad 55$

Target Problems Completed $\quad 73$ 
Academic Performance Accuracy

Total Problems Completed

Relative Problem Completion Rates

VII. GENERAL DISCUSSION

Summary and Implications of Current Study

REFERENCES

APPENDIX A: $\quad$ Informed Consent

APPENDIX B: $\quad$ Psychology Department Research Participation Form

APPENDIX C: $\quad$ Research Participation Sign-Up Sheet

APPENDIX D: $\quad$ Demographic Form

APPENDIX E: $\quad$ Math Assignment Preference Questionnaire

APPENDIX F: $\quad$ Debriefing Statement

APPENDIX G: $\quad$ Reinforcement History Questionnaire

APPENDIX H: $\quad$ Math Assignment: 0:1 Ratio Experimental Worksheet

APPENDIX I: $\quad$ Math Assignment: 0:1 Ratio Control Worksheet

APPENDIX J: $\quad$ Math Assignment: 1:3 Ratio Experimental Worksheet

APPENDIX K: $\quad$ Math Assignment: 1:3 Ratio Control Worksheet

APPENDIX L: $\quad$ Math Assignment: 2:1 Ratio Experimental Worksheet

APPENDIX M: $\quad$ Math Assignment: 2:1 Ratio Control Worksheet

APPENDIX N: $\quad$ Procedural Protocol

APPENDIX O: $\quad$ Procedural Script

APPENDIX P: $\quad$ Training Fidelity Checklist 


\section{TABLES}

Table

Page

1. Aggregate Student Choice Frequencies for Homework Assignment and Preferences for Experimental and Control Assignments as More Difficult, More Time-Consuming, More Effortful to Complete, and Choice for Homework

2. Chooser Choice Frequencies for Homework Assignment and Preferences for Experimental and Control Assignments as More Difficult, More Time-Consuming, More Effortful to Complete, and Choice for Homework

3. Chooser Choice Frequencies for Homework Assignment and Preferences for Experimental and Control Assignments as More Difficult, More Time-Consuming, More Effortful to Complete, and Choice for Homework

4. Non-Chooser Choice Frequencies for Homework Assignment and Preferences for Experimental and Control Assignments as More Difficult, More Time-Consuming, More Effortful to Complete, and Choice for Homework

5. Non-Chooser Choice Frequencies for Homework Assignment and Preferences for Experimental and Control Assignments as More Difficult, More

Time-Consuming, and More Effortful to Complete

6. Mean Target Problems Completed Among

Interspersing Ratios For Choosers, Non-Choosers, and Collapsed Across Groups

7. Mean Academic Performance Accuracy as a 
Percentage Among Interspersing Ratios For Choosers, Non-Choosers, and Collapsed Across Groups

8. Mean Total Problems Completed Among Interspersing

Ratios For Choosers, Non-Choosers, and Collapsed

Across Groups

9. Mean Relative Problem Completion Rates (RPCR)

Among Interspersing Ratios For Choosers,

Non-Choosers, and Collapsed Across Groups

10. Mean Percentage of Time Consequences Following a

Past Assignment Reported For Choosers,

Non-Choosers, and Collapsed Across Groups 


\section{FIGURES}

Figure

Page

1. Choice Proportion for Experimental Assignments with Interspersing as a Function of Relative

Problem Completion Rates Across the Three Ratios of Interspersing 


\section{CHAPTER I}

\section{INTRODUCTION}

Although people might tend to engage in behavior that they enjoy doing, an individual's behavior varies as a function of the person and the situation (Mischel, Shoda, \& Mendoza-Denton, 2002). That is, the person, as a conglomeration of environmental and behavioral histories, interacts conditionally with environmental signals and contingencies. No concept of human behavior might be truer than when considering student academic behavior. For example, it has been established that students who demonstrate lower math fluency rates report higher levels of math anxiety (Cates \& Rhymer, 2003) and also are less likely to engage in math related activities such as taking more complex math courses (LeFevre, Kulak, \& Heymans, 1992). Since students with increased skill fluency require less effortful responding and contact more reinforcement for completing assignments, such as gaining access to preferred activities, teacher praise, or simply escaping the assignment (Billington, Skinner, \& Cruchon, 2002), increased rates of responding might decrease aversive person-situation experiences (e.g., math anxiety; Poncy, Skinner, \& Jaspers, 2007). Students, thus, might choose to engage or not engage in certain academic behaviors as a result of aversive (e.g., anxiety, insufficient learning history) or positive (e.g., earning good grades) person-situation experiences.

Conditional student behavior has implications for academic performance and 
learning. Positive student learning is strongly related to academic engage time (Bloom, 1974; DiPerna, Volpe, \& Elliot, 2002; Greenwood, Horton, \& Utley, 2002; Greenwood, Delquadri, \& Hall, 1984; Greenwood, Terry, Marquis, \& Walker, 1994). Developing academic tasks that improve academic engagement, therefore, is critical. In other words, creating academic tasks in which students choose to engage and enjoy doing is important. Previous research suggests that school-age students choose to work on a math assignment containing higher rates of reinforcement relative to another similar assignment (e.g., Billington, Skinner, \& Crichon, 2004; Cates \& Erkfritz, 2007; Cates \& Skinner, 2000; Logan \& Skinner, 1998; McDonald \& Ardoin, 2007; Wildmon, Skinner, Watson, \& Garrett, 2004). Hypotheses regarding why students engage in academic tasks, thus, have emerged through empirical research.

One hypothesis for explaining student choice for and engagement with certain tasks relative to others is the discrete task completion hypothesis. The discrete task completion hypothesis states that students are more likely to prefer academic assignments that result in high problem completion rates relative to academic assignments that result in lower problem completion rates (Skinner, 2002). The majority of research investigating the discrete task completion hypothesis, however, has done so from a group design perspective. Specifically, groups of students have had opportunities to work on two or more assignments and then respond to questions related to their preferences for the two opposing assignments. On average, students are more likely to choose assignments that produce higher rates of problem completion. Not all students, however, choose assignments that are constructed with the intention of providing more reinforcement relative to opposing, similar assignments. Perhaps students who do not show preferences 
similar to their peers for academic assignments have individual differences in relative assignment completion rates. To understand fully the discrete task completion hypothesis, researchers ought to study preference for academic assignments with participants who initially (i.e., prior to task completion) demonstrate assignment preferences dissimilar to their peers.

The current investigation, therefore, tested the discrete task completion hypothesis with specific emphasis on preferences and choice of students who do not initially show preferences and choice similar to their peers (i.e., non-choosers). The overarching hypothesis for this investigation is that non-choosers do not contact reinforcement sufficiently within assignments. Non-choosers, thus, may require more opportunities to contact reinforcement within assignments (i.e., completing more problems). It is hypothesized, therefore, that non-choosers require assignments to be constructed in a manner that further increases the probability of higher problem completion rates (i.e., more opportunities to respond).

\section{Research Questions and Hypotheses}

Does manipulating the schedules of interspersing among math assignments influence choice consistency for such assignments?

According to the discrete task completion hypothesis, students choose and prefer assignments with interspersing due to increased conditioned reinforcement (Skinner, 2002). Specifically, students' learning histories are based on contacting reinforcement (e.g., escaping the task) contingent upon total assignment completion, and completing each problem within an assignment functions as conditioned reinforcement (i.e., signaling that the onset of reinforcement for task completion is closer; Skinner, 2002). 
Regarding math interspersing procedures, assignments with additional brief problems interspersed among longer problems provide students with increased rates of conditioned reinforcement relative to assignments without brief problems interspersed (e.g., Billington, Skinner, Hutchins, \& Malone, 2004; Cates \& Skinner, 2000; Wildmon et al., 2004).

Within the interspersing research, moreover, relative problem completion rates (i.e., the number of problems completed on an assignment with interspersing relative to a control assignment) have been demonstrated to account for students' choice for assignments with interspersing (e.g., Cates \& Skinner, 2000; Cates \& Dalenberg, 2005; Cates \& Erkfritz, 2007; Logan \& Skinner, 1998; Wildmon et al., 2004). Choice for such assignments, therefore, would presumably vary as a function of manipulating relative problem completion rates. This study, thus, was constructed to investigate the effects that manipulating the rates of problem interspersing within assignments had on student choice for math assignments.

The purpose of the current investigation was to replicate previous research by Cates and Dalenberg (2005) to determine the consistency of students' choice for assignments within pairs as interspersing ratios were systematically manipulated across assignment pairs. Specifically, students completed matched assignment pairs (i.e., control and experimental assignment). One assignment pair (i.e., 0:1) contained two matched control assignments (i.e., only 2-digit x 2-digit multiplication problems), both without interspersing. The ensuing assignment pairs (i.e., 1:3 and 2:1) also contained two matched assignments: one control and one experimental (i.e., 1-digit x 1-digit multiplication problems interspersed among longer $2 \times 2$ multiplication problems). These 
$1 x 1$ problems were placed among longer problems at two different fixed ratios (FR): 2:1 (two brief problems interspersed prior to every longer problem) and 1:3 (one short problem following every third longer problem). Students also completed a preference and choice questionnaire after each assignment pair.

Although the findings on interspersing are generally robust regarding choosing an experimental assignment with interspersing relative to a control assignment without interspersing, some people (i.e., non-choosers) continue to choose the control assignment despite the higher rates of reinforcement provided by interspersing procedures. One hypothesis is that non-choosers are not matching their choice behavior based on variables (e.g., stimuli associated with assignment time and effort) not previously measured. Another hypothesis is that non-choosers are not contacting sufficient rates of reinforcement that would change their choice behavior. If the matching law's account of choice behavior is accurate, two implications are important: a) identifying non-choosers and their choices between assignments might lead to a better understanding of the mechanisms operating within interspersing procedures; and b) interspersing procedures can be altered to manipulate non-choosers' choice behavior. Understanding how to further manipulate student choice for academic assignments could also have beneficial applied consequences.

In addition to replicating the Cates \& Dalenberg (2005) study, therefore, the purpose of this study was also to extend it in four ways. First, a richer schedule of reinforcement was implemented by interspersing brief problems among longer problems at a fixed-ratio of 2:1 (i.e., two brief problems interspersed prior to every longer problem). Second, chooser and non-chooser choice and preference for assignments were 
compared across the interspersing schedules. Third, assignment choice and preference consistency across assignments was measured both within and between choosers and non-choosers. Lastly, this investigation extended the Cates \& Dalenberg (2005) study by asking participants to provide information regarding their reinforcement histories for completing math assignments.

Since relative problem completion rates account for students' choices for assignments with interspersing relative to assignments without interspersing (Skinner, 2002), but some students do not choose the assignments with interspersing, data for choices between assignments in the 0:1 (i.e., no interspersing relative to every longer problem) assignment pair were analyzed between choosers and non-choosers to determine whether differences already exist prior to providing assignments with interspersing. That is, data analysis would facilitate an understanding of the preexisting tendency of non-choosers to choose one assignment over another even though the assignments are the same.

It was hypothesized that non-choosers would demonstrate statistically significantly higher relative problem completion rates for one assignment within the first assignment pair (i.e., control vs. control). These differences in relative problem completion rates would occur because of an insufficient reinforcement history for completing math assignments, which accounts for not matching responding given similar assignments providing equal rates of reinforcement. It was hypothesized that choosers, on the other hand, would demonstrate no statistically significant differences in relative problem completion rates between assignments in the first assignment pair. Chooser's relative problem completion rates would not differ due to an established reinforcement 
history for completing math assignments, which accounts for matching responding given similar assignments providing equal rates of reinforcement.

It was also hypothesized that non-choosers would change their choice behavior as they contacted assignments with richer schedules of interspersing (i.e., reinforcement). Specifically, it was hypothesized that statistically significantly more non-choosers would choose assignments with interspersing with a 2:1 schedule than with the 1:3 schedule. Data analysis focused on non-choosers to test whether problem completion was a reinforcing event (i.e., change student choice behavior). That is, this study extended the current math interspersing literature by determining whether these students demonstrated consistent choice as reinforcement rates were systematically manipulated (i.e., increased or decreased) across assignments.

Since rate of reinforcement seems to have an impact on student preferences for academic tasks (Cates \& Dalenberg, 2005; Cates \& Erkfritz, 2007; Hawkins, Skinner, \& Oliver, 2005), past reinforcement history with completing assignments could have a potential impact on effects of current rates of reinforcement on student preferences. In the current study, participants completed a questionnaire asking about the consequences contacted after completing past math assignments. This questionnaire was exploratory and was designed to further investigate assumptions of the discrete task completion hypothesis. Specifically, if students are hypothesized to have contacted reinforcement for completing math assignments in the past such that the individual math problems within an assignment have become conditioned reinforcement, then understanding the consequences that students have actually contacted after completing math assignments should inform choice and academic performance data. 


\section{CHAPTER II}

\section{GENERAL LITERATURE REVIEW}

Increasing academic achievement and enhancing learning are two feasible outcomes facilitated by engaging students in academic tasks (Bloom, 1974; DiPerna et al., 2002; Greenwood et al., 2002; Greenwood et al., 1984; Greenwood et al., 1994). Decreasing nonacademic related activities (e.g., out-of-seat behaviors, talking to peers, looking out the window) is an important process for combatting detriments to scholastic learning and achievement (DuPaul \& Stoner, 2003; Vile Junod, DuPaul, Jitendra, Volpe, \& Cleary, 2006). Maximizing student academic performance, thus, is the main purpose of increasing study behavior and academic engagement (Kirby \& Shields, 1972). Some research has explored implementing external contingency behavior interventions to decrease inappropriate and disruptive behavior while increasing student task engagement and assignment completion (Brooks, Todd, Tofflemoyer, \& Horner, 2003; Lane, Smither, Huseman, Guffey, Fox, 2007; Rock, 2005; Thorne \& Kamps, 2008; Wallace, Cox, \& Skinner, 2003).

In one study, for example, investigators explored teaching academic on-task skills paired with generalized self-monitoring (Brooks et al., 2003). An elementary-school-age girl learned self-monitoring academic engagement skills for appropriately contacting peer and teacher attention. Results of the self-management intervention package demonstrated 
increased rates of academic engagement behavior and assignment completion in the classroom. Similarly, Lane, Smither, Huseman, Guffey, and Fox (2007) implemented an intervention package (i.e., student self-monitoring, differential reinforcement with teacher praise, and positive home notes) that significantly increased an elementary school student's percentage of academic engaged time and decreased total disruptive behavior percentages in the general education classroom. This study demonstrates a clear inverse relationship between academic engaged time and nonacademic related behavior.

Students, consequently, might engage in inappropriate or disruptive behaviors, as opposed to engaging in academic tasks, for a multitude of reasons. Perhaps students have not learned the prerequisite skills required for completing academic assignments; students might lack sufficient time to complete such assignments; or perhaps the academic task is too effortful (Skinner, Pappas, \& Davis, 2005). Disruptive and off-task behaviors might be maintained by the higher reinforcement rates and values of teacher or peer attention (e.g., Brooks et al.; Lane et al., 2007). Students, therefore, who have learned the skills required for completing an academic task, but refuse to complete such a task (i.e., engaging in alternative activities), are choosing to engage in alternative activities (Skinner et al., 2005).

\section{Choice}

Researchers have also demonstrated that decreasing disruptive, off-task behaviors and increasing academic engaged time can be achieved by providing students with choices for academic tasks (Dunlap et al., 1994; Dunlap \& Kern, 1996; Dunlap et al., 1991; Dyer et al., 1990; Kern et al., 2001; Von Mizener \& Williams, 2009). For example, Dunlap and colleagues (1994) demonstrated with two 11-year-old boys 
diagnosed with an emotional handicap that task engagement was markedly higher than disruptive behavior during sessions where the boys chose from a menu of academic tasks to complete. In a second study conducted with a third five-year-old boy diagnosed with severe emotional disturbance, the investigators obtained similar results to study one, while also demonstrating with a yoked control condition the differential effects of choice versus preference. That is, when given the choice of what books to read, task engagement levels were high and disruptive behavior levels were low. Opposite task engagement and disruptive behaviors were observed when the boy was provided the same books but no choice (Dunlap et al., 1994). Relevant conclusions are twofold: one, providing choice for academic tasks, regardless of preference, reinforced positive engagement behaviors, and two, choice effects on academic task engagement behaviors were stronger than preference effects.

In another applied example of the positive effects of choice, Kern, Mantegna, Vorndran, Bailin, and Hilt (2001) manipulated task choice (i.e., choice vs. no choice) and measured problem behavior rates and percentage of task engagement in a reversal design. Two school-aged children and one adolescent participated, all of whom demonstrated behavior problems. In both choice conditions participants completed academic or daily living activity tasks and contacted social reinforcement (i.e., verbal praise) contingent upon task completion. Results showed, overall, that participant task engagement percentages were higher when provided with task choice than when no choice was provided. Further, participant problem behavior rates were lower when provided with task choice than when no choice was provided. This study demonstrated the beneficial effects of a minimal effort intervention and the results support the reinforcement value of 
choice for programmed or required tasks.

As demonstrated in the above empirical examples (i.e., Dunlap et al., 1994; Kern et al., 2001), choice increases positive engagement behaviors and choice itself may be reinforcement (i.e., increasing target response rates). Students' choices to engage in academic tasks over nonacademic tasks, moreover, may be influenced by the rates of reinforcement of the two tasks (Mace, McCurdy, \& Quigley, 1990; Martens, Lochner, \& Kelly, 1992; Neef, Mace, Shea, \& Shade, 1992; Neef, Mace, \& Shade, 1993; Neef, Shade, \& Miller, 1994; Wallace et al., 2003). As an example, Wallace, Cox, and Skinner (2003) manipulated assignment presentation procedures and consequences for assignment completion in a classroom with a 10 -year-old male diagnosed with mild mental retardation. In an $\mathrm{ABAB}$ reversal design baseline procedures included providing a worksheet with 30 subtraction problems (i.e., typical morning seatwork routine). Intervention procedures differed in that multiple worksheets with fewer problems (e.g., six subtraction) were provided at one time. The student, upon self-monitoring problem completion, sought positive reinforcement from his teacher (i.e., receiving a "high five" paired with verbal praise) and received another brief worksheet. Results showed that, during intervention phases, teacher disapprovals decreased and approvals increased. Concurrently, the student completed a higher number of problems during intervention phases compared to baseline phases. Implications for this study include conceptualizing any or all of the intervention components (i.e., decreasing assignment length, introducing self-monitoring, implementing teacher praise) as either positive (e.g., problem completion rate increases) or negative (e.g., decreases in teacher disapproval) reinforcement (Wallace et al., 2003). One might assume from this study that 
manipulating the consequent relative rates of reinforcement among academic tasks would differentially affect students' academic engagement and choices for such tasks.

Wallace et al. (2003) demonstrated the positive effects of choice using a fixed ratio schedule of reinforcement for assignments completion. In another study, multiple variable-interval schedules of reinforcement were implemented to increase academic responding (Martens, et al., 1992). Two male students (ages 10 and 9 years) identified as demonstrating off-task and frequent inappropriate behavior participated in their respective classrooms. In an $\mathrm{ABCDE}$ design the students engaged in academic tasks and received verbal praise from an experimenter, contingent upon task engagement, on one of four variable-interval (VI) reinforcement schedules (i.e., VI 5 min., VI 4 min., VI 3 min., VI 2 min.). Reinforcement schedule richness increased systematically across intervention phases. Results demonstrated that trends across intervention phases for the percentage of student academic engagement increased. That is, academic engagement increased as reinforcement schedules became richer. Further, when the data were plotted as mean percent engagement and obtained reinforcement per hour, student mean percent engagement for each VI schedule across all four intervention phases fit a mathematical equation that accounted for $99 \%$ and $88 \%$ of the variance in engagement for the two students, respectively. Conceptually, students in this study chose to engage in an academic task, as opposed to an alternative behavior (Herrnstein, 1970, 1974), due to the increased relative reinforcements gained contingent upon academic engagement. The above study conducted by Martens, Lochner, and Kelly (1992) demonstrates an example of applying a quantitative account of choice behavior known as matching law. 


\section{Matching Law}

Many early basic research investigators of choice behavior sought to explain and predict such behavior by deriving and applying mathematical formulas. Generally, experimenters in these studies presented pigeons with opportunities to peck on simultaneously and continuously available keys, where reinforcement for both keys was determined by independent variable interval schedules (i.e., concurrent schedules of reinforcement). Results have demonstrated a reliable relation between relative rates of responding and relative rates of reinforcement obtained for such responding (e.g., Baum \& Rachlin, 1969; Catania, 1963a, 1963b; Chung \& Herrnstein, 1967; Fantino, 1967, 1968, 1969; Herrnstein, 1961, 1970, 1974; Reynolds, 1963).

Herrnstein $(1961,1970)$ found that the quantitative value of relative behavioral responding, given two concurrent operant alternatives, equaled the quantitative value of relative reinforcements obtained for such responding. That is, the comparison of responding for one operant alternative to both possible alternatives (i.e., $R_{1} / R_{1}+R_{2}$ ) matched the comparison of reinforcement received for the first operant alternative to reinforcements obtained for both alternatives (i.e., $\mathrm{r}_{1} / \mathrm{r}_{1}+\mathrm{r}_{2}$ ). Matching relative response rates to relative reinforcement rates, therefore, is accounted for by the independence of operant alternatives (Herrnstein, 1961). In mathematical form, the matching relation is represented proportionally as $B_{1} / B_{1}+B_{2}=r_{1} / r_{1}+r_{2}$ (Herrnstein, 1961, 1970; Reynolds, 1963), where B denotes behavioral responding and $\mathrm{r}$ denotes reinforcement obtained for such responding. The subscript numbers 1 and 2 indicate operant choice alternatives (e.g., pecking key one versus key two). Known as matching law, the above equation quantitatively explains that when faced with two choices, and all else is held constant, an 
organism will likely choose to engage in the behavior that results in a higher relative rate of reinforcement (Herrnstein, 1961, 1970, 1974).

For example, Herrnstein (1961) sought to clarify the properties of relative rates of responding as a function of reinforcement rates. He investigated such responding properties (i.e., pecking one of two keys) while exposing food-deprived pigeons to concurrent, independent variable interval (VI)-variable interval (VI) schedules of reinforcement. After preliminary training, three pigeons separately were placed in an experimental chamber containing two different keys. Subjects contacted reinforcement contingent upon key-pecking responses. The mean interval of reinforcement between keys served as the independent variable and was held constant across conditions at 1.5 minutes. Four VI schedules of reinforcement were employed in total, and the main dependent variable was frequency of responding (i.e., pecking) on either key. A changeover delay (i.e., penalty for switching from one key to the other) of 1.5 seconds was implemented in most conditions to prevent responding for either key from coming under control of the reinforcement schedule of the other key. That is, switching responding from one key to the other resulted in reinforcement withheld for 1.5 seconds immediately following the switch.

Results showed that, when graphed as the total percentage of responses on one key by the total percentage of reinforcements for that key, the data closely matched a line with a slope of 1.0. That is, pigeons allocated a percentage of responding to one key relative to overall responding (i.e., both key choices) that approximated (i.e., matched) the percentage of reinforcement received relative to total reinforcement received (i.e., both key choices; Herrnstein, 1961). Specifically, data fit the proportional equation 
$\mathrm{B}_{1} / \mathrm{B}_{1}+\mathrm{B}_{2}=\mathrm{r}_{1} / \mathrm{r}_{1}+\mathrm{r}_{2}$, as previously described. Herrnstein (1961) also concluded matching when a change-over delay was implemented and deviations from matching (i.e., rapid switching between keys) when a change-over delay was withheld. These results for matching were the first reported that demonstrated an empirically derived quantitative explanation for choice behavior given concurrent response alternatives and schedules of variable interval reinforcement.

Deviations from matching (e.g., undermatching, overmatching, bias) occur, however, and the proportional equation does not account well for such deviations (Myers \& Myers, 1977; Poling, et al., 2011). Undermatching describes data indicating that subjects allocate relatively more responding or time to the alternative providing less reinforcement, whereas overmatching describes data indicating that subjects allocate relatively more responding or time to the alternative providing more reinforcement (Poling et al.). Quantitatively, positive deviations from 1.0 in the slope of the regression equation accounting for matching (i.e., $a$ ) indicate overmatching. Deviations in the slope less than 1.0, conversely, indicate undermatching (Baum, 1979; Meyers \& Meyers, 1977).

Extraneous variables can also account for deviations from matching. Response bias, for example, describes how some reinforcement may have higher value than other reinforcement, and how some responses may have more value than alternative responses. These differences in reinforcement and responses account for biased responding (McDowell, 1989). Bias thus is quantitatively expressed as the y-intercept of the regression equation accounting for matching (i.e., $k$ ) where deviations (i.e., positive or negative direction) in $k$ from 0.0 suggest response preference towards one response 
alternative over another (Baum, 1974).

Regardless of the deviations from matching behavior, the logarithmic proportional equations discussed above have been found in one study to account for an average $90 \%$ of the variance in slopes derived from 103 data sets (Baum, 1979). Extrapolating from Herrnstein's (1961) original study, wide support and replication for matching exists for the proportional relationship between operant responses and reinforcements obtained as a proper quantitative expression of choice behavior. Research subjects include a variety of animal species: pigeons (e.g., Baum, Schwendiman, \& Bell, 1999; Catania, 1963a, 1963b; Herrnstein \& Heyman, 1979; Reynolds, 1963; McSweeney, Farmer, Dougan, \& Whipple, 1986; Todorov, Castro, Hanna, Bittencourt de Sa, \& Barreto, 1983), rats (e.g., Belke \& Heyman, 1994; Heyman \& Monaghan, 1994; MacDonall, 1988), cows (e.g., Foster, Temple, Robertson, Nair, \& Poling, 1996; Matthews \& Temple, 1979), hens (e.g., McAdie, Foster, \& Temple, 1996), possums (e.g., Bron, Sumpter, Foster, \& Temple, 2003), goats (e.g., Foster, Matthews, Temple, \& Poling, 1997), and monkeys (e.g., Woolverton, \& Alling, 1999).

In addition to research with a variety of animals, the matching law has been applied to explain human behavior in the laboratory (e.g., Baum, 1975; Borerro et al., 2007; Bradshaw, Szabadi, \& Bevan, 1976, 1977, 1978; Conger \& Killeen, 1974; Horne \& Lowe, 1993; Kangas et al., 2009; Plaud, 1992; Schroeder \& Holland, 1969; see Kollins et al., 1997 for a review), related to sports behavior (e.g., Alferink, Critchfield, Hitt, \& Higgins, 2009; Reed, Critchfield, \& Martens, 2006; Stilling \& Critchfield, 2010; Vollmer \& Bourret, 2000), and in applied settings (e.g., Borrero \& Vollmer, 2002; Borrero et al., 2010; Martens \& Houk, 1989; Martens, et al., 1992; Shriver \& Kramer, 1997). In a 
laboratory experiment, for example, undergraduate students $(N=6)$ observed four ammeter dials displayed in the four corners (i.e., two on the left and two on the right) of a square viewing area (Schroeder \& Holland, 1969). Participants were instructed to watch for as many needle movements as possible in each of the four dials and to press either a left or right button according to which side they observed movement. Needle movements between left and right dials were manipulated on concurrent variable-interval schedules of reinforcement. An eye-movement camera measured participants' fixation frequency on the two left-hand and two right-hand dials. Changeover delays (i.e., none, one second, two and a half seconds) were implemented across sessions and participants. Investigators defined a changeover as looking horizontally or diagonally between left and right dials. Results showed that participants matched relative eye-movement rates to relative reinforcement rates, and implementing a changeover delay affected matching. Specifically, the one-second changeover delay produced stronger matching than the two and a half second changeover delay. Further, matching was poor with no changeover delay and worsened as the difference between concurrent schedule reinforcement rates increased.

Other laboratory investigations have demonstrated the applicability of the matching law to human behavior. In a study of social behavior, participants in a focus group matched the proportion of verbal reinforcement obtained from an individual with verbal responses toward that same individual (Conger \& Killeen, 1974). In another experimental example, Bradshaw, Szabadi, and Bevan (1976) demonstrated participants matching behavior on concurrent variable-interval variable-interval schedules of reinforcement where relative monetary reinforcements earned matched relative response 
(i.e., button pressing) rates. These studies (i.e., Bradshaw et al., 1976; Conger \& Killeen, 1974; Schroeder \& Holland, 1969) validate the universal utility of the matching law accounting for the proportional relation of relative response rates and relative reinforcement rates. That is, although a mathematical explanation for choice behavior is robust with animal subject, people's choice behavior is accounted for in the same way: people choose to respond to stimuli that produce higher rates of reinforcement relative to other stimuli. Since humans allocate more behavioral responding to behaviors that lead to higher rates of reinforcement, increasing student behaviors (e.g., choice) associated with higher academic achievement may be obtainable by intentionally programming additional reinforcement into curriculum and specific academic assignments.

Choice for behaviors associated with higher rates of reinforcement relative to behaviors associated with lower rates of reinforcement has been demonstrated with children in applied settings. One such study tested the matching law by experimentally manipulating reinforcement presented contingent upon severe problem and appropriate behavior responses (Borerro et al., 2010). Three participants who were diagnosed with developmental disabilities participated. Each participant had at least one appropriate and one problem behavior in his or her behavioral repertoire. Using a reversal design, experimenters analyzed response allocation for problem and appropriate behavior on concurrent reinforcement schedules during experimental functional analysis sessions. The experimental design included a problem behavior (i.e., rich schedule of reinforcement) condition, an appropriate behavior (i.e., rich schedule of reinforcement) condition, an equal concurrent schedules condition, and a full treatment (i.e., problem behavior put on extinction and appropriate behavior put on a continuous reinforcement 
schedule). One participant participated in tangible experimental functional analysis sessions; one participant participated in escape experimental functional analysis sessions; and one participant participated in escape and tangible experimental functional analysis sessions.

Results demonstrated that participants differentiated responding as a function of reinforcement schedule (Borerro et al., 2010). That is, when problem behavior was reinforced on a richer schedule, rates of problem behavior were higher relative to appropriate behavior responding and vice versa. Matching results demonstrated that the generalized matching equation accounted for 81 and 69 percent of variance across sessions respectively for the subject who participated in tangible and escape sessions. For the subject who participated in escape sessions, the generalized matching equation accounted for 41 percent of variance across sessions. The generalized matching equation accounted for 86 percent of variance across sessions for the subject who participated in tangible sessions. These results show that the generalized matching equation, on the whole, explained response allocation for problem and appropriate behaviors under concurrent schedules of reinforcement. Specifically, the relative rate of responding was influenced by the relative rate of reinforcement.

Researchers have also investigated the applicability of the matching law regarding student choice behavior for academic tasks (e.g., Billington \& DiTommaso, 2003; Dunlap et al., 1994; Mace et al., 1990, 1994, 1996; Neef et al., 1992, 1993, 1994; Murray \& Collins, 2000; Reed \& Martens, 2008). Students in the classroom are typically subjected to academic assignments under conditions when neither feedback nor reinforcement is presented for each discrete response (e.g., writing a word, writing the 
answer to a math problem). Completing academic tasks may be positively reinforcing events (e.g., receiving grades) or negatively reinforcing events (i.e., the assignment is complete and the student can access more preferable activities). If completing an academic assignment is a reinforcing event, then we can treat the discrete tasks within a given assignment (e.g., individual math problems) as conditioned reinforcement (Skinner, 2002). Corresponding with the matching law, increasing task completion rates within an academic assignment is akin to increasing rates of reinforcement. In considering student choice behavior for academic tasks, students should then theoretically choose an assignment with higher task completion rates (i.e., higher rates of reinforcement) relative to a similar assignment with lower task completion rates (Skinner, Robinson, Johns, Logan, \& Belfiore, 1996). Interspersing is one area of academic intervention research that applies the matching law for investigating choice behavior for academic assignments.

\section{Mathematics Interspersing}

Reinforcement rates. Math interspersing research has been plentiful since the mid-1990s (Billington \& Skinner, 2002; Billington, \& Skinner, 2006; Billington, Skinner, \& Cruchon, 2004; Billington, Skinner, Hutchins et al., 2004; Calderhead, Filter, \& Albin, 2006; Cates \& Dalenberg, 2005; Cates \& Erkfritz, 2007; Cates \& Skinner, 2000; Cates et al., 1999; Clark \& Rhymer, 2003; Hawkins et al., 2005; Jaspers, Skinner, Williams, \& Saecker, 2007; Johns, Skinner, \& Nail, 2000; Logan \& Skinner, 1998; McCurdy, Skinner, Grantham, Watson, \& Hindman, 2001; McDonald \& Ardoin, 2007; Montarello \& Martens, 2005; Rhymer \& Cates, 2006; Rhymer \& Morgan, 2005; Robinson \& Skinner, 2002; Skinner, 2002; Skinner, Fletcher, Wildmon, \& Belfiore, 1996; Skinner et al., 1999; Skinner, Hurst, Teeple, \& Meadows, 2002; Skinner, Pappas, \& Davis, 2005; 
Skinner, Robinson et al., 1996; Wildmon, Skinner, McCurdy, \& Sims, 1999; Wildmon, Skinner, \& McDade, 1998; Wildmon et al., 2004; see Cates, 2005 for a review). These procedures typically include presenting students with one or more math assignment pairs, where one assignment has longer math problems and the other contains similar longer problems with short, brief problems interspersed among the longer problems. Students, thus, are presented with opportunities to respond to two or more assignments with differentiated rates of reinforcement (i.e., multiple operants on concurrent reinforcement schedules) and asked to choose between paired assignments after completion.

For example, in a seminal study (Skinner, Robinson et al., 1996), investigators sought to extend choice research by interspersing additional brief mathematics problems among more time-consuming problems. In Experiment 1, undergraduate students ( $N=$ 55; data from 51 were analyzed) worked on a control (i.e., 3-digit x 2-digit multiplication problems) and an interspersing (i.e., similar $3 \times 2$ problems with 1-digit x 1-digit problems interspersed every third longer problem) assignment for $5 \mathrm{~min}$. and $5 \mathrm{sec}$. Problems were equated for difficulty such that the same digits in the first problem on the control assignment were rearranged in the first problem on the matching assignment with interspersing. Students completed a forced-choice form after completing both assignments where they chose which assignment would take longer to complete from start to finish, would take more effort, and which was more difficult to complete. Students also chose which of the two assignments they would prefer to complete as a third assignment (a third assignment was not actually completed). The total number of problems completed, total number of $3 \times 2$ problems completed, and percentage of $3 \times 2$ problems completed on both assignments were computed. Results showed that students 
completed significantly more total problems on the assignment with interspersing than the control assignment, and that the number and accuracy of completed $3 \times 2$ problems did not differ between assignments. Further, a significantly greater percentage of students chose the assignment with interspersing as less time consuming, difficult, and effortful. A significantly greater percentage of students also preferred the assignment with interspersing as a future assignment.

One potential explanation for the results from the above experiment is that the novelty of the assignment with interspersing was the factor that explained participant choice behavior. In Experiment 2 the investigators (Skinner, Robinson et al., 1996) sought to control for the possibility of novelty effects of the assignment with interspersing. Undergraduate students $(N=30)$ worked on three assignments: similar control assignments and assignments with interspersing from Experiment 1 and a third assignment with interspersing where 3-digit divided by 2-digit division problems were interspersed among the 3-digit x 2-digit multiplication problems. The interspersed division problems were theorized to represent novelty, but sacrificed brevity. Students indicated preferences for and choice of assignments after completing all three. Results mirrored those from Experiment 1 such that students completed more total problems on the brief assignment with interspersing (i.e., 1 x 1 problems interspersed). Students also completed significantly more $3 \times 2$ problems on both the brief interspersing and the control assignments. Overall rates of accuracy for the $3 \times 2$ problems did not differ across assignments. Rankings based on time, difficulty, and effort revealed that students rated the brief assignment with interspersing more favorable than both the control assignments and assignments with division problems interspersed, and they also chose for 
homework the assignment with brief interspersing over the other two. Further, rankings for the control assignments and assignments with division problems interspersed only differed on the dimension of effort (i.e., the control was rated less effortful). These results suggest that the brevity and ease of the interspersed items accounts for the differences in student choice and preference. Moreover, the interspersed items also account for increased problem completion rates. To rule out further explanations, the investigators demonstrated in a third experiment that the $3 \times 2$ multiplication problems across the three assignments did not differ in difficulty or time to complete.

The above studies were the first known attempts to manipulate relative problem completion rates on a mathematics assignment, and they demonstrated that students chose an assignment that resulted in significantly greater problem completion rates relative to another similar assignment. Further, these studies showed that student performance (i.e., accuracy) on target problems (i.e., 3-digit x 2-digit multiplication) was not compromised as a result of interspersing additional 1-digit x 1-digit multiplication problems (Skinner, Robinson et al., 1996).

Another early study on interspersing (Skinner, Fletcher, Wildmon, \& Belfiore, 1996) was similar in procedure to Skinner, Robinson et al. (1996), but the investigators attempted to determine whether the effort or time required to complete additional interspersed problem could explain student assignment preference. Undergraduate students $(N=53$; data were analyzed for 48$)$ worked for 4 min. on different mathematics assignments. Control assignments included 163 -digit x 2-digit multiplication problems. Experimental assignments included similar $3 \times 2$ multiplication problems (i.e., target problems) with either 2-digit divided by 1-digit division problems or 4-digit plus 4-digit 
addition problems interspersed every third target problem. After completing each assignment, students ranked them in terms of time to finish (i.e., least, moderate, most) and difficulty to finish (i.e., least, moderate, most), and students also chose one assignment as an additional assignment. Results showed that participants completed significantly more total problems on both assignments with interspersing than on the control assignment, and total problems completed were higher on the 2 divided by 1 assignment with interspersing than the $4+4$ assignment with interspersing. Additionally, participants completed significantly more $3 \times 2$ problems (i.e., target problems) on both the 2 divided by 1 interspersing and control assignments than the $4+4$ assignment with interspersing.

Difficulty and time rankings for both assignments with interspersing were significantly lower than for the control assignment. Participants ranked the 2 divided by 1 assignment with interspersing as taking significantly less time to complete than the $4+$ 4 assignment with interspersing. Results for choice revealed that significantly more students chose the 2 divided by 1 assignment with interspersing over both the $4+4$ interspersing and control assignments. These choice results, thus, support those found by Skinner, Robinson et al. (1996), namely that students chose the assignment with interspersing over a matched control assignment. The investigators assumed that students would complete the 2 divided by 1 problems in less time than the $3 \times 2$ and $4+4$ problems and that the $4+4$ problems would be rated easier than the 2 divided by 1 problems. The researchers conclude that students' choice for the 2 divided by 1 assignment with interspersing over the $3 \times 2$ control was likely a function of brevity to complete these problems; interspersing additional briefer problems, therefore, may be 
more important than interspersing less difficult problems (Skinner, Fletcher et al., 1996).

Both of the above investigations (i.e., Skinner, Fletcher et al., 1996; Skinner, Robinson et al., 1996) provided the impetus for a host of further research in the area of math interspersing and choice with both university and school-aged students (e.g., Billington, Skinner, Hutchins et al., 2002; Cates, \& Skinner, 2000; Johns, Skinner, \& Nail, 2000; Logan, \& Skinner, 1998; Robinson, \& Skinner, 2002; Skinner et al., 1999; Skinner et al., 2002; Wildmon et al., 1998; 1999). These studies continued to investigate and support theory of the increased reinforcing properties of math interspersing procedures and the matching law. Further, students tended to complete more total problems on assignments with interspersing without sacrificing accuracy for target (i.e., longer) problems, and they also tended to choose and prefer the assignments with interspersing relative to an assignment with only target problems.

Further research on math interspersing procedures has directly and systematically manipulated relative problem completion rates (e.g., manipulating interspersing ratios) to influence student choice behavior for math assignments (e.g., Cates, \& Dalenberg, 2005; Cates, \& Erkfritz, 2007; Hawkins et al., 2005). Cates and Erkfritz (2007), for example, administered mathematics worksheets to 70 middle-school-aged students. Control worksheets contained multiplication problems (i.e., 3 x 2 digit), while experimental worksheets contained similar problems with briefer problems (i.e., 1 digit x 1 digit) interspersed at various fixed ratios: a) no interspersing $(0: 1)$, b) every other $(1: 1)$, c) every third (1:3), d) or every fifth (1:5). Control and experimental worksheets were paired (i.e., four paired assignments) and students completed rating of each assignment pair after finishing both. 
Results showed that accuracy was not significantly affected by interspersing ratios. Ratio of interspersing and assignment type had no significant interaction effect for target problems completed, but students completed more target problems when brief problems were interspersed more frequently (e.g., 1:1). Specifically, relative problem completion rates were highest during the 1:1 condition. Students rated the assignments with interspersing as easier, less time-consuming, and requiring less effort in the 1:1 and 1:3 conditions. Further, student choice for the assignment with interspersing increased as problem completion rates on the assignment with interspersing increased relative to the control assignment. The correlation of relative problem completion rates on the assignments with interspersing relative to the number of problems completed on the control was 0.97 (Cates \& Erkfritz, 2007).

This study was the first to manipulate problem completion rates by manipulating interspersing ratios with school-aged students. Student choice for assignments was directly proportional to the ratio of reinforcement on the assignments. Results showed that, overall, students completed more total problems on the experimental assignments. Moreover, students completed more target problems when briefer problems were interspersed at richer ratios (e.g., 1:1). Accuracy, however, was not significantly affected by interspersing ratio. Students rated the lower ratio assignments with interspersing as easier, less time-consuming, and requiring less effort (Cates \& Erkfritz, 2007).

Cates, and Dalenberg (2005) also demonstrated the effects of manipulating relative problem completion rates, but with a group of undergraduate participants $(N=$ 60). Participants completed four assignment pairs where, for each pair, one assignment contained only 3-digit x 2-digit multiplication problems (i.e., control assignment) and the 
other sheet contained similar $3 \times 2$ problems with 1-digit $\times 1$-digit multiplication problems interspersed at various fixed ratios (i.e., no interspersing [0:1], interspersed every other long problem [1:1], interspersed every third long problem [1:3], interspersed every fifth long problem [1:5]). Participants worked each assignment sheet for 3 min. and then indicated choice and preference for either assignment for each assignment pair. Results showed that, overall, participants completed significantly more total problems on assignments with interspersing than on matched control assignments. Overall, participants preferred, assignments with interspersing for homework and rated them as less difficult, time consuming, and effortful than matched control assignments.

Analysis of relative problem completion rates revealed that as richer schedules of interspersing were employed, high relative problem completion rates were observed. Relative problem completion rates were highest for the 1:1 assignment. Students who completed significantly more problems on the assignment with interspersing relative to the control were more likely to choose the assignment with interspersing for homework. These results support the hypothesis that problem completion reinforces choice behavior and that increasing problem completion rates makes students more likely to choose an assignment. Choice for academic assignments also appears to be predictable relative to increases in problem completion rates.

Interspersing procedures, as concluded from these studies that analyzed reinforcement rates, could have some important applied implications. Decreasing nonacademic related activities (e.g., out-of-seat behaviors, talking to peers, looking out the window) is an important process for combatting detriments to scholastic learning and achievement (DuPaul \& Stoner, 2003; Vile Junod et al., 2006). Creating academic tasks 
in which students choose to engage and enjoy doing, therefore, is important. Research has shown that providing students with choices for academic tasks can decrease disruptive, off-task behaviors and increase academic engaged time (Dunlap et al., 1994; Dunlap \& Kern, 1996; Dunlap et al., 1991; Dyer et al., 1990; Kern et al., 2001; Von Mizener \& Williams, 2009). Research on interspersing has demonstrated that these procedures increase the likelihood of choosing such an assignment. These procedures could thus have a positive effect on increasing student academic engagement behavior.

On-task and engagement behavior. Math interspersing procedures have been further investigated in applied settings (e.g., schools) to determine whether these procedures can increase student on-task behavior (e.g., Calderhead et al., 2006; McCurdy et al., 2001; Montarello \& Martens, 2005; Skinner et al., 2002). In one such study (McCurdy et al., 2001) a student completed control (i.e., an unaltered curriculum assignment) and interspersing (i.e., briefer, easier problems interspersed after every third longer problem) workbook assignments based on her current math curriculum. The student completed these assignments over 16 sessions where she worked on either assignment for between $5 \mathrm{~min}$. and $15 \mathrm{~min}$. per session. Researchers observed and recorded on-task behavior data while the student worked on each assignment. Results showed that the student's on-task behavior increased $17 \%$ overall when working on assignments with interspersing. The student's average on-task behavior levels were at $72.25 \%$ during interspersing conditions, while a comparison student was on-task during $85 \%$ of the control assignments. This study demonstrated the utility of interspersing procedures in an applied setting combined with the use of the student's current curriculum. 
Another study (Skinner et al., 2002) sought to determine whether math interspersing procedures could increase the on-task behaviors of four students (aged 9 to 11 yrs.) diagnosed as emotionally disturbed. Assignments with interspersing contained the same number of similar target problems per set plus 1-digit plus or minus 1-digit problems interspersed every third target problem. Results showed that three of the four participants engaged in higher mean levels of on-task behavior while completing assignments with interspersing as opposed to control assignments. Overall, problem completion rates for assignments with interspersing were higher than control assignments across participants.

Montarello and Martens (2005) examined the effects of interspersing on student task completion rates over long, repeated intervals (i.e., persistence). The investigators compared students' $(N=4)$ total digits correct and digits correct per minute across three conditions: baseline without interspersing, brief problems interspersed every third longer problem, and interspersing plus token reinforcement. Data were collected across 15 sessions. Across 15 sessions, data showed that student persistence increased, across students, with interspersing and interspersing plus token reinforcement compared to baseline. Further, students, overall, preferred the interspersing and interspersing plus token reinforcement methods relative to baseline methods.

Math interspersing procedures are effective in increasing student perceptions (i.e., effort, time consumption, difficulty of assignment) of mathematics assignments while also accounting for student choice for these assignments relative to a more traditional academic mathematics assignment (i.e., no interspersing). Research suggests, moreover, that increasing student perceptions for academic assignments can increase the likelihood 
that they will complete such tasks. Herrnstein's $(1961,1970,1974)$ matching law generally accounts for student choice and preference such that the assignments with interspersing contain higher relative ratios of reinforcement. Understanding how interspersing procedures are responsible for positive applied effects, however, is theoretically important if educators are to employ scientifically-based interventions. Further research has investigated the causal mechanisms for the reinforcing properties of the assignments with interspersing and, specifically, the interspersed brief problems.

The discrete task completion hypothesis. Theory in math interspersing research grew in 2002 with the publication of a meta-analysis on math interspersing that posed the discrete task completion hypothesis (Skinner, 2002), which attempted to explain the causal mechanisms of interspersing procedures. Of the studies that he included in his meta-analysis, Skinner (2002) identified only two (Cates \& Skinner, 2000; Skinner, HallJohnson, Skinner, Cates, Weber, \& Johns, 1999) that reported data obtained by systematically manipulating relative problem completion rates among assignments by manipulating relative problem length/difficulty. In such a study (Skinner et al., 1999), undergraduate students $(N=109$; data were analyzed from 94) were given 4 min. and 15 sec. to work on four assignment pairs. Assignment pairs consisted of one control assignment (i.e., 18 4-digit x 1-digit, 4 x 2, 4 x 3, or 4 x 4 multiplication problems) and one matched experimental assignment with interspersing (i.e., similar 4 x 1, 4 x 2, 4 x 3, or 4 x 4 multiplication problems with $1 \times 1$ multiplication problems interspersed every third longer problem). After completing each assignment pair the participants rated both assignments according to which was more difficult, time consuming, and effortful. Students were also instructed to choose one of the two assignments to complete as a third 
assignment.

Analyses of relative problem completion rate ratios (i.e., total number of problems completed on the assignment with interspersing divided by the total number of problems completed on the control assignment) revealed that a) relative problem completion rates increased as target problems lengthened (e.g., $4 \times 1$ versus $4 \times 4$ ), b) the percentage of students who chose the experimental assignment increased as relative problem completion rate ratios increased across assignment pairs, and c) the percentage of students who rated the assignment with interspersing as less difficult, effortful, and time consuming increased as relative problem completion rate ratios increased across assignment pairs. In addition, relative problem completion rate ratios and the percentage of students who chose the assignment with interspersing and rated it more preferably for time, difficulty, and effort were significantly higher for the assignment with interspersing in the $4 \times 3$ and $4 \times 4$ conditions when compared to the $4 \times 1$ condition. By manipulating relative problem completion rate ratios, this study was the first of its kind to support the hypothesis that completing discrete problems or tasks during independent seatwork is a reinforcing behavior.

Skinner (2002) explained that research showed that academic engagement is important for increasing student learning, but that students need to choose to engage in academic tasks. Other research on choice (e.g., matching law) showed that educators could manipulate reinforcement rates (e.g., providing tokens) between differing academic behaviors and thus increase positive engagement behaviors. Skinner posed the discrete task completion hypothesis, which states that academic assignments are composed of multiple discrete tasks (e.g., individual math problems) and that students' learning 
histories include contacting reinforcement for completing an entire academic assignment. Teachers traditionally instruct students to complete a given assignment (e.g., math worksheet), and when the students complete the entire assignment they presumably contact some sort of reinforcement. Reinforcement of academic assignment completion may be positive (e.g., receiving a good grade) or negative (e.g., not receiving detention). Completion of an academic assignment, therefore, acts as conditioned reinforcement (i.e., acknowledges to a student that reinforcement follows completion of the assignment).

More specifically, within a given academic assignment completion of each discrete task (e.g., math problems) signals chained behavior (e.g., moving on to subsequent problems) and serves as conditioned reinforcement, signaling to the student that access to reinforcement (i.e., completing the entire assignment) is available sooner. For example, the student responds to the first problem on the assignment, and this initial completion of the problem serves as a secondary discriminative stimulus for the student to begin the next problem on the assignment. The student attains total assignment completion quicker as he or she continues to follow this chain of events.

Skinner (2002) argued that the implications for the discrete task completion hypothesis in the academic literature are relevant to interspersing research. Theoretically, if completing discrete tasks on assignments is reinforcing to students, then increasing the rates of problem completion on an academic task should increase rates of conditioned reinforcement and, thus, affect choice. Interspersing research at the group design level infers that student academic behavior is reinforced by completing each problem and has found that problem completion rates increase as briefer problems are added to assignments. 
In his meta-analysis Skinner (2002) sought to determine the relationship between, and predictability of, relative problem completion rates and student choice behavior from published studies on interspersing. Experiments included in the meta-analysis $(N=8)$ were required to meet the following criteria: published or accepted for publication in a nationally refereed journal; employed group design and analysis procedures; included a dependent variable of the percentage of students who chose one assignment over another; students worked on assignments containing discrete tasks; methods of adding and interspersing briefer tasks were used to alter discrete problem completion rates; relative problem completion rate data were reported across assignments; interspersing and control assignment target problems were equated across assignments; students chose between one of two assignments (i.e., a control assignment or an assignment with interspersing; Skinner, 2002).

Data from seven experiments were included in the analysis as results from one were deemed an outlier. Results from this meta-analysis revealed that relative problem completion rates could be used to predict student choice behavior correctly $97 \%$ of the time. This linear relationship was in a direction related to the matching law and strongly supported the discrete task hypothesis. A second linear regression that compared data from interspersing research to the matching law revealed that choice behavior for interspersing related to the matching law with $98 \%$ accuracy. The linear equation, however, indicated overmatching such that the matching law would have predicted fewer students to choose the assignment with interspersing. The discrete task completion hypothesis states, however, that students have different reinforcement histories for completing math assignments. Perhaps, then, the overmatching is a function of the 
contingent effects of extraneous behaviors (Herrnstein, 1970) or noncontingent reinforcement (McDowell, 1989), which are individual variables that are under the control of one's reinforcement history.

Irrespective of overmatching effects, the evidence for math interspersing strongly suggests that student choice for math assignments containing brief problems interspersed is accounted for by manipulating relative problem completion rates between assignments. Although the consistent choice results obtained in interspersing research demonstrate that students, overall, choose assignments with brief problems interspersed among longer problems relative to similar assignments without interspersing, all of these studies also consistently demonstrate that some students do not choose the assignments with interspersing. Thus, the question that remains is why some students continue to demonstrate choice for academic assignments inconsistent with the discrete task completion hypothesis. That is, why do some students choose assignments without interspersing when assignments with interspersing provide more conditioned reinforcement, consistent with reinforcement histories for completing math assignments?

The current investigation seeks to address this question under the hypothesis that those students (i.e., non-choosers) who demonstrate choice for assignments without interspersing do so because of a history of contacting insufficient reinforcement. Specifically, non-choosers have not had sufficient opportunities to respond to problems within assignments, and, therefore, have not sufficiently contacted conditioned reinforcement, accounting for their assignment choice behavior.

It is hypothesized that non-choosers require assignments to be constructed in a manner that further increases the probability of higher problem completion rates (i.e., 
more opportunities to respond). That is, as relative problem completion rates are manipulated across assignments to provide greater differentiated reinforcement between assignments in pairs, non-choosers might shift their choice to assignments with interspersing. The purpose of the current investigation, therefore, was to replicate previous research by Cates and Dalenberg (2005) regarding manipulating relative problem completion rates. The current study also sought to extend the Cates and Dalenberg study. First, a richer schedule of reinforcement was implemented by interspersing brief problems among longer problems at a fixed-ratio of 2:1 (i.e., two brief problems interspersed prior to every longer problem). Second, chooser and non-chooser choice and preference for assignments were compared across the interspersing schedules. Lastly, this investigation sought to extend the Cates \& Dalenberg study by asking participants to provide information regarding their reinforcement histories for completing math assignments.

Participants completed a questionnaire asking about the outcomes of completing past math assignments. This questionnaire was exploratory and was designed to further investigate assumptions of the discrete task completion hypothesis. Specifically, if students are hypothesized to have contacted reinforcement for completing math assignments in the past such that the individual math problems within an assignment have become conditioned reinforcers, then understanding the consequences that students have actually contacted after completing math assignments should inform choice and academic performance data. These data might also help inform whether differences in reinforcement history exist between students who choose assignments with interspersing and those who do not choose such assignments. 
Choice consistency. Results of the interspersing literature regarding such variables as choice and preference (e.g., Billington et al., 2004; Cates, \& Erkfritz, 2007; Cates \& Dalenberg, 2005; Cates \& Skinner, 2000; Hawkins et al., 2005; Logan, \& Skinner, 1998; Skinner, 2002; Skinner, Robinson et al., 1996) and academic on-task behaviors (McCurdy et al., 2001; Montarello \& Martens, 2005; Skinner et al., 2002) suggest, to a certain degree, a lasting effect of interspersing as an academic intervention. As a conclusion to his meta-analysis, Skinner (2002) suggested that future research on math interspersing should seek to determine whether the matching law more closely explains data regarding student repeated exposure to assignments with and without interspersing, paired with multiple opportunities to choose between the two. Although interspersing procedures, as an intervention, may have positive effects on student behaviors over time, interspersing literature investigating student choice over time (i.e., consistency) is overwhelmingly scarce.

McDonald and Ardoin (2007), however, found with elementary school students that, among those who were either fluent or less fluent with grade-level math facts, more students chose the assignment with interspersing relative to the control assignment across four school days. The range in percentages of those students choosing the assignment with interspersing relative to the control assignment was $73 \%-90 \%$ across the four sessions.

Rhymer and Morgan (2005) also measured student choice between assignments with interspersing and assignments without interspersing over time. Elementary school students completed an interspersing and an explicit timing assignment across three trials and then chose which assignment they preferred. Explicit timing is a procedure where 
the amount of time provided and the amount of time remaining are verbally stated at set increments while students complete the task. Rhymer and Morgan (2005) found that students chose the assignment with interspersing relative to the explicit timing assignment in all three trials. Further, the percentage of students choosing the assignment with interspersing across the three trials ranged from $71 \%$ to $76 \%$. These percentages appear consistent, but in another similar study with college students Clark and Rhymer (2003) found that student choice between explicit timing and assignments with interspersing changed over just two trials. That is, the majority of students (74\%) chose the assignment with interspersing in trial one, but just over half (58\%) of students chose a similar assignment with interspersing in trial two. These results demonstrate, thus, that previous research findings on math interspersing were not replicated in the second study. Interestingly, Clark and Rhymer (2003) pitted interspersing against explicit timing, another empirically based math intervention procedure. Although student choice for assignments with interspersing decreased from trial one to trial two, according to the matching law, we could expect students to choose equally between assignments that provide equal reinforcement. That is, although we cannot determine from the Clark and Rhymer study the relative reinforcement rates of both interventions, explicit timing, as an empirically supported intervention, presumably provides rates of reinforcement. When students demonstrated choice changes, overall, between trials one and two, perhaps they behaved as the matching law would predict. Further, students were only provided with two opportunities to choose between the two assignments. Given more than two opportunities to respond, therefore, students might have demonstrated choice shifting back to the assignments with interspersing. 
In both of the above studies (i.e., Clark and Rhymer, 2003; Rhymer and Morgan, 2005) the interspersing ratio of every third longer problem (i.e., 1:3 ratio) was held constant. The statistical significance of the differences of students who chose the assignments with interspersing between, or among, trials, however, was not reported. The extent to which students' choice for assignments with interspersing relative to control assignments, therefore, requires further investigation. This investigation, consequently, further extended the Cates and Dalenberg (2005) study by measuring assignment choice and preference consistency across assignments with interspersing both within and between participant groups (i.e., choosers and non-choosers).

Since relative problem completion rates account for students' choices for assignments with interspersing relative to assignments without interspersing (Skinner, 2002), but some students do not choose the assignments with interspersing, data for choices between assignments in the 0:1 assignment pair were analyzed between choosers and non-choosers to determine whether differences already exist prior to providing assignments with interspersing. That is, data analysis would facilitate an understanding of the preexisting tendency of non-choosers to choose one assignment over another even though the assignments are the same. Choosers and non-choosers were identified by choice for either assignment within the 1:3 assignment pair. The majority of the research on interspersing has employed a 1:3 ratio and generated consistent results regarding participant choice for the assignment with interspersing relative to one without interspersing.

It was hypothesized that non-choosers would demonstrate statistically significantly higher relative problem completion rates for one assignment within the first 
assignment pair (i.e., control vs. control). These differences in relative problem completion rates would occur because of an insufficient reinforcement history for completing math assignments, which accounts for not matching responding given similar assignments providing equal rates of reinforcement. It was hypothesized that choosers, on the other hand, would demonstrate no statistically significant differences in relative problem completion rates between assignments in the first assignment pair. Choosers' relative problem completion rates would not differ due to an established reinforcement history for completing math assignments, which accounts for matching responding given similar assignments providing equal rates of reinforcement.

Choosers were also hypothesized to demonstrate consistent choice for assignments with interspersing as relative problem completion rates increased across assignments. All non-choosers were hypothesized to choose the assignment without interspersing for the 1:3 assignment pair, but their choice was hypothesized to switch with the introduction of the 2:1 interspersing ratio (i.e., contact a higher rate of problem completion).

Overall, participant total problems completed and accuracy for total problems completed were hypothesized to not differ between assignments across interspersing ratios. Participants, overall, were hypothesized to complete more total problems on assignments with interspersing relative to assignments without interspersing for the 1:3 and 2:1 ratios. The same was hypothesized for choosers, but non-choosers were hypothesized to complete equal numbers of total problems between assignments for the 1:3 ratio. For the 2:1 ratio, however, non-choosers were hypothesized to complete more total problems on assignments with interspersing relative to assignments without 
interspersing. Relative problem completion rates, furthermore, were hypothesized to equal 1.00 for the $0: 1$ interspersing ratio and increase with the richer ratios of interspersing. Relative problem completion rates were hypothesized to be significantly higher for the 2:1 ratio relative to the 1:3 and 0:1 ratios, and relative problem completion rates for the 1:3 interspersing ratio were hypothesized to be significantly higher compared to the $0: 1$ ratio. 


\section{CHAPTER III}

\section{STUDY}

\section{Purpose}

According to the discrete task completion hypothesis, students choose and prefer assignments with interspersing due to increased conditioned reinforcement (Skinner, 2002). Specifically, students' learning histories are based on contacting reinforcement (e.g., escaping the task) contingent upon total assignment completion, and completing each problem within an assignment functions as conditioned reinforcement (i.e., signaling that the onset of reinforcement for task completion is closer; Skinner, 2002). Regarding math interspersing procedures, assignments with additional brief problems interspersed among longer problems provide students with increased rates of conditioned reinforcement relative to assignments without brief problems interspersed (e.g., Billington, Skinner, Hutchins, \& Malone, 2004; Cates \& Skinner, 2000; Wildmon et al., 2004).

Within the interspersing research, moreover, relative problem completion rates (i.e., the number of problems completed on an assignment with interspersing relative to a control assignment) have been demonstrated to account for students' choice for assignments with interspersing (e.g., Cates \& Skinner, 2000; Cates \& Dalenberg, 2005; Cates \& Erkfritz, 2007; Logan \& Skinner, 1998; Wildmon et al., 2004). Choice for such assignments, therefore, would presumably vary as a function of manipulating relative 
problem completion rates. This study, thus, was constructed to investigate the effects that manipulating the rates of problem interspersing within assignments had on student choice for math assignments.

The purpose of the current investigation was to replicate previous research by Cates and Dalenberg (2005) to determine the consistency of students' choice for assignments within pairs as interspersing ratios were systematically manipulated across assignment pairs. Specifically, students completed matched assignment pairs (i.e., control and experimental assignment). One assignment pair (i.e., 0:1) contained two matched control assignments (i.e., only 2 -digit x 2 -digit multiplication problems). The ensuing assignment pairs (i.e., 1:3 and 2:1) also contained two matched assignments: one control and one experimental (i.e., 1-digit x 1-digit multiplication problems interspersed among longer $2 \times 2$ multiplication problems). These $1 \times 1$ problems were placed among longer problems at two different fixed ratio (FR) rates: 2:1 (two brief problems interspersed prior to a longer problem) and 1:3 (every third longer problem). Students also completed a preference and choice questionnaire after each assignment pair.

Although the findings in the interspersing literature are generally robust regarding choosing an experimental assignment with interspersing relative to a control assignment without interspersing, some people continue to choose the control assignment despite the higher rates of reinforcement provided by interspersing procedures. One hypothesis is that those (i.e., non-choosers) who do not choose assignments with interspersing are not matching their choice behavior based on variables (e.g., stimuli associated with assignment time and effort) not previously measured. Another hypothesis is that nonchoosers are not contacting sufficient rates of reinforcement that would change their 
choice behavior. If the matching law's account of choice behavior is accurate, two implications are important: a) identifying non-choosers and their choices between assignments might lead to a better understanding of the mechanisms operating within interspersing procedures; and b) interspersing procedures can be altered to manipulate non-choosers' choice behavior. Understanding how to further manipulate student choice for academic assignments could have beneficial applied consequences.

In addition to replicating the Cates \& Dalenberg (2005) study, therefore, the purpose of this study was also to extend it in four ways. First, a richer schedule of reinforcement was implemented by interspersing brief problems among longer problems at a fixed-ratio of 2:1 (i.e., two brief problems interspersed prior to a longer problem). Second, chooser and non-chooser choice and preference for assignments were compared across the interspersing schedules. Third, assignment choice and preference consistency across assignments was measured both within and between choosers and non-choosers. Lastly, this investigation extended the Cates \& Dalenberg (2005) study by asking participants to provide information regarding their reinforcement histories for completing math assignments.

Since relative problem completion rates account for students' choices for assignments with interspersing relative to assignments without interspersing (Skinner, 2002), but some students do not choose the assignments with interspersing, data for choices between assignments in the 0:1 assignment pair were analyzed between choosers and non-choosers to determine whether differences already exist prior to providing assignments with interspersing. That is, data analysis would facilitate an understanding of the preexisting tendency of non-choosers to choose one assignment over another even 
though the assignments are the same. It was hypothesized that non-choosers would demonstrate statistically significantly higher relative problem completion rates for one assignment within the first assignment pair (i.e., control vs. control). These differences in relative problem completion rates would occur because of an insufficient reinforcement history for completing math assignments, which accounts for not matching responding given similar assignments providing equal rates of reinforcement. It was hypothesized that choosers, on the other hand, would demonstrate no statistically significant differences in relative problem completion rates between assignments in the first assignment pair. Chooser's relative problem completion rates would not differ due to an established reinforcement history for completing math assignments, which accounts for matching responding given similar assignments providing equal rates of reinforcement.

It was also hypothesized that non-choosers would change their choice behavior as they contacted assignments with richer schedules of interspersing (i.e., reinforcement). Specifically, it was hypothesized that statistically significantly more non-choosers would choose assignments with interspersing with a 2:1 schedule than with the 1:3 schedule. Data analysis will focus on non-choosers to test whether problem completion was a reinforcing event (i.e., change student choice behavior). That is, this study extended the current math interspersing literature by determining whether these students demonstrated consistent choice as reinforcement rates were systematically manipulated (i.e., increased or decreased) across assignments.

Participants completed a questionnaire asking about the outcomes of completing past math assignments. This questionnaire was exploratory and was designed to further investigate assumptions of the discrete task completion hypothesis. Specifically, if 
students are hypothesized to have contacted reinforcement for completing math assignments in the past such that the individual math problems within an assignment have become conditioned reinforcers, then understanding the consequences that students have actually contacted after completing math assignments should inform choice and academic performance data.

\section{Method}

\section{Participants}

Participants included undergraduate students from a Midwestern public institution. According to the G*Power analysis program (Faul, Erdfelder, Lang, \& Buchner, 2007), this study required approximately 58 to 82 undergraduate participants to obtain a small (i.e., between $\mathrm{d}=0.25$ and $\mathrm{d}=0.30)$ effect size (Cohen, 1988) for a repeated measures ANOVA for two groups and four measurements at the $\alpha=.05$ level. This study, according to the $\mathrm{G}^{*}$ Power analysis program, also required 88 participants to obtain a small (i.e., $\mathrm{w}=0.30)$ effect size $($ Cohen, 1988) for a chi-square test of independence with one degree of freedom. These samples sizes were estimated to achieve a power of .80, which is considered conventional for Type I and Type II error risks (Cohen, 1992). For the proposed study, thus, 150 participants (34 male, 115 female; one no data) were recruited. Data for nine participants were invalid (e.g., skipping problems within assignments, providing no data) and discarded during data analysis. A total of 141 participants ( 31 male, 110 female), therefore, were included in the data analysis for the current study. Participant age ranged from 18 to 40 years old with a mean age of 19.75 years $(\mathrm{SD}=2.25)$.

A notice for participating in the study (Appendices B \& C) was posted on the 
undergraduate participant pool bulletin board to recruit participants for the current study. Only students who signed up prior to the date and time listed on the sign-up sheet were allowed to participate. Further, participants under the age of 18 years old were excluded such that they were ineligible to independently sign a consent form for participation. Multiple sessions were conducted until the desired number of participants was obtained. Students who participated in the study previously, therefore, were excluded from participating a second time.

\section{Materials}

Math reinforcement history questionnaire. Participants initially completed a questionnaire (Appendix G), printed on one side of an 8.5-inch x 11-inch white sheet of paper, asking participants to respond to items related to their experiences with math assignments they completed as part of their academic history. Specifically, participants were asked to provide a percentage of time that each of the following occurred as a consequence of completing math assignments: a) time away from working on math (e.g., early dismissal from a class or assignment, a day without homework), b) an undesirable outcome (e.g., a bad grade, reprimand, or extra homework), c) a loss of privileges (e.g., "grounding," forced time away from friends, detention, being sent to the principal's office), d) a desirable outcome (e.g., a good grade, praise, permission to do a special activity, etc.). The questionnaire prompted participants to write percentages that all add to $100 \%$.

Math worksheets. All students worked on three math assignment pairs (i.e., one control and one experimental worksheet). Both assignments within a pair contained 152 digit by 2-digit (2x2) multiplication problems and one assignment contained additional 
$1 \times 1$ multiplication problems interspersed among $2 \times 2$ problems at various fixed rates: two prior to every longer problem (2:1), every third (1:3), and no interspersing (0:1). Math worksheets in the 0:1 assignment pair (Appendices H \& I) contained 15 2x2 multiplication problems. Both worksheets were control worksheets and matched for difficulty such that the numbers in each corresponding problem between worksheets were the same. For example, if the first problem on the first worksheet read $57 \times 78$, then the first problem on the matched second worksheet read $77 \times 85$ or some other combination of the same four digits. Problems on these matched worksheets contained digits between four and nine to ensure consistent carrying and regrouping. Moreover, the rows of problems on both assignments were inconsistently spaced to guard against participants quickly assessing the number of problems and their difficulty on both assignments. Problems were printed on one side of one 8.5-inch x 11-inch white sheet of paper. One worksheet was labeled with the letter $\mathrm{L}$ in the upper right-hand corner of the paper, and the other was labeled with the letter $\mathrm{M}$ in the same fashion. The letters $\mathrm{L}$ and $\mathrm{M}$ were counterbalanced between worksheets. A sheet of questions followed the worksheet pair, asking students to choose between the two assignments.

Math worksheets in the 1:3 (Appendices J \& K) and 2:1 (Appendices L \& M) assignment pairs consisted of one control assignment as described above and one experimental assignment. The experimental assignments contained 15 matched $2 \times 2$ multiplication problems with $1 \mathrm{x} 1$ multiplication problems interspersed among the $2 \times 2$ problems at one of the two fixed rates (i.e., every third longer problem or two prior to every longer problem). Worksheets within assignment pairs for the 1:3 and 2:1 interspersing ratios were constructed in the same manner described for the $0: 1$ 
interspersing ratio. The additional $1 \mathrm{x} 1$ multiplication problems on the experimental worksheets, however, contained digits lower than five, not including zero, to ensure brevity. Both assignments were presented in the same manner (i.e., worksheet layout and dimensions) as stated above, including preference and choice questionnaires following the assignment pair.

Math assignment preference questionnaire. Preference questions (Appendix E) were printed on one side of an 8.5-inch $x$ 11-inch white sheet of paper, following the assignment pair, asking students to choose which of the two assignments (L or M) was: (a) more time consuming to complete, (b) took more effort to complete, (c) was more difficult to complete, and (d) which they would prefer to complete for homework. Math assignments were labeled with either the letter $\mathrm{L}$ or the letter $\mathrm{M}$ in the upper right-hand corner of the paper. The letters aided students in distinguishing between the two assignments when answering the choice questions.

\section{Procedure}

The following procedures were carried out in a laboratory room. Participants for the current investigation received an informed consent form (Appendix A) to read and sign prior to completing any materials. Participants were told that they were allowed to leave the laboratory room and exit the study without repercussions if they declined to participate in the current investigation.

After completing an informed consent form, participants received an assignment packet. Packets contained a demographic form (e.g., age, sex, race/ethnicity, academic year, major; Appendix D), two matched control assignments (i.e., 0:1), and two assignment pairs containing interspersing at different fixed ratios (i.e., 1:3 and 2:1). The 
order of interspersing ratios was randomized such that all participants were not completing assignments in the same order. Each assignment pair had an accompanying preference questionnaire. Each participant initially completed two matched assignments, where assignments pairs were counterbalanced among participants such that all participants were not working simultaneously on the same worksheet. Worksheets within assignment pairs (i.e., experimental and control) were also presented randomly in a counterbalanced order such that all participants were not working simultaneously on the same worksheet.

Prior to beginning each assignment pair, participants were told to work all of the problems on each page from left to right as quickly as possible, without skipping problems or making errors, starting with the first problem on the top left. The experimenter demonstrated the instructions using a randomly chosen copy of an assignment. Before beginning, participants were told they could sit quietly and wait if they finished before being told to stop.

Participants were then asked to complete as many problems as they could on a brief (i.e., 4 min.) mathematics assignment. After explaining these instructions the experimenter told participants to begin working and started a stopwatch. The experimenter told participants to stop and put their pencils down after four minutes elapsed. Participants were then asked to turn the page and work on the next assignment (i.e., the control or interspersing worksheet left for completion) after the experimenter acknowledged that time was up. Participants heard the same instructions prior to beginning subsequent assignments, and the experimenter timed participants for four minutes while they complete each worksheet. 
After each assignment pair, the experimenter asked participants to complete a brief choice form by circling either L or M. The questions presented were: (a) "Which assignment would require more time to complete from start to finish?" (b) "Which assignment would require more effort to complete from start to finish?" (c) "Which assignment was more difficult?" and (d) "Which assignment do you prefer for homework?" Participants were prompted to refer back to the letters in the upper righthand corner of the two assignments pertaining to that preference form to recall the order in which they completed the assignments. These procedures were repeated for each assignment pair. After students completed the three assignment pairs and their preference forms, the experimenter debriefed (i.e., read debriefing statement; Appendix F) participants and answered any questions asked. Each participant received an extra credit voucher for participating in the study that they were able to submit to their respective professors to earn extra credit points in their psychology course.

Research training. All researchers who collected data read a procedural protocol (Appendix N) and script (Appendix O) and were trained to $100 \%$ procedural fidelity via role-play practice sessions. All practice session procedures included tasks to criterion following the training fidelity checklist (Appendix P). The script was also included in the materials for collecting data and read to participants to ensure procedural fidelity while collecting data.

\section{Design, Dependent Variables, and Data Analysis}

Choice and preference behavior. Participants' choice and preference for assignments were dependent variables measured as: a) choice for homework, b) preference for difficulty to complete, c) preference for effort to complete, and d) 
preference for time to complete. These variables were measured between groups of choosers and non-choosers. Participant choice was determined consistent if the same assignment (e.g., control) chosen for homework initially was chosen for homework two or more times in subsequent assignment pairs. The design for this analysis was a 2 (control vs. experimental) x 2 (chooser vs. non-chooser) repeated measures design. The analysis for this design was a chi-square goodness-of-fit test.

Academic performance accuracy. Participant accuracy for problems within each assignment was one dependent variable for academic performance. Accuracy was operationally defined as having the final answer to a problem correct (i.e., each digit correct in its correct place value). Incomplete problems (e.g., the participant showing his or her work and not providing a final product) received no credit for accuracy. The design for testing the differences in accuracy performance was a 2 (control vs. experimental) x 2 (chooser vs. non-chooser) x 3 (0:1 vs. 1:3 vs. $2: 1$ ) factorial design with repeated measures on the first (i.e., assignment type) and third (i.e., interspersing ratio) factors. The analysis for this design was a multivariate mixed model repeated measures ANOVA.

Target problems completed. Target problems were operationally defined as $2 \times 2$ multiplication problems within each assignment. Target problems completed were calculated as the sum of $2 \times 2$ multiplication problems where participants provided a final product regardless of accuracy of that product. The design for analyzing target problems completed was a 2 (control vs. experimental) x 2 (chooser vs. non-chooser) x 3 (0:1 vs. 1:3 vs. 2:1) factorial design with repeated measures on the first (i.e., assignment type) and third (i.e., interspersing ratio) factors. The analysis for this design was a multivariate 
mixed model repeated measures ANOVA.

Total problems completed. Participants' academic performance for total problems completed was measured as the sum of the total number of problems a participant attempted and completed (i.e., provided a final product as an answer). Total problems included $2 \times 2$ multiplication problems and $1 \times 1$ multiplication problems. The design for analyzing total problems completed was a 2 (control vs. experimental) x 2 (chooser vs. non-chooser) x 3 (0:1 vs. 1:3 vs. 2:1) factorial design with repeated measures on the first (i.e., assignment type) and third (i.e., interspersing ratio) factors. The analysis for this design was a multivariate mixed model repeated measures ANOVA.

Relative problem completion rates. Relative problem completion rates for the assignment pairs were calculated by dividing the total number of problems completed on the experimental assignment by the sum of the total number of problems completed on both the matched control and experimental assignments (i.e., experimental/control). For the first assignment pair (i.e., assignment without interspersing 1 vs. assignment without interspersing 2) one assignment was labeled as the control assignment and one as the experimental assignment for calculation, choice, and preference consistency, although both assignments were matched and contained only $2 \times 2$ multiplication problems. A relative problem completion rate ratio of 1.0 suggests that participants completed equal numbers of problems on both assignments. A relative problem completion rate ratio greater than 1.0 suggests that participants completed more problems on the experimental assignment relative to the matched control assignment. A relative problem completion rate ratio less than 1.0 suggests that participants completed fewer problems on the experimental assignment relative to the matched control assignment. The design for 
measuring relative problem completion rates was a 2 (chooser vs. non-chooser) x 3 (0:1

vs. 1:3 vs. $2: 1$ ) factorial design with repeated measures on the second (i.e., interspersing ratio) factor. The analysis for this design was a mixed model repeated measures

\section{ANOVA.}

Reinforcement history questionnaire. Time away from working on math, an undesirable outcome, loss of privileges, and a desirable outcome were dependent variables measured by the percentage of time with which participants responded. These variables were used to predict relative problem completion rate ratios for each interspersing ratio since relative problem completion rates have been demonstrated to account for choice behavior (e.g., Cates \& Dalenberg, 2005; Cates \& Erkfritz, 2007; Skinner, 2002). Multiple regression analyses were used to interpret these data.

\section{Hypotheses}

1. It was hypothesized that, overall, participant choice and preference frequencies for assignments in the 0:1 assignment pair (i.e., assignment without interspersing vs. assignment without interspersing) would not statistically significantly differ (i.e., establish that both assignments were equated for problem difficulty and problem type) on the dimensions of a) choice for homework, b) preference for difficulty to complete, c) preference for effort to complete, and d) preference for time to complete. It was hypothesized for the 1:3 and 2:1 assignment pairs, however, that statistically significantly more participants would choose and more frequently prefer the experimental assignment relative to the matched control assignment a) for homework, b) as less difficult to complete, c) as requiring less effort to complete, and d) as requiring less time to complete. It was also 
hypothesized that non-choosers would change their choice behavior (i.e., choose and prefer experimental assignments relative to matched control assignments) on the dimensions of a) choice for homework, b) preference for difficulty to complete, c) preference for effort to complete, and d) preference for time to complete as they contacted assignments with richer schedules of interspersing (i.e., reinforcement). That is, statistically significantly more non-choosers were hypothesized to choose the assignment with brief problems interspersed at 2:1 relative to the assignment with brief problems interspersed at 1:3.

2. It was hypothesized that choosers would complete statistically significantly more total problems on experimental assignments relative to matched control assignments for the 1:3 and 2:1 interspersing ratios. It was hypothesized, conversely, that non-choosers would demonstrate no statistically significant differences in total problems completed for the 1:3 assignment pair. Nonchoosers were hypothesized, however, to complete statistically significantly more total problems on the 2:1 experimental assignment relative to its matched control assignment. It was also hypothesized that the number of total problems completed on both assignments in the 0:1 assignment pair would statistically significantly differ among non-choosers.

3. It was hypothesized that the number of target problems completed on experimental assignments relative to the matched control assignments, for all interspersing ratios, would not statistically significantly differ between choosers and non-choosers.

4. It was hypothesized that chooser and non-chooser accuracy performance would 
not statistically significantly differ between assignments for all assignment pairs.

5. It was hypothesized that, overall, relative problem completion rates would be statistically significantly higher for the $2: 1$ assignment pair relative to the $1: 3$ and 0:1 (i.e., no interspersing) assignment pairs. It was also hypothesized that relative problem completion rates would be statistically significantly higher for the 1:3 assignment pair relative to the 0:1 assignment pair. Further, it was hypothesized that non-choosers would demonstrate statistically significantly higher relative problem completion rates for the experimental assignment relative to the matched control assignment for the 0:1 assignment pair (i.e., assignment without interspersing vs. assignment without interspersing), whereas choosers would demonstrate no statistically significant differences in relative problem completion rates between assignments for the 0:1 assignment pair. It was hypothesized that non-choosers would demonstrate statistically significantly higher relative problem completion rates for the 2:1 assignment pair relative to the $1: 3$ and $0: 1$ assignment pairs.

\section{Results}

\section{Choice and Preference}

Chi-square goodness-of-fit tests were conducted to test whether the observed preference frequencies among participants (i.e., choosers and non-choosers) differed significantly between assignments types (i.e., experimental and control) for each assignment pair on the dimensions of a) choice for homework, b) preference for difficulty to complete, c) preference for effort to complete, and d) preference for time to complete. It was hypothesized that, overall, participant choice and preference frequencies for 
assignments in the 0:1 assignment pair would not statistically differ (i.e., establish that both assignments were equated for problem difficulty and problem type) on the dimensions of a) choice for homework, b) preference for difficulty to complete, c) preference for effort to complete, and d) preference for time to complete. To test this hypothesis, expected frequencies were set at $50 \%$ for both experimental and control assignments when analyzing the aggregate data. Table 1 displays the aggregate preference data on the dimensions of time, effort, difficulty, and choice for homework across the three rates (i.e., $0: 1,1: 3,2: 1)$ of interspersing.

For the assignments in the 0:1 interspersing assignment pair, the difference between the observed frequencies was not significant for time $(\chi 2[1, \mathrm{~N}=138]=1.86, \mathrm{p}=$ $.17)$, effort $(\chi 2[1, \mathrm{~N}=139]=1.22, \mathrm{p}=.27)$, difficulty $(\chi 2[1, \mathrm{~N}=138]=0.12, \mathrm{p}=.73)$, or choice for homework $(\chi 2[1, \mathrm{~N}=139]=0.01, \mathrm{p}=.93)$. These results indicate that participant choice and preference for either assignment within the 0:1 assignment pair did not differ (i.e., they chose either assignment equally often), thus confirming that the assignments were essentially the same. For the assignments in the 1:3 interspersing assignment pair, however, the difference between the observed frequencies was significant for time $(\chi 2[1, \mathrm{~N}=140]=13.83, \mathrm{p}<.001)$, effort $(\chi 2[1, \mathrm{~N}=141]=46.53, \mathrm{p}<$ $.001)$, difficulty $(\chi 2[1, \mathrm{~N}=141]=26.39, \mathrm{p}<.001)$, and choice for homework $(\chi 2[1, \mathrm{~N}=$ $141]=15.67, \mathrm{p}<.001)$. For the assignments in the $2: 1$ interspersing assignment pair, the difference between the observed frequencies was also significant for time $(\chi 2[1, N=141]$ $=18.45, \mathrm{p}<.001)$, effort $(\chi 2[1, \mathrm{~N}=141]=69.51, \mathrm{p}<.001)$, difficulty $(\chi 2[1, \mathrm{~N}=140]=$ $89.60, \mathrm{p}<.001)$, and choice for homework $(\chi 2[1, \mathrm{~N}=141]=48.86, \mathrm{p}<.001)$. These results indicate that interspersing, both the 1:3 and 2:1 ratios, caused most participants to 
change their choices and choose the experimental assignment relative to the control assignment as less time consuming, less effortful, less difficult, and as an assignment to complete for homework. 


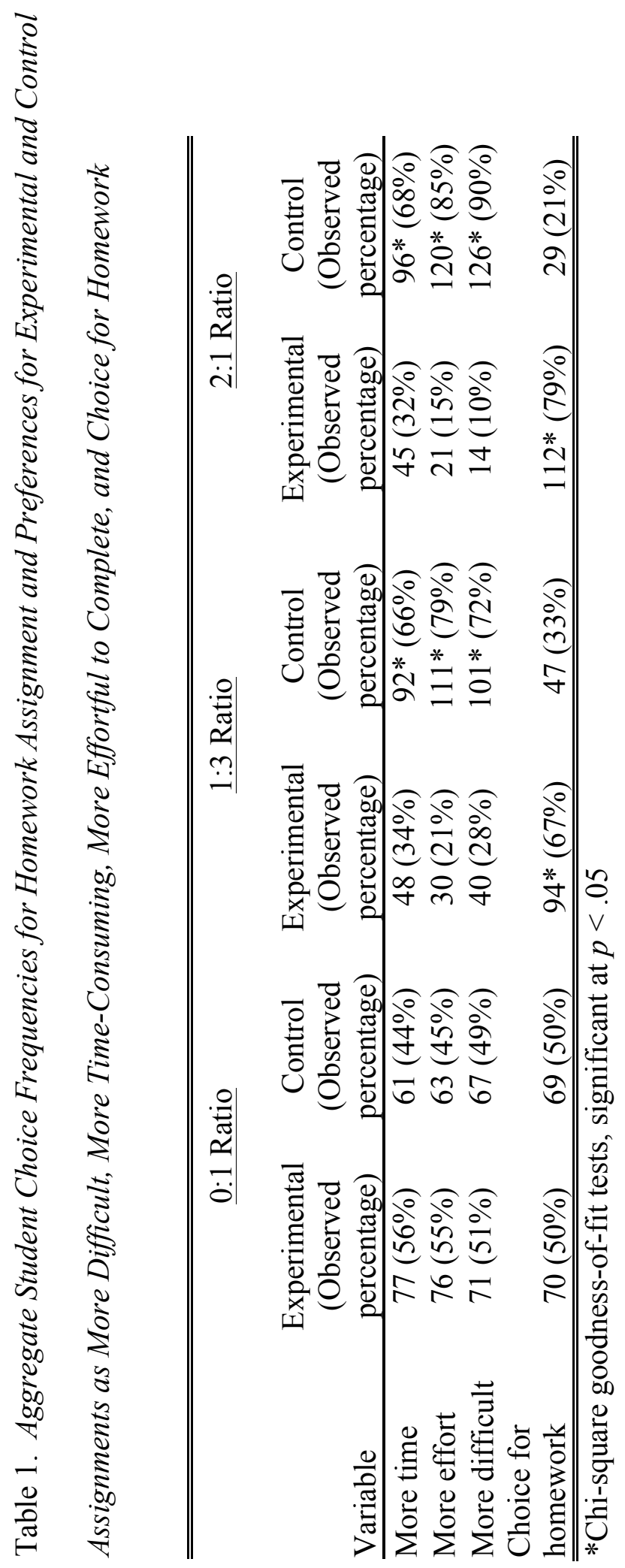


Choosers. Chooser data were analyzed separately to determine the consistency of choice and preferences for assignments within assignment pairs across the three ratios of interspersing. Chi-square goodness-of-fit tests were conducted to test whether the observed choice and preference frequencies among choosers differed significantly between assignment types (i.e., experimental and control) for each assignment pair on the dimensions of a) choice for homework, b) preference for difficulty to complete, c) preference for effort to complete, and d) preference for time to complete. Expected frequencies were based on the percentages obtained for each preference and choice dimension in two separate analyses: one for the $0: 1$ interspersing ratio and another for the 2:1 interspersing ratio. Table 2 displays preference data for non-choosers on the dimensions of time, effort, difficulty, and choice for homework across the three rates (i.e., 0:1, 1:3,2:1) of interspersing. The expected percentages for experimental and control assignments for the 0:1 interspersing ratio were set at $50 \%$ to observe how many choosers chose either assignment across the four preference and choice dimensions. The percentages obtained for the 0:1 interspersing ratio were then used as the expected percentages for the 1:3 and 2:1 interspersing ratios to test whether interspersing in fact had an effect on chooser's choice and preference on the four dimensions compared to no interspersing (i.e., 0:1). 


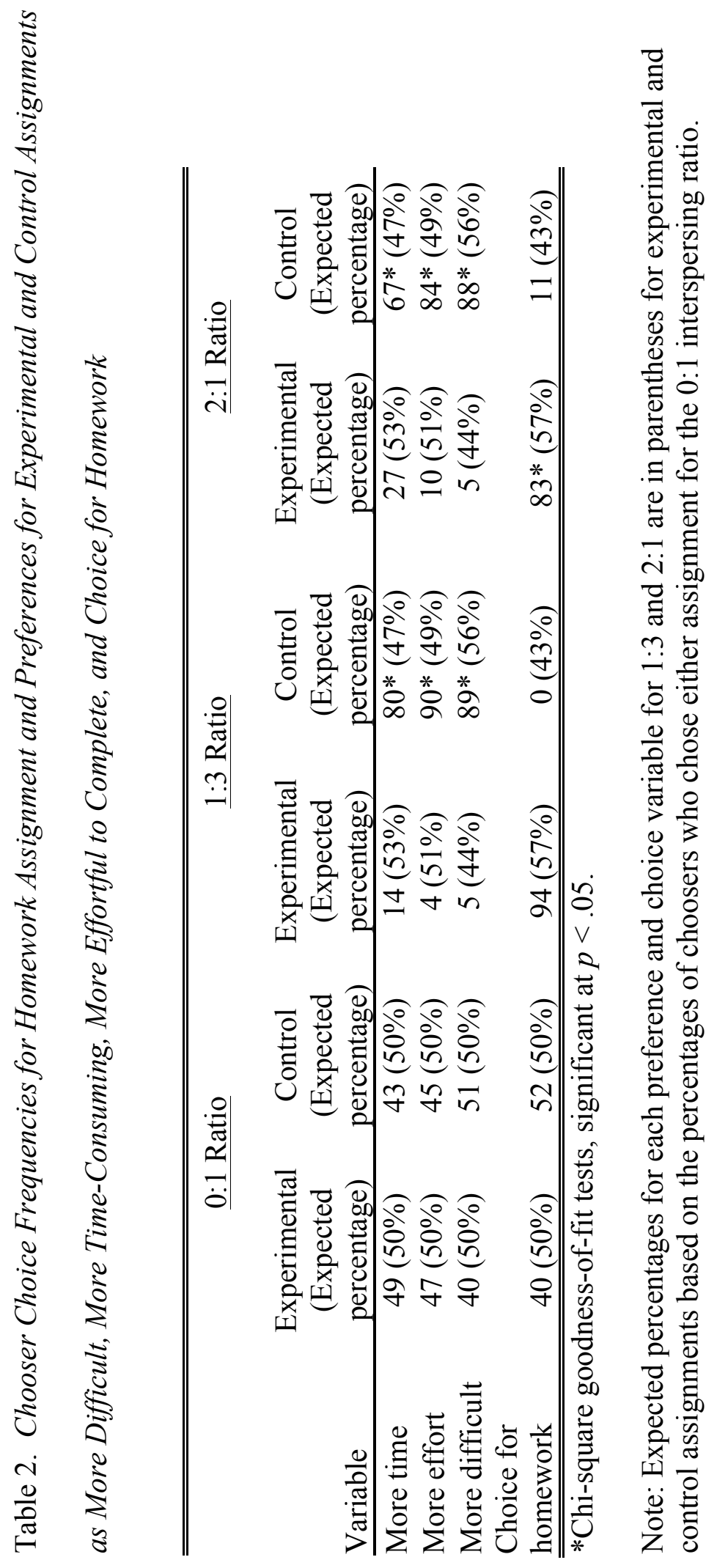


For the assignments in the 0:1 interspersing assignment pair, the difference between the observed frequencies was not significant for time $\left(\chi^{2}[1, N=92]=0.39, p=\right.$ $.53)$, effort $\left(\chi^{2}[1, N=92]=0.04, p=.84\right)$, difficulty $\left(\chi^{2}[1, N=91]=1.33, p=.25\right)$, or choice for homework $\left(\chi^{2}[1, N=92]=1.57, p=.21\right)$. These results indicate choosers' choice and preference for either assignment within the 0:1 assignment pair did not differ (i.e., they chose either assignment equally often).

For the assignments in the 1:3 interspersing assignment pair, the difference between the observed frequencies was significant for time $\left(\chi^{2}[1, N=94]=54.80, p<\right.$ $.001)$, effort $\left(\chi^{2}[1, N=94]=82.19, p<.001\right)$, and difficulty $\left(\chi^{2}[1, N=94]=57.08, p<\right.$ $.001)$. The difference between the observed frequencies $(N=94)$ for choice for homework could not be analyzed since a frequency of zero was in the cell for the control assignment in the chi-square analysis. That is, by definition choosers all chose the experimental assignment for homework and the observed frequency for the control assignment on this dimension was zero. These results also show choosers' preferences and choice between 1:3 experimental and control assignments differed from their preferences and choice between 0:1 experimental and control assignments. That is, interspersing at a 1:3 ratio changed choosers' behavior.

For the assignments in the 2:1 interspersing assignment pair, the difference between the observed frequencies was significant for time $\left(\chi^{2}[1, N=94]=22.24, p<\right.$ $.001)$, effort $\left(\chi^{2}[1, N=94]=61.28, p<.001\right)$, difficulty $\left(\chi^{2}[1, N=93]=56.30, p<.001\right)$, and choice for homework $\left(\chi^{2}[1, N=94]=37.57, p<.001\right)$. These results show that choosers' choice and preferences changed from what was observed with the 0:1 assignment pair when the 2:1 interspersing ratio was introduced. 
Another set of chi-square goodness-of-fit tests were conducted in a similar manner as described above to determine whether interspersing at the 2:1 ratio had an effect on chooser's choice and preferences on the four dimensions compared to no interspersing (i.e., 0:1) and interspersing at a 1:3 ratio. The observed percentages for the 1:3 interspersing ratio were applied to the $0: 1$ and 2:1 interspersing ratios as the expected percentages of observed frequencies for experimental and control assignments. The expected percentages for experimental and control assignments for the 1:3 interspersing ratio were set at $50 \%$ to observe how many choosers chose either assignment across the four preference and choice dimensions. Table 3 displays preference data for choosers on the dimensions of time, effort, difficulty, and choice for homework across the three ratios (i.e., $0: 1,1: 3,2: 1)$ of interspersing. 


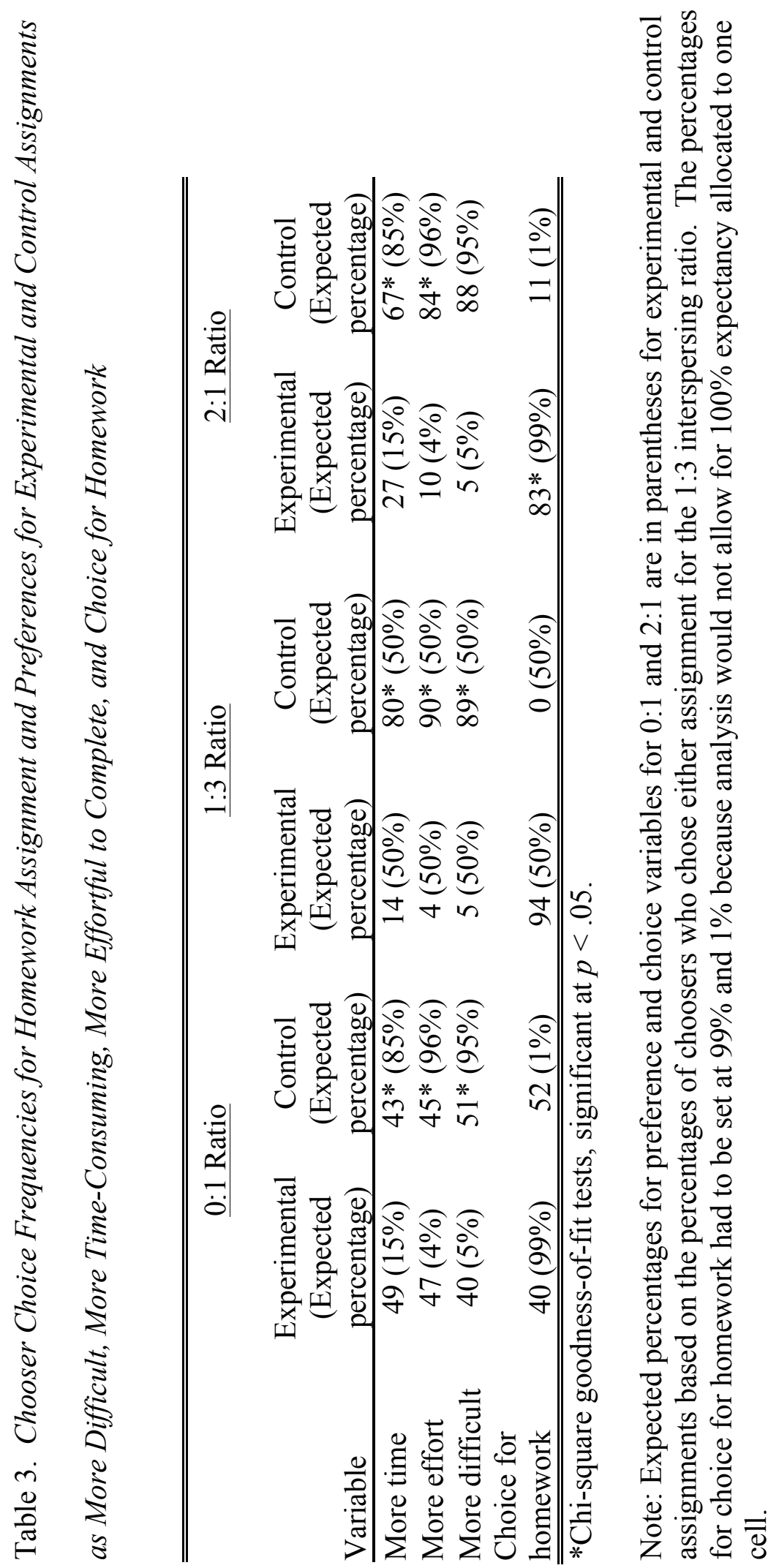


For the assignments in the 0:1 interspersing assignment pair, the difference between the observed frequencies was significant for time $\left(\chi^{2}[1, N=92]=105.63, p<\right.$ $.001)$, effort $\left(\chi^{2}[1, N=92]=531.20, p<.001\right)$, difficulty $\left(\chi^{2}[1, N=91]=290.74, p<\right.$ $.001)$, and choice for homework $\left(\chi^{2}[1, N=92]=1676.82, p<.001\right)$. These results indicate choosers' choice and preference for either assignment within the 0:1 assignment pair differed significantly from the preferences and choice for assignments in the 1:3 assignment pair. Specifically, significantly more choosers chose the experimental assignment for homework and preferred the experimental assignment as less time consuming, less effortful, and less difficult.

For the assignments in the 1:3 interspersing assignment pair, the difference between the observed frequencies was significant for time $\left(\chi^{2}[1, N=94]=46.34, p<\right.$ $.001)$, effort $\left(\chi^{2}[1, N=94]=78.68, p<.001\right)$, and difficulty $\left(\chi^{2}[1, N=94]=75.06, p<\right.$ $.001)$. The difference between the observed frequencies $(N=94)$ for choice for homework could not be analyzed since a frequency of zero was in the cell for the control assignment in the chi-square analysis. That is, by definition choosers all chose the experimental assignment for homework and the observed frequency for the control assignment on this dimension was zero. These results also show that choosers preferred the experimental assignment relative to the control assignment as less time consuming, less effortful, and less difficult, and they chose it for homework, relative to the control assignment for the 1:3 interspersing ratio.

For the assignments in the 2:1 interspersing assignment pair, the difference between the observed frequencies was significant for time $\left(\chi^{2}[1, N=94]=13.88, p<\right.$ $.001)$, effort $\left(\chi^{2}[1, N=94]=10.79, p=.001\right)$, and choice for homework $\left(\chi^{2}[1, N=94]=\right.$ 
$37.57, p<.001)$. These results show choosers' choice and preferences changed from what was observed with the 1:3 assignment pair when the 2:1 interspersing ratio was introduced. The difference between the observed frequencies for difficulty, however, was not significant $\left(\chi^{2}[1, N=93]=0.03, p=.87\right)$, indicating that choosers' preference for the experimental assignment relative to the control assignment based on difficulty was the same for 1:3 and 2:1 interspersing ratios.

Non-choosers. It was hypothesized that non-choosers would change their choice behavior (i.e., choose and prefer experimental assignments relative to matched control assignments) on the dimensions of a) choice for homework, b) preference for difficulty to complete, c) preference for effort to complete, and d) preference for time to complete as they contacted assignments with richer schedules of interspersing (i.e., reinforcement). That is, statistically significantly more non-choosers were hypothesized to choose the assignment with brief problems interspersed at 2:1 relative to the assignment with brief problems interspersed at 1:3. To test this hypothesis for non-choosers, expected frequencies were based on the percentages obtained for each preference and choice dimension in two separate analyses: one for the 0:1 interspersing ratio and another for the 2:1 interspersing ratio. Table 4 displays preference data for non-choosers on the dimensions of time, effort, difficulty, and choice for homework across the three rates (i.e., 0:1, 1:3, 2:1) of interspersing. The expected percentages for experimental and control assignments for the $0: 1$ interspersing ratio were set at $50 \%$ to observe how many non-choosers chose either assignment across the four preference and choice dimensions. The percentages obtained for the 0:1 interspersing ratio were then used as the expected percentages for the 1:3 and 2:1 interspersing ratios to test whether interspersing in fact 
had an effect on non-chooser's choice and preference on the four dimensions compared to no interspersing (i.e., 0:1). 


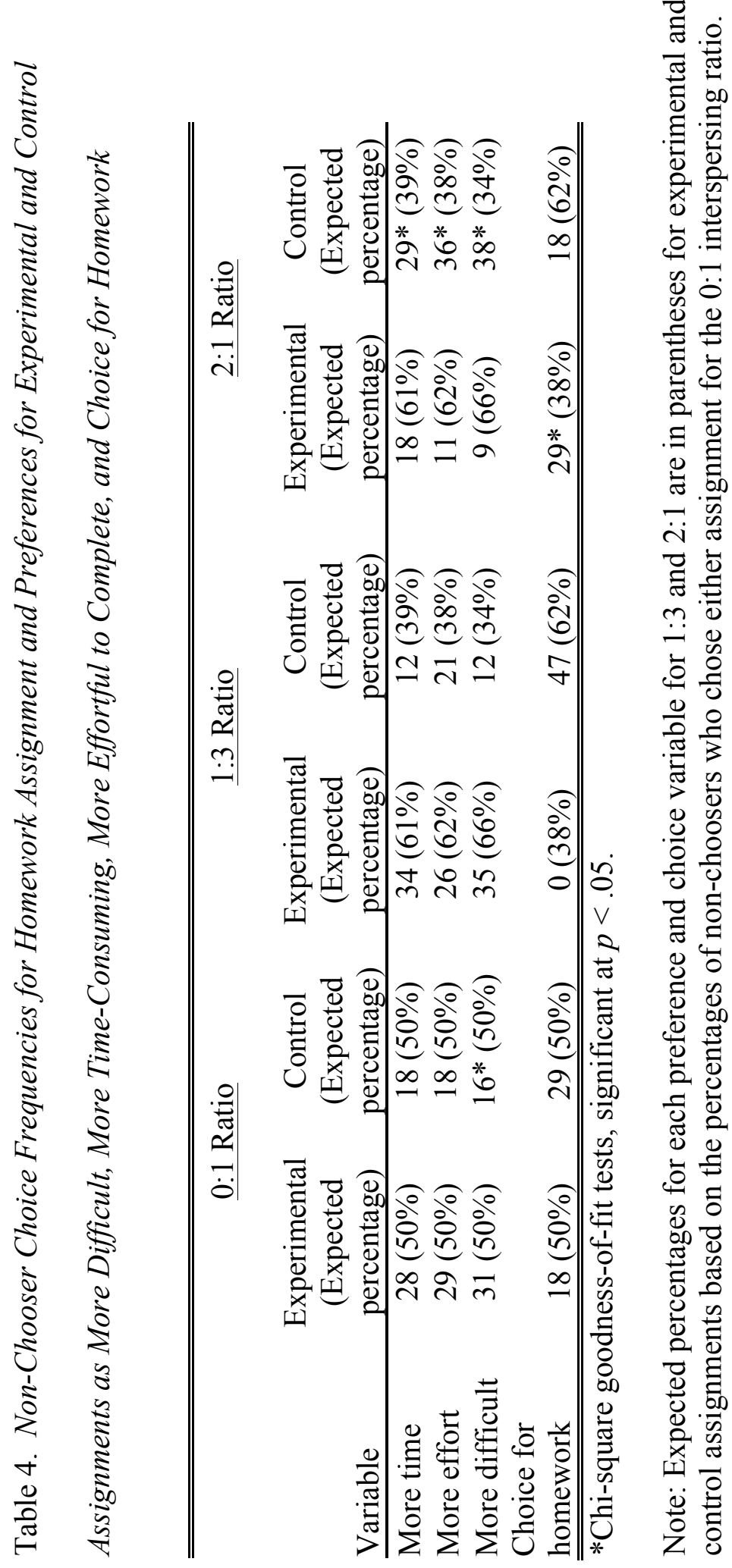


For the assignments in the 0:1 interspersing assignment pair, the difference between the observed frequencies was not significant for time $\left(\chi^{2}[1, N=46]=2.17, p=\right.$ $.14)$, effort $\left(\chi^{2}[1, N=47]=2.57, p=.11\right)$, or choice for homework $\left(\chi^{2}[1, N=47]=2.57\right.$, $p=.11)$. The difference between the observed frequencies was significant, however, for difficulty $\left(\chi^{2}[1, N=47]=4.79, p=.03\right)$. These results suggest that non-choosers, when choosing an assignment as more time consuming and more effortful, and when choosing an assignment to complete for homework, chose either the experimental or control assignment equally often after completing similar assignments with no interspersing (i.e., 0:1 ratio). When choosing an assignment as more difficult, however, non-choosers preferred the control assignment relative to the experimental assignment after completing similar assignments with no interspersing.

For the assignments in the 1:3 interspersing assignment pair, the difference between the observed frequencies was not significant for time $\left(\chi^{2}[1, N=46]=3.22, p=\right.$ $.07)$, effort $\left(\chi^{2}[1, N=47]=0.89, p=.35\right)$, and difficulty $\left(\chi^{2}[1, N=47]=1.50, p=.22\right)$. The difference between the observed frequencies $(N=47)$ for choice for homework could not be analyzed since a frequency of zero was in the cell for the experimental assignment in the chi-square analysis. That is, by definition non-choosers all chose the control assignment for homework and the observed frequency for the experimental assignment on this dimension was zero. These results also show that non-choosers' preferences and choice between 1:3 experimental and control assignments did not differ from their preferences and choice between 0:1 experimental and control assignments. That is, interspersing at a 1:3 ratio did not change non-choosers' behavior.

For the assignments in the 2:1 interspersing assignment pair, the difference 
between the observed frequencies was significant for time $\left(\chi^{2}[1, N=47]=10.18, p=\right.$ $.001)$, effort $\left(\chi^{2}[1, N=47]=29.72, p<.001\right)$, difficulty $\left(\chi^{2}[1, N=47]=45.97, p<.001\right)$, and choice for homework $\left(\chi^{2}[1, N=47]=11.21, p=.001\right)$. These results show that nonchoosers' choice and preferences changed from what was observed with the $0: 1$ assignment pair when the 2:1 interspersing ratio was introduced. That is, interspersing at a 2:1 ratio caused non-choosers to choose the control assignment as more time consuming, more effortful, and more difficult relative to the experimental assignment, and to choose the experimental assignment for homework relative to the control assignment compared to the $0: 1$ assignment pair preference and choice frequencies. These results support the second hypothesis.

To test whether significantly more non-choosers preferred and chose the interspersing assignment relative to the control assignment when the 2:1 interspersing ratio was introduced, chi-square goodness-of-fit tests were run in a similar manner as described above. The observed percentages for the 1:3 interspersing ratio were applied to the $0: 1$ and 2:1 as the expected percentages of observations for experimental and control assignments. The percentages obtained for the $1: 3$ interspersing ratio were used as the expected percentages for the $0: 1$ and 2:1 interspersing ratios to test whether interspersing at the 2:1 ratio had an effect on non-chooser's choice and preference on the four dimensions compared to no interspersing (i.e., 0:1) and interspersing at a 1:3 ratio. The expected percentages for experimental and control assignments for the 1:3 interspersing ratio were set at $50 \%$ to observe how many non-choosers chose either assignment across the four preference and choice dimensions. Table 5 displays preference data for nonchoosers on the dimensions of time, effort, difficulty, and choice for homework across 
the three rates (i.e., $0: 1,1: 3,2: 1)$ of interspersing. 


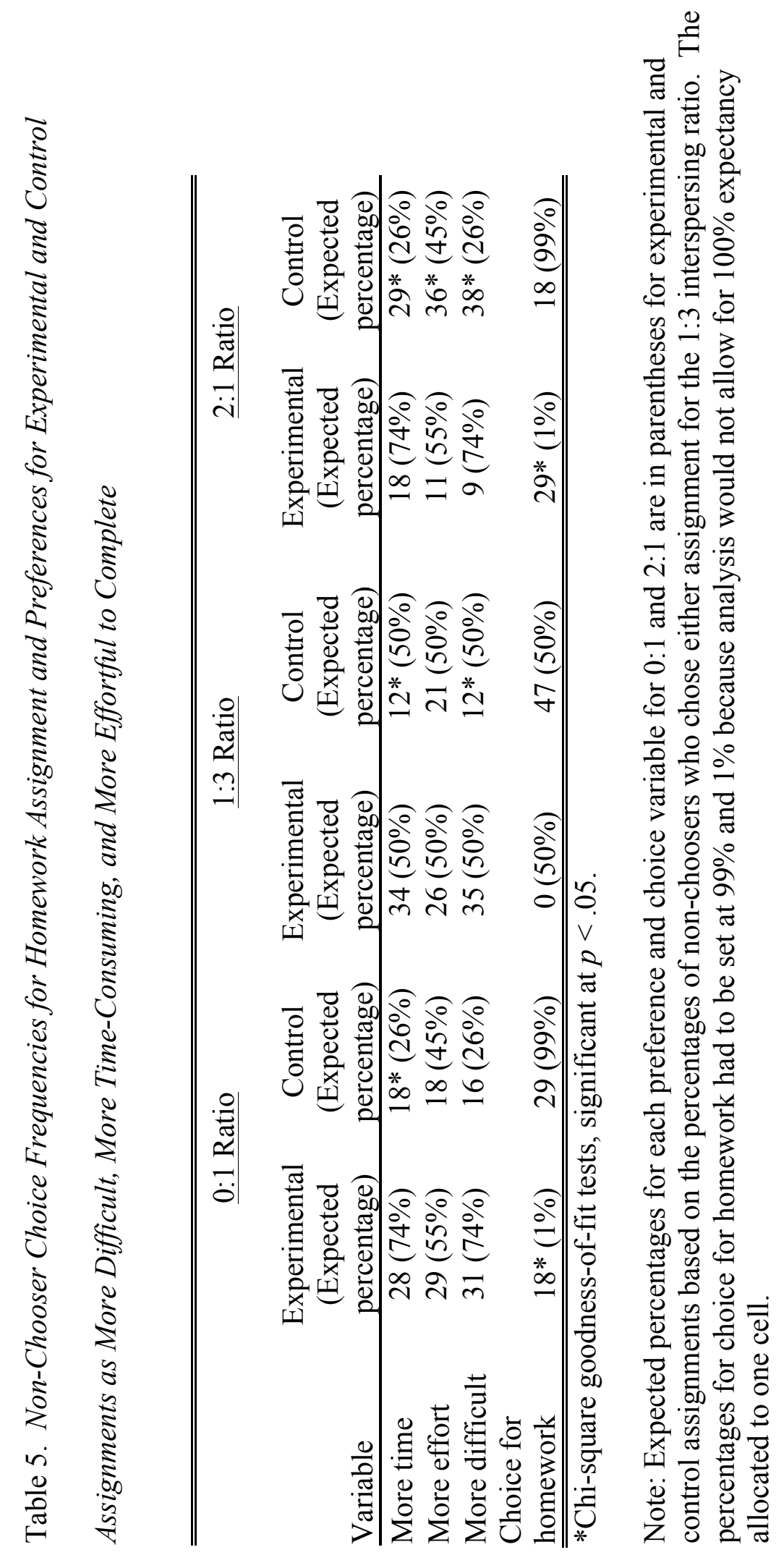


For the assignments in the 0:1 interspersing assignment pair, the difference between the observed frequencies was significant for time $\left(\chi^{2}[1, N=46]=4.12, p=.04\right)$ and choice for homework $\left(\chi^{2}[1, N=47]=660.44, p<.001\right)$. These results indicate that the number of non-choosers who chose the control assignment as more time consuming and for homework differed between 1:3 and 0:1 interspersing ratios, suggesting an effect of interspersing. The difference between the observed frequencies was not significant, however, for effort $\left(\chi^{2}[1, N=47]=0.85, p=.36\right)$ and difficulty $\left(\chi^{2}[1, N=47]=1.58, p=\right.$ .21). These results show that the number of non-choosers who chose the control assignments as more effortful and more difficult did not differ between 1:3 and 0:1 interspersing ratios.

For the assignments in the 1:3 interspersing assignment pair, the difference between the observed frequencies was significant for time $\left(\chi^{2}[1, N=46]=10.52, p=\right.$ $.001)$ and difficulty $\left(\chi^{2}[1, N=47]=11.26, p=.001\right)$, but not for effort $\left(\chi^{2}[1, N=47]=\right.$ $0.53, p=.47)$. The difference between the observed frequencies $(N=47)$ for choice for homework could not be analyzed since a frequency of zero was in the cell for the experimental assignment in the chi-square analysis. That is, by definition non-choosers all chose the control assignment for homework and the observed frequency for the experimental assignment on this dimension was zero. These results show that, although non-choosers exclusively chose the control assignment for homework, they demonstrated no preference for either assignment based on which was more effortful to complete and they preferred the experimental assignment as more time consuming and more difficult.

For the assignments in the 2:1 interspersing assignment pair, the difference between the observed frequencies was highly significant for time $\left(\chi^{2}[1, N=47]=31.14\right.$, 
$p<.001)$, effort $\left(\chi^{2}[1, N=47]=18.96, p<.001\right)$, difficulty $\left(\chi^{2}[1, N=47]=73.50, p<\right.$ $.001)$, and choice for homework $\left(\chi^{2}[1, N=47]=1749.33, p<.001\right)$. These results indicate that interspersing at a richer ratio (i.e., 2:1 vs. 1:3) caused non-choosers to change their choices and choose the experimental assignment for homework while choosing the control assignment as more time consuming, more effortful, and more difficult.

\section{Target Problems Completed}

A multivariate mixed model ANOVA was conducted for the 2 (chooser vs. nonchooser) x 2 (experimental assignment vs. control assignment) x 3 (0:1 vs. 1:3 vs. 2:1) design to evaluate the effects of participant choice, assignment type, and interspersing ratio on target problems completed. The between-subjects factor was participant choice for homework (as analyzed for the 1:3 assignment pair), and the within-subjects factors were assignment type and interspersing ratio. Table 6 displays the means and standard deviations for the number of target problems completed on experimental and control assignments across the three interspersing ratios for choosers, non-choosers, and collapsed across the two participant groups. It was hypothesized that the number of target problems completed on experimental assignments relative to the matched control assignments, for all interspersing ratios, would not statistically significantly differ between choosers and non-choosers. The interaction of participant choice, assignment type, and interspersing ratio was not statistically significant $(F[2,270]=.94, M S E=2.45$, $\left.p=.39, \eta_{\mathrm{p}}{ }^{2}=0.007\right)$, thus supporting the above hypothesis. 
Table 6. Mean Target Problems Completed Among Interspersing Ratios For Choosers, Non-Choosers, and Collapsed Across Groups

\begin{tabular}{lcccccc}
\hline \hline & \multicolumn{2}{c}{$\frac{\text { Choosers }}{(\mathrm{N}=91)}$} & \multicolumn{2}{c}{ Non-choosers } & \multicolumn{2}{c}{$\begin{array}{c}\text { Collapsed } \\
(\mathrm{N}=46)\end{array}$} \\
$\begin{array}{l}\text { Interspersing } \\
\text { Ratio }\end{array}$ & $\mathrm{M}$ & $\mathrm{SD}$ & $\mathrm{M}$ & $\mathrm{SD}$ & $\mathrm{M}$ & $\mathrm{SD}$ \\
\hline $0: 1$ & & & & & & \\
$\quad$ Experimental & 8.32 & 3.85 & 7.52 & 3.49 & 8.05 & 3.74 \\
$\quad$ Control & 8.38 & 3.93 & 8.48 & 3.87 & 8.42 & 3.90 \\
$\begin{array}{l}1: 3 \\
\quad \text { Experimental }\end{array}$ & 9.30 & 3.82 & 7.89 & 3.95 & 8.82 & 3.90 \\
$\quad$ Control & 8.96 & 3.64 & 8.76 & 3.88 & 8.89 & 3.71 \\
2:1 & & & & & & \\
$\quad$ Experimental & 8.93 & 3.40 & 8.35 & 3.50 & 8.74 & 3.43 \\
$\quad$ Control & 8.80 & 4.03 & 8.65 & 3.65 & 8.75 & 3.89 \\
\hline \hline
\end{tabular}

The interaction of participant choice and assignment type was statistically significant, $F(2,135)=10.26, M S E=3.19, p=.002, \eta_{\mathrm{p}}{ }^{2}=0.07$. This result indicates that the number of target problems completed by choosers and non-choosers differed between experimental and control assignments. Follow-up comparisons revealed, however, that the difference between choosers' mean target problems completed on control $(M=8.71)$ and experimental $(M=8.85)$ assignments did not significantly differ $(p=.38)$. Nonchoosers, however, completed more target problems on control assignments $(M=8.63)$ compared to experimental assignments $(M=7.92 ; p=.001)$.

The main effect for interspersing ratio was statistically significant, $F(2,270)=$ 3.29, MSE $=6.98, p=.04, \eta_{\mathrm{p}}{ }^{2}=0.02$. This result indicates that the number of target problems participants completed collapsed across experimental and control assignments differed among the three interspersing ratios. Follow-up analyses revealed that 
participants completed significantly more target problems on assignments for the 1:3 ( $M$ $=8.73)$ interspersing ratio than the $0: 1(M=8.18)$ interspersing ratio $(p=.04)$. Further, participants completed significantly more target problems on assignments for the 2:1 ( $M$ $=8.68)$ interspersing ratio than the $0: 1(M=8.18)$ interspersing ratio $(p=.04)$. The differences between means for target problems completed on assignments for the 1:3 ( $M$ $=8.73)$ and 2:1 $(M=8.68)$ interspersing ratios, however, did not significantly differ $(p=$ $.85)$.

The main effect for assignment type was statistically significant, $F(1,135)=4.74$, $M S E=3.19, p=.03, \eta_{\mathrm{p}}^{2}=0.03$. This result indicates that participants, overall, completed more target problems on one assignment compared to the other. Pairwise comparisons revealed that participants completed significantly more target problems on control assignments compared to experimental assignments $(p=.03)$.

\section{Academic Performance Accuracy}

A multivariate mixed model ANOVA was conducted for the 2 (chooser vs. nonchooser) $\mathrm{2} 2$ (experimental assignment vs. control assignment) $\mathrm{x} 3$ (0:1 vs. $1: 3$ vs. $2: 1)$ design to evaluate the effects of participant choice, assignment type, and interspersing ratio on performance accuracy. The between-subjects factor was participant choice for homework (as analyzed for the 1:3 assignment pair), and the within-subjects factors were assignment type and interspersing ratio. It was hypothesized that chooser and nonchooser accuracy performance would not statistically significantly differ between assignments for all assignment pairs. Table 7 displays the means and standard deviations for academic performance accuracy on experimental and control assignments across the three interspersing ratios for choosers, non-choosers, and collapsed across the two 
participant groups. The interaction of participant choice, assignment type, and interspersing ratio was not statistically significant $(F[2,258]=.30, M S E=203.91, p=$ $.74, \eta_{\mathrm{p}}{ }^{2}=0.002$ ), thus supporting the above hypothesis.

Table 7. Mean Academic Performance Accuracy as a Percentage Among Interspersing Ratios For Choosers, Non-Choosers, and Collapsed Across Groups

\begin{tabular}{|c|c|c|c|c|c|c|}
\hline \multirow[b]{2}{*}{$\begin{array}{l}\text { Interspersing } \\
\text { Ratio } \\
\end{array}$} & \multicolumn{2}{|c|}{$\frac{\text { Choosers }}{(\mathrm{N}=87)}$} & \multicolumn{2}{|c|}{$\frac{\text { Non-choosers }}{(\mathrm{N}=44)}$} & \multicolumn{2}{|c|}{$\frac{\text { Collapsed }}{(\mathrm{N}=131)}$} \\
\hline & $\mathrm{M}$ & SD & M & SD & $\mathrm{M}$ & SD \\
\hline \multicolumn{7}{|l|}{$0: 1$} \\
\hline Experimental & 56.68 & 34.85 & 63.09 & 35.62 & 58.83 & 35.10 \\
\hline Control & 58.50 & 34.85 & 65.90 & 35.09 & 60.98 & 34.97 \\
\hline \multicolumn{7}{|l|}{$1: 3$} \\
\hline Experimental & 63.35 & 37.01 & 68.81 & 34.64 & 65.18 & 36.19 \\
\hline Control & 61.56 & 36.62 & 72.07 & 32.90 & 65.09 & 35.63 \\
\hline \multicolumn{7}{|l|}{$2: 1$} \\
\hline Experimental & 63.61 & 36.60 & 66.13 & 36.00 & 66.91 & 34.91 \\
\hline Control & 65.18 & 35.24 & 70.34 & 34.38 & 64.46 & 36.28 \\
\hline
\end{tabular}

The main effect for interspersing, however, was statistically significant, $F(2,258)$ $=6.36, M S E=349.73, p=.002, \eta_{\mathrm{p}}{ }^{2}=0.05$. Pairwise comparisons showed that, overall, participant accuracy on 1:3 $(M=66.45, S D=3.21 ; p=.001)$ and $2: 1(M=66.32, S D=$ $3.18 ; p=.004)$ assignment pairs was higher than on $0: 1(M=61.04, S D=3.05)$ assignment pairs. Further, overall participant accuracy did not significantly differ between 1:3 $(M=66.45, S D=3.21)$ and 2:1 $(M=66.32, S D=3.18)$ assignment pairs $(p$ $=.94)$. 


\section{Total Problems Completed}

A multivariate mixed model ANOVA was conducted for the 2 (chooser vs. nonchooser) x 2 (experimental assignment vs. control assignment) x 3 (0:1 vs. 1:3 vs. 2:1) design to evaluate the effects of participant choice, assignment type, and interspersing ratio on total problems completed. The between-subjects factor was participant choice for homework (as analyzed for the 1:3 assignment pair), and the within-subjects factors were assignment type and interspersing ratio.

Mauchly's test indicated that the assumption of sphericity was violated for the interaction of assignment type and interspersing ratio $\left(\chi^{2}[2]=120.90, p<.001\right)$, and the degrees of freedom, therefore, were corrected using Greenhouse-Geisser estimates of sphericity $(\varepsilon=0.63)$. The Greenhouse-Geisser adjustment is a more conservative estimate based on the value of $\varepsilon$, which is biased, and this bias increases as true values of $\varepsilon$ approach 1.0. The Greenhouse-Geisser adjustment, therefore, provides better protection against type I error, as opposed to the Huynh-Feldt correction, as the obtained value of $\varepsilon$ was 0.63 (Bathke, Schabenberger, Tobias, \& Madden, 2009). This correction yielded reduced degrees of freedom of 1.25 from 2.00. Despite the reduction in degrees of freedom, the Greenhouse-Geisser correction did not change the conclusions of the results.

Table 8 displays the means and standard deviations for total problems completed on experimental and control assignments across the three interspersing ratios for choosers, non-choosers, and collapsed across the two participant groups. The interaction effect of assignment type and interspersing ratio was statistically significant, $F(1.25$, $169.35)=725.16, M S E=15.13, p<.001, \eta_{\mathrm{p}}{ }^{2}=0.84$. Pairwise comparison analyses 
using paired samples t-tests revealed that participants $(N=141)$ overall demonstrated no significant differences between mean total problems completed on experimental and control assignments for the $0: 1$ interspersing ratio, $t(140)=-1.85, p=.067, d=0.09$. The differences between mean total problems completed on experimental and control assignments was significant for all participants $(N=141)$ for the $1: 3(t[140]=12.80, p<$ $.001, d=0.64)$ interspersing ratio. The differences between mean total problems completed on experimental and control assignments for all participants $(N=131)$ was also significant for the $2: 1(t[136]=31.25, p<.001, d=2.70)$ interspersing ratio.

Table 8. Mean Total Problems Completed Among Interspersing Ratios For Choosers, Non-Choosers, and Collapsed Across Groups

\begin{tabular}{|c|c|c|c|c|c|c|}
\hline \multirow[b]{2}{*}{$\begin{array}{l}\text { Interspersing } \\
\text { Ratio }\end{array}$} & \multicolumn{2}{|c|}{$\frac{\text { Choosers }}{(\mathrm{N}=91)}$} & \multicolumn{2}{|c|}{$\frac{\text { Non-choosers }}{(\mathrm{N}=46)}$} & \multicolumn{2}{|c|}{$\frac{\text { Collapsed }}{(\mathrm{N}=137)}$} \\
\hline & M & $\mathrm{SD}$ & M & SD & M & SD \\
\hline \multicolumn{7}{|l|}{$0: 1$} \\
\hline Experimental & 8.32 & 3.85 & $7.52 *$ & 3.49 & $8.11 *$ & 3.73 \\
\hline Control & 8.38 & 3.93 & 8.48 & 3.87 & 8.44 & 3.86 \\
\hline \multicolumn{7}{|l|}{$1: 3$} \\
\hline Experimental & $12.35^{*}$ & 5.03 & $10.52 *$ & 5.15 & $11.86^{*}$ & 5.13 \\
\hline Control & 8.96 & 3.64 & 8.76 & 3.88 & 8.98 & 3.71 \\
\hline \multicolumn{7}{|l|}{$2: 1$} \\
\hline Experimental & $29.07 *$ & 9.46 & $26.83^{*}$ & 9.42 & $28.31^{*}$ & 9.47 \\
\hline Control & 8.80 & 4.03 & 8.65 & 3.65 & 8.75 & 3.89 \\
\hline
\end{tabular}

*Mean differences significant at $p<.05$.

The interaction effect of participant choice and assignment type was also statistically significant, $F(1,270)=8.30, M S E=13.07, p=.005, \eta_{\mathrm{p}}{ }^{2}=0.06$. It was 
hypothesized that non-choosers would complete statistically significantly more total problems on the experimental assignment relative to the matched control assignment for the 0:1 assignment pair (i.e., assignment without interspersing vs. assignment without interspersing), whereas choosers would demonstrate no statistically significant differences in total problems completed between assignments for the 0:1 assignment pair. To test this hypothesis, pairwise comparison analyses were conducted using paired samples t-tests. The analysis for the 0:1 interspersing ratio revealed that choosers $(N=$ 94) demonstrated no statistically significant differences in mean total problems completed on experimental assignments $(M=8.40, S D=3.85)$ relative to control assignments $(M=8.43, S D=3.90), t(93)=-.10, p=.92, d=0.01$, whereas non-choosers $(N=47)$ demonstrated statistically significant differences in mean total problems completed on experimental assignments $(M=7.53, S D=3.45)$ relative to control assignments $(M=8.47, S D=3.83), t(46)=-3.07, p=.004, d=0.26$. Data, therefore, supported this first hypothesis.

It was hypothesized that choosers would complete statistically significantly more total problems on experimental assignments relative to matched control assignments for both the 1:3 and 2:1 interspersing ratios. To test this hypothesis, planned comparison analyses were conducted using paired samples t-tests. For the 1:3 interspersing ratio, choosers $(N=94)$ completed significantly more total problems on experimental assignments $(M=12.46, S D=5.03)$ relative to control assignments $(M=9.04, S D=$ 3.64), $t(93)=13.27, p<.001, d=0.78$. For the $2: 1$ interspersing ratio, choosers $(N=91)$ also completed significantly more total problems on experimental assignments $(M=$ 29.07, $S D=9.46)$ relative to control assignments $(M=8.80, S D=4.03), t(90)=26.32, p$ 
$<.001, d=2.79$. This second hypothesis, therefore, was supported by these data.

It was hypothesized, conversely, that non-choosers would demonstrate no statistically significant differences in total problems completed for the 1:3 assignment pair. To test this hypothesis, a planned comparison analysis was conducted using a paired samples t-tests. For the 1:3 interspersing ratio non-choosers $(N=47)$ completed significantly more total problems on experimental assignments $(M=10.66, S D=5.18)$ relative to control assignments $(M=8.85, S D=3.89), t(46)=4.57, p<.001, d=0.40$. These data, therefore, do not support this third hypothesis.

Lastly, non-choosers were hypothesized to complete statistically significantly more total problems on the 2:1 experimental assignment relative to its matched control assignment. To test this hypothesis, planned comparison analyses were conducted using paired samples t-tests. For the 2:1 interspersing ratio non-choosers $(N=46)$ completed significantly more total problems on experimental assignments $(M=26.83, S D=9.42)$ relative to control assignments $(M=8.65, S D=3.65), t(45)=17.20, p<.001, d=2.54$. These data, thus, support this last hypothesis.

Mauchly's test indicated that the assumption of sphericity was violated for the interspersing ratio factor $\left(\chi^{2}[2]=22.77, p<.001\right)$, and the degrees of freedom therefore were corrected using Huynh-Feldt estimates of sphericity $(\varepsilon=0.88)$. The Huynh-Feldt estimate of sphericity was used due to its accuracy in correcting for sphericity violations (i.e., guarding against type I error) when comparing the sample estimate of $\varepsilon$ to the $F$ sampling distribution when $\varepsilon$ is greater than 0.75 (Keselman, Algina, \& Kowalchuk, 2001). This correction yielded reduced degrees of freedom of 1.76 from 2.00. Despite the reduction in degrees of freedom, the Huynh-Feldt correction did not change the 
conclusions of the results.

The main effect of interspersing ratio was statistically significant $(F[1.76,238.02]$ $\left.=453.34, M S E=17.76, p<.001, \eta_{\mathrm{p}}{ }^{2}=0.77\right)$ such that participants completed more total problems on the 2:1 experimental assignment relative to the $0: 1(p<.001)$ and 1:3 $(p<$ .001) experimental assignments. Moreover, participants completed more total problems on the $1: 3$ experimental assignment relative to the $0: 1(p<.001)$ experimental assignment. Mauchly's test indicated that the assumption of sphericity was not violated for the assignment type factor and, thus, the main effect of assignment type was tested assuming sphericity. The main effect for assignment type was statistically significant $(F[1,135]=706.13, M S E=13.07, p<.001)$ such that participants completed more total problems on the experimental assignments relative to the control assignments $(p<.001)$. The main effect for participant choice, however, was not statistically significant, $F(1$, $135)=1.21, M S E=109.88, p=.27, \eta_{\mathrm{p}}{ }^{2}=0.01$.

\section{Relative Problem Completion Rates}

To analyze relative problem completion rates a two-way mixed model ANOVA was conducted for the 2 (chooser vs. non-chooser) x 3 (0:1 vs. 1:3 vs. 2:1) design to evaluate the effects of participant choice and interspersing ratio on relative problem completion rates. The between-subjects factor was participant choice for homework (as analyzed for the 1:3 assignment pair), and the within-subjects factor was interspersing ratio. Mauchly's test indicated that the assumption of sphericity was violated for the main effect of interspersing ratio $\left(\chi^{2}(2)=137.95, p<.001\right)$, and the degrees of freedom, therefore, were corrected using Greenhouse-Geisser estimates of sphericity $(\varepsilon=0.60)$. The Greenhouse-Geisser adjustment is a more conservative estimate based on the value 
of $\varepsilon$, which is biased, and this bias increases as true values of $\varepsilon$ approach 1.0. The Greenhouse-Geisser adjustment, therefore, provides better protection against type I error, as opposed to the Huynh-Feldt correction, as the obtained value of $\varepsilon$ was 0.60 (Bathke, et al., 2009). This correction yielded reduced degrees of freedom of 1.21 from 2.00. Despite the reduction in degrees of freedom, the Greenhouse-Geisser correction did not change the conclusions of the results.

Table 9 displays the means and standard deviations for relative problem completion rates across the three interspersing ratios for choosers, non-choosers, and collapsed across the two participant groups. It was hypothesized that, overall, relative problem completion rates would be statistically significantly higher for the 2:1 assignment pair relative to the 1:3 and 0:1 (i.e., no interspersing) assignment pairs. The main effect of interspersing ratio was statistically significant $(F[1.21,156.93]=211.92$, $\left.M S E=1.67, p<.001, \eta_{\mathrm{p}}{ }^{2}=.62\right)$ such that mean relative problem completion rate for the 2:1 assignment pair was higher than the $0: 1(p<.001)$ and $1: 3(p<.001)$ assignment pairs. Further, it was hypothesized that relative problem completion rates would be statistically significantly higher for the 1:3 assignment pair relative to the $0: 1$ assignment pair. Pairwise comparisons revealed that mean relative problem completion rates, overall, were statistically significantly higher for the 1:3 assignment pair relative to the $0: 1(p<.001)$ assignment pair. These results demonstrate that relative problem completion rate ratios increased as participants contacted richer schedules of interspersing. 
Table 9. Mean Relative Problem Completion Rates (RPCR) Among Interspersing Ratios For Choosers, Non-Choosers, and Collapsed Across Groups

\begin{tabular}{|c|c|c|c|c|c|c|}
\hline \multirow{2}{*}{$\begin{array}{l}\text { Interspersing } \\
\text { Ratio } \\
\end{array}$} & \multicolumn{2}{|c|}{$\frac{\text { Choosers }}{(\mathrm{N}=87)}$} & \multicolumn{2}{|c|}{$\frac{\text { Non-choosers }}{(\mathrm{N}=45)}$} & \multicolumn{2}{|c|}{$\frac{\text { Collapsed }}{(\mathrm{N}=132)}$} \\
\hline & $\mathrm{M}$ & SD & M & SD & M & SD \\
\hline $0: 1$ & & & & & & \\
\hline $\begin{array}{l}\text { RPCR } \\
1: 3\end{array}$ & $1.04 *$ & 0.34 & $0.89^{*}$ & 0.29 & $0.99^{*}$ & 0.33 \\
\hline $\begin{array}{l}\text { RPCR } \\
2: 1\end{array}$ & $1.41^{*}$ & 0.36 & $1.29 *$ & 0.82 & $1.37^{*}$ & 0.56 \\
\hline RPCR & $3.59 *$ & 1.66 & $3.32 *$ & 1.46 & $3.50^{*}$ & 1.66 \\
\hline
\end{tabular}

* Mean differences significant at $p<.05$.

The interaction effect of interspersing ratio and participant choice was not significant, $F(1.21,156.93)=.21, M S E=1.01, p=.70$. It was hypothesized, however, that non-choosers would demonstrate statistically significantly higher relative problem completion rates for the 2:1 assignment pair relative to the 1:3 and 0:1 assignment pairs. To test this hypothesis, planned comparison analyses were conducted using paired samples t-tests. This analysis revealed that non-choosers' mean relative problem completion rate for the $2: 1$ interspersing ratio was statistically significantly higher than that of the $0: 1$ interspersing ratio, $t(44)=11.29, p<.001, d=2.31$. Further, nonchoosers' mean relative problem completion rate for the 2:1 interspersing ratio was statistically significantly higher than that of the $1: 3$ interspersing ratio, $t(44)=8.67, p<$ $.001, d=1.71$. Lastly, non-choosers' mean relative problem completion rate for the $1: 3$ interspersing ratio was statistically significantly higher than that of the $0: 1$ interspersing ratio, $t(44)=3.17, p=.003, d=0.65$. These results demonstrate that non-choosers 
completed more problems on experimental assignments with interspersing relative to matched control assignments for the 1:3 and 2:1 interspersing ratios compared to the $0: 1$ rate, where the difference between the two assignments was the largest for the 2:1 interspersing ratio. The univariate test for the main effect for participant choice revealed non-significant results, $F(1,130)=2.54, M S E=1.16, p=.113, \eta_{\mathrm{p}}{ }^{2}=0.02$.

A Pearson product moment correlation coefficient was calculated to quantify the relationship between relative problem completion rate ratios and participants' choice of assignment for homework. Mean relative problem completion rates were calculated among all participants for 0:1 $(M=1.00 ; N=138), 1: 3(M=1.38 ; N=141)$, and $2: 1(M=$ $3.57 ; N=135$ ) interspersing ratios. The proportion of participants who chose the experimental assignment for each interspersing ratio was calculated by dividing the number of participants who chose the experimental assignment with interspersing by the sum of those who chose the experimental assignment and those who chose the control assignment. Two students did not indicate a choice for either assignment (i.e., either did not circle an assignment letter or circled both assignment letters) for the 0:1 interspersing ratio and their data were excluded from the analysis. The sample sizes for analyzing the proportions across interspersing ratios, therefore, were not all equal. The proportion of people who chose the experimental assignment for the 0:1 interspersing ratio was .50; the proportion for the 1:3 interspersing ratio was .67; and the proportion for the $2: 1$ interspersing ratio was .79 . Figure 1 depicts the mean relative problem completion rate ratios and the proportion of people who chose the experimental assignment with interspersing across the three ratios of interspersing. The primary y-axis (left) corresponds to values for mean relative problem completion rate data, while the 
secondary $y$-axis (right) corresponds to values for choice proportion data. The

correlation was .88. These data indicate that as participants' problem completion rates on the experimental assignment with interspersing increased relative to the matched control assignment, the number of participants who chose the experimental assignment also increased. Relative problem completion rate ratios accounted for approximately $78 \%$ of the variance in participants' choice of assignment for homework.

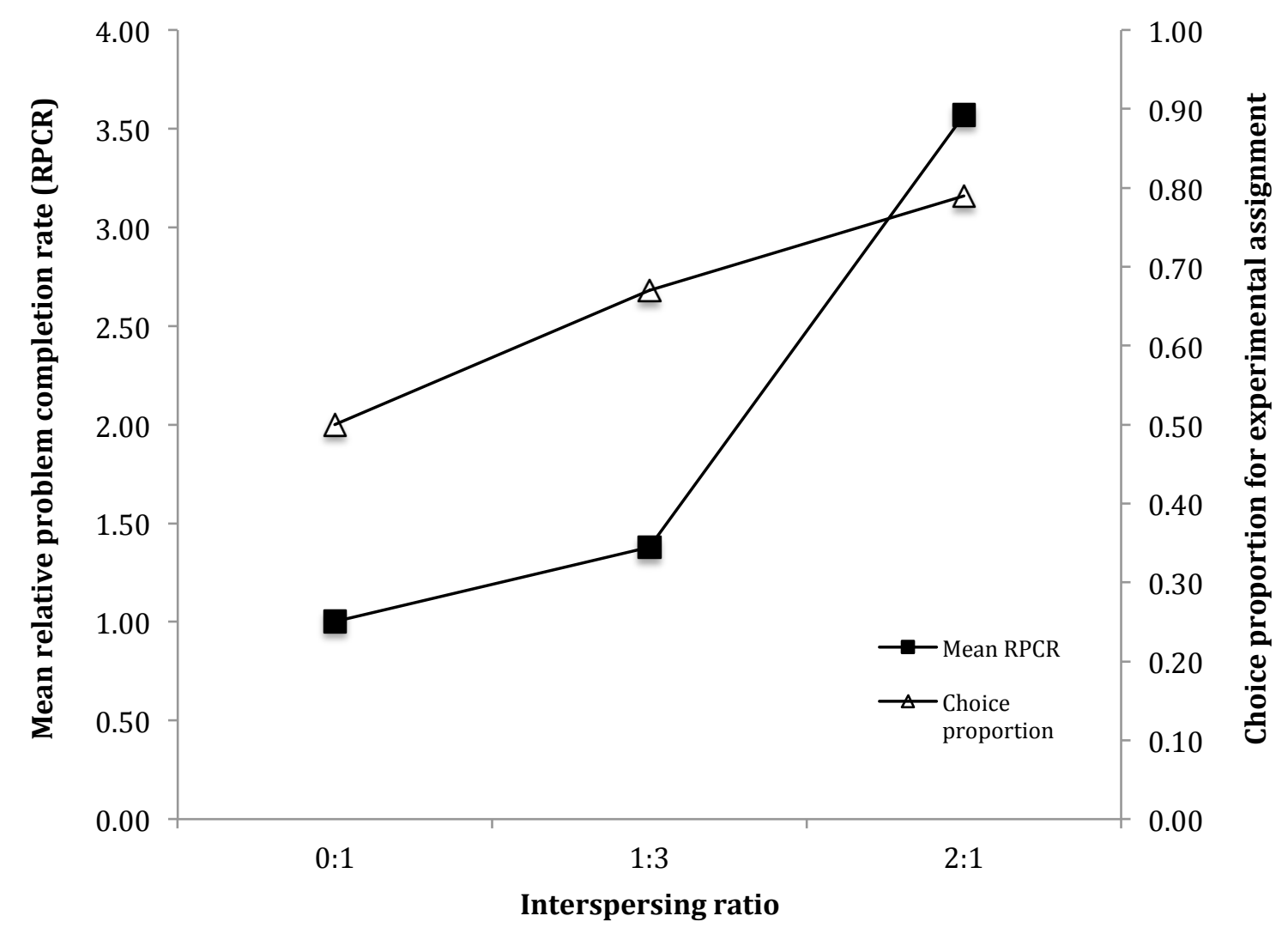

Figure 1. Choice Proportion for Experimental Assignments with Interspersing as a Function of Relative Problem Completion Rates Across the Three Ratios of Interspersing. 


\section{Reinforcement History Questionnaire}

Of the 141 participants included in data analysis, 136 completed the reinforcement history questionnaire. Of the 136 who completed the reinforcement questionnaire, five participants did not follow directions appropriately and their total percentages did not sum to 100 , so these data were discarded from the analyses. Thus, a total of 131 participant responses were included in the data analysis. The 131 participants reported receiving a desirable outcome a mean of $51.99 \%(S D=23.02)$ of the time after completing a math assignment, an undesirable outcome a mean of $24.43 \%$ ( $S D$ $=18.37)$ of the time, time away from work a mean of $18.72 \%(S D=14.55)$ of the time, and a loss of privileges a mean of $4.86 \%(S D=8.00)$ of the time. Participants, therefore, reported receiving a desirable outcome most often after completing math assignments in the past, while losing privileges after completing a math assignment in the past was reported to occur the least often.

Table 10. Mean Percentage of Time Consequences Following a Past Assignment Reported For Choosers, Non-Choosers, and Collapsed Across Groups

\begin{tabular}{|c|c|c|c|c|c|c|}
\hline \multirow[b]{2}{*}{ Past assignment consequence } & \multicolumn{2}{|c|}{$\frac{\text { Choosers }}{(\mathrm{N}=87)}$} & \multicolumn{2}{|c|}{$\frac{\text { Non-choosers }}{(\mathrm{N}=44)}$} & \multicolumn{2}{|c|}{$\frac{\text { Collapsed }}{(\mathrm{N}=131)}$} \\
\hline & $\mathrm{M}$ & SD & M & SD & M & SD \\
\hline Desirable outcome & 51.56 & 22.69 & 52.84 & 23.90 & 51.99 & 23.02 \\
\hline Undesirable outcome & 25.14 & 18.94 & 23.02 & 17.31 & 24.43 & 18.37 \\
\hline Time away from work & 18.01 & 12.76 & 20.11 & 17.64 & 18.72 & 14.55 \\
\hline Loss of privileges & 5.29 & 8.15 & 4.02 & 7.23 & 4.86 & 8.00 \\
\hline
\end{tabular}

Three separate multiple regression models were constructed to determine whether 
consequences for completing math assignments (i.e., time away from work, an undesirable outcome, loss of privileges, desirable outcome) predicted relative problem completion rate ratios for each of the three interspersing ratios (i.e., 0:1, 1:3, 2:1). For each regression analysis the predictor variables of time away from work, undesirable outcome, loss of privileges, and desirable outcome were entered to predict relative problem completion rate ratios for each interspersing ratio. Results showed that the predictor variables did not predict relative problem completion rates for the $0: 1(p=.64)$, $1: 3(p=.25)$, or $2: 1(p=.15)$ interspersing ratios. 


\section{CHAPTER VII}

\section{GENERAL DISCUSSION}

\section{Summary and Implications of Current Study}

The current study sought to investigate the effects of manipulating rates of problem interspersing within an assignment on student choice for math assignments. Specifically, in an attempt to replicate previous research (i.e., Cates and Dalenberg, 2005) and to determine the consistency of students' choice for academic assignments, interspersing ratios were systematically manipulated across assignment pairs. In addition to replicating the research by Cates and Dalenberg (2005), this investigation attempted to extend it in multiple ways: first, this study implemented a richer schedule of reinforcement (i.e., 2:1) by interspersing two brief problems prior to a longer problem; second, chooser and non-chooser choice and preference for assignments were compared across the interspersing schedules; third, assignment choice and preference consistency across assignments was measured both within and between choosers and non-choosers; and lastly, this study sought to further investigate the discrete task completion hypothesis by asking participants to provide information regarding their reinforcement histories for completing math assignments.

Results from this investigation showed that participant choice and preference for either assignment at the group level did not differ between assignments for the 0:1 assignment pair. For the 1:3 and 2:1 assignment pairs, however, participants preferred 
the assignments with interspersing relative to the matched control assignments as taking less time, requiring less effort, being less difficult to complete. Further, participants also chose for homework the assignments with interspersing relative to the matched control assignments within the $1: 3$ and $2: 1$ assignment pairs.

Choosers consistently chose and preferred assignments with interspersing relative to control assignments as they contacted richer ratios of interspersing. Specifically, choosers' choices and preferences for assignments with interspersing for 1:3 and 2:1 interspersing ratios were significantly higher than the $0: 1$ ratio, and choosers' preferences for assignments with interspersing for the $2: 1$ ratio were higher for time and effort dimensions, although less choosers chose the 2:1 assignment with interspersing than the $1: 3$

Non-choosers' choices and preferences for assignments across interspersing ratios were inconsistent. Specifically, preferences for assignments on the dimensions of time and difficulty and choices for assignments were inconsistent across interspersing ratios. The 2:1 interspersing ratio, interestingly, affected non-choosers' preferences and choice such that more non-choosers preferred the experimental assignment relative to the control assignment as less time consuming, less effortful, and less difficult, and they chose it for homework, than those preferences and choice observed for the 1:3 experimental assignment. That is, non-choosers' preferences and choice for assignments for the 1:3 interspersing ratio changed to more closely resemble the preferences and choices of choosers with the introduction of the $2: 1$ interspersing ratio.

Differences were found for target problems completed. Choosers completed equal amounts of target problems on control and experimental assignments, overall, 
while non-choosers completed more target problems on control assignments compared to experimental assignments. Choosers completed more target problems and were more accurate at completing target problems for the $1: 3$ and 2:1 interspersing ratios compared to the $0: 1$ interspersing ratio, but target problems completed and accuracy did not differ between 1:3 and 2:1 interspersing ratios. Participants, overall, also completed more target problems on control assignments compared to experimental assignments.

Overall, participants completed more total problems on experimental assignments than control assignments. Specifically, participants completed more total problems on experimental assignments for the 1:3 and 2:1 interspersing ratios compared to $0: 1$, and participants completed more total problems on the experimental assignment for 2:1 than the 1:3 experimental assignment. Participants completed more total problems on experimental versus control assignments for the 1:3 and 2:1 interspersing ratios; no differences were found for the 0:1 interspersing ratio. For the 0:1 interspersing ratio, non-choosers completed more total problems on the experimental assignment relative to the control assignment, whereas choosers demonstrated no differences between assignments. Choosers, however, completed more total problems on experimental relative to control assignments for the 1:3 and 2:1 interspersing ratios. Non-choosers' total problems completed on experimental and control assignments for the 1:3 interspersing ratio did not differ, but non-choosers completed more total problems on experimental assignments relative to control assignments for the $2: 1$ interspersing ratio.

Participants reported most often receiving a desirable consequence (i.e., positive reinforcement) after completing a math assignment in the past, while receiving a loss of privileges (i.e., negative punishment) least often. These results support the assumption of 
the discrete task completion hypothesis that students have a history of contacting reinforcement after completing mathematics assignments. Participants in this study specifically indicated that positive reinforcement was the most contacted consequence.

Results from the current investigation support earlier findings in the interspersing literature (e.g., Billington et al., 2004; Billington, Skinner, Hutchins et al., 2002; Cates et al., 1999; Cates \& Dalenberg, 2005; Cates \& Erkfritz, 2007; McDonald \& Ardoin, 2007; Skinner et al., 1999) that students prefer and choose assignments with interspersing relative to matched assignments without interspersing. Thus, the current study's findings support the robust effects of math interspersing as an effective antecedent manipulation for increasing the likelihood of evoking choice behavior for such academic assignments.

Understanding and targeting the causal mechanism of math interspersing procedures has been a goal of previous research. In the current study, results indicated that problem completion rates were higher on assignments with interspersing relative to control assignments, thus supporting previous findings in the interspersing literature (e.g., Billington et al., 2004; Cates, \& Dalenberg, 2005; Cates, \& Erkfritz, 2007; Hawkins et al., 2005; Logan and Skinner, 1998; Skinner, 2002; Skinner, Robinson et al., 1996). Specifically, relative problem completion rates increased as ratios of interspersing became richer. Moreover, as relative problem completion rates increased so too did the proportion of people choosing the assignment with interspersing. These current results replicate those from previous research that directly manipulated relative problem completion rates and, thus, manipulated participant choice behavior (Cates, \& Dalenberg, 2005; Cates, \& Erkfritz, 2007).

The current investigation not only replicated previous research by Cates and 
Dalenberg (2005) by manipulating relative problem completion rate ratios in a similar manner (i.e., 0:1 and 1:3 interspersing ratios), but also extended their research. In the current study, participants completed an assignment pair at a novel interspersing ratio (i.e., 2:1) and this interspersing ratio caused more participants to choose and prefer the assignments with interspersing than the 1:3 interspersing ratio. Further, participants completed significantly more total problems on the experimental assignment with interspersing for the $2: 1$ ratio $(M=28.31)$ than the $1: 3$ ratio $(M=11.86)$. Although measuring the efficacy of the difference in total problem completion rate means is not possible in the current study, the assignment with interspersing for the 2:1 rate caused participants to complete more than double the amount of work as completed for the 1:3 assignment with interspersing. This increase in task completion came without compromising the number of target problems completed or the accuracy of completing such problems.

Perhaps the mechanism responsible for the effects of the 2:1 interspersing ratio can be conceptualized from a behavioral momentum (Nevin, Mendell, \& Atak, 1983) perspective. In behavioral momentum theory, the two primary components of operant behavior are response rate and a behavior's resistance to change (Nevin, 1992). Rate changes in operant behavior, therefore, are indicators of behavioral momentum (Nevin, 1974; Fath, Fields, Malott, \& Grossett, 1983). Participant responding clearly increased as a function of increased rates of problem completion. Specifically, participants completed an average of 8.11 total problems on the $0: 1$ experimental assignment, 11.86 on the $1: 3$ experimental assignments, and 28.31 on the $2: 1$ experimental assignment. Responding rates for the 2:1 ratio, therefore, suggest that the stimulus established sufficient 
reinforcement to maintain response rates that resisted change. If the stimulus established sufficient reinforcement, however, the discrete task completion hypothesis provides a better account for the properties and effects of the academic stimulus on responding. Participants' task completion was also terminated non-contingently in the current study, so resistance to change was not fully measured.

Apart from behavioral momentum, interspersing at a 2:1 ratio may have functioned more as a high-probability (high-p) command sequence (Mace et al., 1988). In a high- $p$ command sequence a series (e.g., three to five) of task demands with the greatest likelihood of compliance are presented followed by a task demand with the least likelihood of compliance (low- $p$ ). When reinforcement is provided following this complete sequence (i.e., after compliance with the low- $p$ task demand), research demonstrates that responding persists following this stimulus presentation sequence (e.g., Lee, Belfiore, Scheeler, Hua, \& Smith, 2004; Mace et al., 1988; Patel et al., 2007).

In the current study the 2:1 interspersing ratio presented problems within an assignment in a similar manner. Thus, completing long problems (i.e., low- $p$ ) following brief problems (i.e., high- $p$ task demands) might demonstrate resistance to change following an alternative stimulus presentation (i.e., when a long problem is presented). The experimental design of the current study, however, does not allow for conclusions regarding the resistance to change of responding, nor does it allow for conclusions regarding whether the long mathematics problems in fact functioned as low- $p$ task demands. Future investigations should consider assessment methods that capture the degree to which completing long problems is a low probability task demand.

Replicating and extending results from Cates and Dalenberg (2005) regarding 
increases in relative problem completion rate ratios also supports the hypothesis that problem completion is a reinforcing event. Specifically, participants chose and preferred assignments when they completed more problems on such assignments. The current investigation further supported the theoretical basis of interspersing procedures. The matching law (Herrnstein, 1961; 1970) would predict that participant choice behavior would increase as relative rates of reinforcement increased between assignments. The results obtained currently for relative problem completion rate ratios supports this prediction.

In addition to replicating previous interspersing research, the current investigation extended such research by focusing on non-choosers. Although interspersing procedures have been shown to increase problem completion rates and the choice for such assignments, these studies consistently identify participants who do not choose assignments with interspersing despite increases in relative problem completion rates. The current study extended previous research on interspersing by showing that nonchoosers demonstrate higher relative problem completion rates when completing assignments pairs containing an experimental assignment with interspersing. These increased relative problem completion rates, however, are not accounting for choice behavior as the discrete task completion hypothesis would predict. Non-choosers completed more problems on experimental assignments with interspersing relative to control assignments for the 1:3 assignment pair, yet they all chose the control assignment for homework.

Interestingly, as hypothesized, non-choosers completed statistically significantly more problems on one assignment relative to the other for the 0:1 interspersing ratio. 
According to the matching law, non-choosers would be predicted to complete the same number of problems on both assignments and choose both with equal frequency. Nonchoosers by default, thus, are not matching their behavior provided equal rates of reinforcement as was observed with choosers. The percentages of non-choosers that indicated preference for either assignment in the 0:1 assignment pair based on time, effort, and difficulty were more discrepant than choosers. That is, most non-choosers indicated a preference for the experimental assignment for the 0:1 interspersing ratio and the discrepancy between the percentages for the two assignments was greater than the discrepancy observed for choosers. Perhaps non-choosers' are more sensitive to the discriminative stimuli associated with completing academic assignments. Latency to complete an assignment, response effort, and the relationship between the student's skill level and the demand of the instructional material are variables to which non-choosers may be more sensitive.

Some findings from the current investigation contradict those from previous research. Previous research has widely supported that interspersing procedures do not negatively impact accuracy or target problems completed (e.g., Billington et al., 2004; Billington, Skinner, Hutchins et al., 2002; Cates et al., 1999; Cates \& Dalenberg, 2005; Cates \& Erkfritz, 2007; McDonald \& Ardoin, 2007; Skinner et al., 1999). Participants in the current study, however, completed more target problems and were more accurate at completing target problems for the 1:3 and 2:1 interspersing ratios compared to the $0: 1$ interspersing ratio. Participants also completed more target problems on control assignments compared to experimental assignments. Similar to previous research designs, in the current study worksheets within assignment pairs were counterbalanced 
and the presentation of assignment pairs within packets was randomized. Thus, order affects cannot account for target problem completion and accuracy differences. This increased accuracy and overall number of target problems completed may also play a role in choice differentially across choosers and non-choosers.

The current study presented participants with 2-digit x 2-digit $(2 \times 2)$ multiplication problems as target problems, whereas many previous studies presented $3 \mathrm{x}$ 2 multiplication problems as target problems. This slight difference, however, should not have had enough of an effect to influence the number of target problems completed or accuracy of completing such problems. One study by Hawkins, Skinner, and Oliver (2005) demonstrated that participants were more accurate in completing target problems with interspersing on a fixed-ratio (FR1) schedule compared to no interspersing. No differences in accuracy were found for the FR3 interspersing schedule employed. In the Hawkins et al. study, however, participants were fifth-grade students who completed problems containing a two-digit followed by three, one-digit numbers and the operations were mixed addition and subtraction (e.g., $78+3-4+5$ ). In another study participants completed multiple assignment pairs with target problems of differing lengths (i.e., $4 \times 1$, 4 × 2, 4 × 3, 4 x 4; Skinner et al., 1999). Results showed that participant accuracy decreased systematically as the target problem length increased. These findings, however, do not support findings from the current study, as target problem length was held consistent in the current study. Current data suggest that interspersing did not necessarily have a negative effect on accuracy such that accuracy differences were among aggregate results across interspersing ratios, not between assignment types. Target problem accuracy findings from the current study might also be considered an anomaly 
compared to previous interspersing research until replicated.

\section{Limitations and Future Research}

One limitation of the current study is that the academic material was not matched to current material in which participants engage in classes. Participants were assumed to have the skills required to complete 2-digit x 2-digit multiplication problems. The average accuracy for all participants, even when dichotomized into choosers and nonchoosers, never exceeded 75 percent. Further, the standard deviations for the average accuracy scores were consistently between 32 and 38, indicating a wide range of variance of participant accuracy. For students to build fluency with an academic skill, they must first acquire accurate responding to the academic stimulus (Haring \& Eaton, 1978). Perhaps many participants have not fully acquired the skill to accurately complete 2 x 2 multiplication problems, or participants might not have practiced this skill for a long period of time. Future research should include academic material matched to the participants' current instructional material or instructional level.

One further factor that might modify the external validity of the current study is that academic material at a mastery skill level was presented to participants. Students in school, presumably, learn correct, accurate, and efficient responding to academic material in a series of stages and academic interventions targeting these different stages can facilitate such learning (e.g., Cates \& Rhymer, 2003; Daly, Martens, Barnett, Witt, \& Olson, 2007; Daly, Martens, Dool, \& Hintze, 1998; Haring \& Eaton, 1978; Wilbur \& Cushman, 2006). While the 2:1 experimental assignments resulted in the highest problem completion rates and the highest proportion of students choosing, it is unknown for which type of academic material (e.g., that for building fluency, mastered) preceding 
target problems is most effective. Future researchers should compare target academic material at different stages of instruction to determine the best benefit of procedures used in the current study.

The population sampled in the current study was college students, which might establish a limitation. The extent to which the current findings hold external validity are unknown, but considering that interspersing procedures have been utilized in school settings as an intervention for on-task behavior (Calderhead et al., 2006; McCurdy et al., 2001; Montarello \& Martens, 2005; Skinner et al., 2002), future research should consider attempts to replicate the current results with school-age students in schools. Further, it is unknown whether the interspersing procedures implemented in the current study would impart the same effect with students who receive special education accommodations for behavior disorders (e.g., Teeple \& Skinner, 2004) or specific learning disabilities (Wildmon et al., 2004). Future research should also consider students receiving such services in schools.

A further limitation of the current study could be how choosers and non-choosers were identified. In the current study, choice indicated by participants after responding to worksheets in the 1:3 assignment pair was the criterion for identifying choosers and nonchoosers. Previous research on interspersing has implemented interspersing at a 1:3 rate and established its positive effects on choice behavior (e.g., Billington et al., 2004; Cates, \& Dalenberg, 2005; Cates, \& Erkfritz, 2007; Hawkins et al., 2005; Logan and Skinner, 1998; Skinner, 2002; Skinner, Robinson et al., 1996). The current study presented participants with multiple opportunities to respond to academic assignments, some with different rates of reinforcement. Results from the current study did show, however, that 
only non-chooser choice changed after introducing a richer ratio of interspersing. Other designs, nonetheless, could possibly establish consistency or stability in choice behavior. Perhaps future researchers could consider longitudinal experimental designs to further explore participant choice consistency for interspersing assignments.

The discrete task completion hypothesis is the most parsimonious explanation of the effects of interspersing procedures. Its main premise, however, is that students have a learned history of contacting reinforcement for assignment completion, and problem completion within an assignment, therefore, serves as conditioned reinforcement. This reinforcement history is a plausible assumption that has not been tested directly with regard to distal events. Future researchers might attempt to directly test the reinforcement history component of the discrete task completion hypothesis by providing participants with multiple opportunities to complete academic assignments and contact reinforcement outside of the conditioned reinforcement programmed into assignments (e.g., escaping the task for a brief period of time, receiving a tangible item). Moreover, repeated exposure to academic assignment completion and contacting reinforcement would establish a learned history of reinforcement for completing academic assignments. Researchers should consider designs apart from that employed in the current study to further establish a reinforcement history and test the extent to which the discrete task completion hypothesis explains choice behavior for concurrent academic assignments.

The discrete task completion hypothesis has encouraged researchers to consider the effects of interspersing on academic task engagement (Calderhead et al., 2006; McCurdy et al., 2001; Montarello \& Martens, 2005; Skinner et al., 2002). Although engaging students in responding to academic tasks increases achievement and learning 
(Bloom, 1974; DiPerna et al., 2002; Greenwood et al., 2002; Greenwood et al., 1984; Greenwood et al., 1994), continued success (i.e., maintenance) with an academic skill is contacted with fluent responding that is generalized to multiple stimuli and settings (Haring \& Eaton, 1978). Current research in interspersing has yet to analyze at what level of skill development (e.g., acquisition, fluency) interspersing procedures might have an enhancing effect on academic responding.

\section{Implications for Practice}

Interspersing procedures have demonstrated success with engaging students in academic tasks (Calderhead et al., 2006; McCurdy et al., 2001; Montarello \& Martens, 2005; Skinner et al., 2002). One of the potential pitfalls of behavior management and reinforcement contingency plans for students in schools is that they can quickly consume resources (e.g., time, staff). Further, creating a separate, specialized intervention plan for multiple students who do not meet qualifications for special education or individualized services can be inefficient. Identifying an intervention for some students who demonstrate behavior problems when presented with academic material or who generally do not respond to such material, thus, can be problematic.

Mathematics interspersing is a research-based procedure that has demonstrated increases in student perceptions of academic material (e.g., Billington et al., 2004; Cates, \& Dalenberg, 2005; Cates, \& Erkfritz, 2007; Hawkins et al., 2005; Logan and Skinner, 1998; Skinner, 2002; Skinner, Robinson et al., 1996). Educators, thus, could implement interspersing procedures (e.g., provide a choice of two similar assignments, one with interspersing and one without) as a quick, efficient method of increasing student perceptions of academic material by amplifying programmed rates of reinforcement 
within assignments without compromising the integrity of academic demands (e.g., presenting less work). Interspersing procedures also do not negatively affect student response accuracy (the current study actually demonstrated an increase in accuracy), consequently providing an effective academic stimulus presentation for practical use. 


\section{REFERENCES}

Alferink, L. A., Critchfield, T. S., Hitt, J. L., \& Higgins, W. J. (2009). Generality of the matching law as a descriptor of shot selection in basketball. Journal of Applied Behavior Analysis, 42, 595-608. doi:10.1901/jaba.2009.42-595

Ashcraft, M. H. (2002). Math anxiety: Personal educational and cognitive consequences. Current Directions in Psychological Science, 11, 181-185. doi:10.1111/14678721.00196

Ashcraft, M.H., \& Kirk, E.P. (2001). The relationships among working memory, math anxiety, and performance. Journal of Experimental Psychology: General, 130, 224-237. doi:10.1037//0096-3445.130.2.224

Bathke, A.C., Schabenberger, O., Tobias, R.D., \& Madden, L.V. (2009). GreenhouseGeisser adjustment and the ANOVA-type statistic: Cousins or twins? The American Statistician, 63, 239-246. doi:10.1198/tast.2009.08187

Baum, W. M. (1974). On two types of deviation from the matching law: Bias and undermatching. Journal of the Experimental Analysis of Behavior, 22, 231-242. doi:10.1901/jeab.1974.22-231

Baum, W. M. (1975). Time allocation in human vigilance. Journal of the Experimental Analysis of Behavior, 23, 45-53. doi:10.1901/jeab.1975.23-45

Baum, W. M. (1979). Matching, undermatching, and overmatching in studies of choice. Journal of the Experimental Analysis of Behavior, 32, 269-281. doi:10.1901/jeab.1979.32-269

Baum, W. M., \& Rachlin, H. C. (1969). Choice as time allocation. Journal of the Experimental Analysis of Behavior, 12, 861-874. doi:10.1901/jeab.1969.12-86

Baum, W. M., Schwendiman, J. W., \& Bell, K. E. (1999). Choice, contingency discrimination, and foraging theory. Journal of the Experimental Analysis of Behavior, 32, 355-373. doi:10.1901/jeab.1999.71-355

Baum, W. M., Schwendiman, J. W., \& Bell, K. E. (1999). Choice, contingency discrimination, and foraging theory. Journal of the Experimental Analysis of Behavior, 32, 355-373. doi:10.1901/jeab.1999.71-355

Belfiore, P. J., Lee, D. L., Vargas, A. U., \& Skinner, C. H. (1997). Effects of highpreference single-digit mathematics problem completion on multiple-digit mathematics problem performance. Journal of Applied Behavior Analysis, 30, 327-330. doi:10.1901/jaba.1997.30-327

Belke, T. W., \& Heyman, G. M. (1994). A matching law analysis of the reinforcing efficacy of wheel running in rats. Animal Learning \& Behavior, 22, 267-274. doi:10.3758/BF03209834

Billington, E., \& DiTommaso, N. M. (2003). Demonstrations and application of the matching law in education. Journal of Behavioral Education, 12, 91-104. doi:10.1023/A:1023881502494 
Billington, E. J., \& Skinner, C. H. (2002). Getting students to choose to do more work: Evidence of the effectiveness of the interspersal procedure. Journal of Behavioral Education, 11, 105-116. doi:10.1023/A:1015431309847

Billington, E. J., \& Skinner, C. H. (2006). Reducing perceptions of time required to complete math assignments by adding problems to assignments: A synthesis of the additive interspersal research. Journal of Behavioral Education, 15, 183-190. doi:10.1007/s10864-006-9015-9

Billington, E. J., Skinner, C. H., \& Cruchon, N. M. (2004). Improving sixth-grade students perceptions of high-effort assignments by assigning more work: Interaction of additive interspersal and assignment effort on assignment choice. Journal of School Psychology, 42, 477-490. doi:10.1016/j.jsp.2004.08.003

Billington, E. J., Skinner, C. H., Hutchins, H. M., \& Malone, J. C. (2004). Varying problem effort and choice: Using the interspersal technique to influence choice towards more effortful assignments. Journal of Behavioral Education, 13, 193207. doi:10.1023/B:JOBE.0000037629.97526.ab

Bloom, B. (1974). Time and learning. American Psychologist, 29, 682-688. doi: $10.1037 / \mathrm{h} 0037632$

Borrero, C. S. W., Vollmer, T. R., Borrero, J. C., Bourret, J. C., Sloman, K. N., Samaha, A. L., \& Dallery, J. (2010). Concurrent reinforcement schedules for problem behavior and appropriate behavior: Experimental applications of the matching law. Journal of the Experimental Analysis of Behavior, 93, 455-469. doi:10.1901/jeab.2010.93-455

Borerro, J. C., Crisolo, S. S., Tu, Q., Rieland, W. A., Ross, N. A., Francisco, M. T., \& Yamamoto, K. Y. (2007). An application of the matching law to social dynamics. Journal of Applied Behavior Analysis. 40, 589-601. doi: 10.1901/jaba.2007.589601

Borrero, J. C., \& Vollmer, T. R. (2002). An application of the matching law to severe problem behavior. Journal of Applied Behavior Analysis, 35, 13-27. doi:10.1901/jaba.2002.35-13

Bradshaw, C. M., Szabadi, E., \& Bevan, P. (1976). Behavior of human in variableinterval schedules of reinforcement. Journal of the Experimental Analysis of Behavior, 27, 275-279. doi:10.1901/jeab.1976.26-135

Bradshaw, C. M., Szabadi, E., \& Bevan, P. (1977). Effect of punishment on human variable-interval performance. Journal of the Experimental Analysis of Behavior, 27, 275-279. doi:10.1901/jeab.1977.27-275

Bradshaw, C. M., Szabadi, E., \& Bevan, P. (1978). Effect of variable-interval punishment on the behavior of humans in variable-interval schedules of monetary reinforcement. Journal of the Experimental Analysis of Behavior, 29, 161-166. doi:10.1901/jeab.1978.29-161

Bron, A., Sumpter, C. E., Foster, T. M., \& Temple, W. (2003). Contingency discriminability, matching, and bias in the concurrent-schedule responding of possums (Trichosurus vulpecula). Journal of the Experimental Analysis of Behavior, 79, 289-306. doi:10.1901/jeab.2003.79-289

Brooks, A., Todd, A. W., Tofflemoyer, S., \& Horner, R. H. (2003). Use of functional assessment and a self-management system to increase academic engagement and 
work completion. Journal of Positive Behavior Interventions, 5, 144-152. doi:10.1177/10983007030050030301

Calderhead, W. J., Filter, K. J., \& Albin, R. W. (2006). An investigation of incremental effects of interspersing math items on task-related behavior. Journal of Behavioral Education, 15, 53-67. doi:10.1007/s10864-005-9000-8

Catania, A. C. (1963a). Concurrent performances: A baseline for the study of reinforcement magnitude. Journal of the Experimental Analysis of Behavior, 6, 299-300. doi:10.1901/jeab.1963.6-299

Catania, A. C. (1963b). Concurrent performances: Reinforcement interaction and response independence. Journal of the Experimental Analysis of Behavior, 6, 253263. doi:10.1901/jeab.1963.6-253

Cates, G. L. (2005). A review of the effects of interspersing procedures on the stages of academic skill development. Journal of Behavioral Education, 14, 305-325. doi:10.1007/s10864-005-8652-8

Cates, G. L., \& Dalenberg, A. E. (2005). Effects of interspersing rate on student preferences for mathematics assignments. Journal of Behavioral Education, 14, 89-103. doi:10.1007/s10864-005-2704-y

Cates, G. L., \& Erkfritz, K. N. (2007). Effects of interspersing rates on students' performance on and preferences for mathematics assignments: Testing the discrete task completion hypothesis. Psychology in the Schools, 44, 615-625. doi:10.1002/pits.20251

Cates, G. L., \& Rhymer, K. N. (2003). Examining the relationship between mathematics anxiety and mathematics performance: An instructional hierarchy perspective. Journal of Behavioral Education, 12, 23-34. doi: 10.1023/A:1022318321416

Cates, G. L., \& Skinner, C. H. (2000). Getting remedial mathematics students to prefer homework with $20 \%$ and $40 \%$ more problems: An investigation of the strength of the interspersing procedure. Psychology in the Schools, 37, 339-347. doi:10.1002/1520-6807(200007)37:4<349::AID-PITS5>3.3.CO;2-Z

Cates, G. L., Skinner, C. H., Watkins, C. E., Rhymer, K. N., McNeill, B. S., \& McCurdy, M. (1999). Effects of interspersing additional brief math problems on student performance and perception of math assignments: Getting students to prefer to do more work. Journal of Behavioral Education, 9, 177-193. doi:10.1023/A:1022135514692

Cates, G. L., \& Erkfritz, K. N. (2007). Effects of interspersing rates on students' performance on and preferences for mathematics assignments: Testing the discrete task completion hypothesis. Psychology in the Schools, 44, 615-625. doi:10.1002/pits.20251

Cates, G. L., \& Rhymer, K. N. (2003). Examining the relationship between mathematics anxiety and mathematics performance: An instructional hierarchy perspective. Journal of Behavioral Education, 12, 23-34. doi:10.1023/A:1022318321416

Chung, S. H. \& Herrnstein, R. J. (1967). Choice and delay of reinforcement. Journal of the Experimental Analysis of Behavior, 10, 67-74. doi:10.1901/jeab.1967.10-67

Clark, S. L., \& Rhymer, K. N. (2003). Student preference for explicit timing and interspersal procedures as a function of math problem completion rates: Testing the discrete task completion hypothesis. Journal of Behavioral Education, 12, 
275-286. doi:10.1023/A:1025965707565

Cohen, J. (1992). A power primer. Psychological Bulletin, 112, 155-159. doi:10.1037//0033-2909.112.1.155

Cohen, J. (1988). Statistical power analysis for the behavioral sciences (2nd ed.). Hillsdale, NJ: Erlbaum.

Conger, R., \& Killeen, P. (1974). Use of concurrent operants in small group research: A demonstration. The Pacific Sociological Review, 17, 399-416. doi: $10.2307 / 1388548$

Daly, E. J., Martens, B. K., Barnett, D., Witt, J. C., \& Olson, S. C. (2007). Varying intervention delivery in response to intervention: Confronting and resolving challenges with measurement, instruction, and intensity. School Psychology Review, 36, 562-581. http://www.nasponline.org/publications/spr/index-list.aspx

Daly, E. J., Martens, B. K., Dool, E. J., \& Hintze, J. M. (1998). Using brief functional analysis to select interventions for oral reading. Journal of Behavioral Education, 8, 203-218. doi: 10.1023/A:1022835607985

DiPerna, J. C., Volpe, R. J., \& Elliot, S. N. (2002). A model of enablers and elementary reading/language arts achievement. School Psychology Review, 31, 298-312. http://www.nasponline.org/publications/spr/index-list.aspx

Dunlap, G., DePerczel, M., Clarke, S., Wilson, D., Wright, S., White, R., \& Gomez, A. (1994). Choice making to promote adaptive behavior for students with emotional and behavioral challenges. Journal of Applied Behavior Analysis, 27, 505-518. doi:10.1901/jaba.1994.27-505

Dunlap, G., \& Kern, L. (1996). Modifying instructional activities to promote desirable behavior: A conceptual and practical framework. School Psychology Quarterly, 11, 297-312. doi:10.1037/h0088936

Dunlap, G., Kern-Dunlap, L., Clarke, S., \& Robbins, F. R. (1991). Functional assessment, curricular revision, and severe behavior problems. Journal of Applied Behavior Analysis, 24, 387-397. doi:10.1901/jaba.1991.24-387

DuPaul, G. J., \& Stoner, G. (2003). ADHD in the schools: Assessment and intervention strategies (2nd ed.). New York: Guilford.

Dyer, K., Dunlap, G., \& Winterling, V. (1990). Effects of choice making on the serious problem behaviors of students with severe handicaps. Journal of Applied Behavior Analysis, 23, 515-524. doi:10.1901/jaba.1990.23-515

Fantino, E. (1967). Preference for mixed- versus fixed-ratio schedules. Journal of the Experimental Analysis of Behavior, 10, 35-43. doi:10.1901/jeab.1967.10-35

Fantino, E. (1968). Effects of required rates of responding upon choice. Journal of the Experimental Analysis of Behavior, 11, 15-22. doi:10.1901/jeab.1968.11-15

Fantino, E. (1969). Choice and rate of reinforcement. Journal of the Experimental Analysis of Behavior, 12, 723-730. doi:10.1901/jeab.1969.12-723

Fath, S. J., Fields, L., Malott, M. K., \& Grossett, D. (1983). Response rate, latency, and resistance to change. Journal of the Experimental Analysis of Behavior, 39, 267274. doi: 10.1901/jeab.1983.39-267

Faul, F., Erdfelder, E., Lang, A.-G., \& Buchner, A. (2007). G*Power 3: A flexible statistical power analysis program for the social, behavioral, and biomedical sciences. Behavior Research Methods, 39, 175-191. doi: 10.3758/BF03193146 
Foster, T. M., Matthews, L. R., Temple, W., Poling, A. (1997). Concurrent schedule performance in domestic goats: Persistent undermatching. Behavioral Processes, 40, 231-237. doi:10.1016/S0376-6357(97)00018-1

Foster, T. M., Temple, W., Robertson, B., Nair, V., \& Poling, A. (1996). Concurrentschedule performance in dairy cows: Persistent undermatching. Journal of the Experimental Analysis of Behavior, 65, 57-80. doi:10.1901/jeab.1996.65-57

Greenwood, C. R., Delquadri, J., \& Hall, R. V. (1984). Opportunity to respond and student academic performance. In W. Heward, T. Heron, D. Hill, \& J. Trap-Porter (Eds.), Behavior analysis in education (pp. 58-88). Columbus, $\mathrm{OH}$ : Merrill.

Greenwood, C. R., Horton, B. T., \& Utley, C. A. (2002). Academic engagement: Current perspectives on research and practice. School Psychology Review, 31, 328-349. http://www.nasponline.org/publications/spr/index-list.aspx

Greenwood, C. R., Terry, B., Marquis, J., \& Walker, D. (1994). Confirming a performance-based instructional model. School Psychology Review, 23, 625-668.

Haring, N. G., \& Eaton, M. D. (1978). Systematic instructional technology: An instructional hierarchy. In N. G. Haring, T. C. Lovitt, M. D. Eaton, \& C. L. Hansen (Eds.), The fourth R: Research in the classroom (pp. 23-40). Columbus, $\mathrm{OH}$ : Merrill.

Hawkins, J., Skinner, C. H., \& Oliver, R. (2005). The effects of task demands and additive interspersal ratios on fifth-grade students' mathematics accuracy. School Psychology Review, 34, 543-555. http://www.nasponline.org/publications/spr/index-list.aspx

Herrnstein, R. J. (1961). Relative and absolute strength of response as a function of frequency of reinforcement. Journal of the Experimental Analysis of Behavior, 4, 267-272. doi:10.1901/jeab.1961.4-267

Herrnstein, R. J. (1970). On the law of effect. Journal of the Experimental Analysis of Behavior, 13, 243-266. doi:10.1901/jeab.1970.13-243

Herrnstein, R. J. (1974). Formal properties of the matching law. Journal of the Experimental Analysis of Behavior, 21, 159-164. doi:10.1901/jeab.1974.21-159

Herrnstein, R. J., \& Heyman G. M. (1979). Is matching compatible with reinforcement maximization on concurrent variable interval, variable ratio? Journal of the Experimental Analysis of Behavior, 31, 209-223. doi:10.1901/jeab.1979.31-209

Heyman, G. M., \& Monaghan, M. M. (1994). Reinforcer magnitude (sucrose concentration) and the matching law theory of response strength. Journal of the Experimental Analysis of Behavior, 61, 505-516. doi:10.1901/jeab.1994.61-505

Horne, P. J., \& Lowe, C. F. (1993). Determinants of human performance on concurrent schedules. Journal of the Experimental Analysis of Behavior, 59, 29-60. doi:10.1901/jeab.1993.59-29

Jaspers, K. E., Skinner, C. H., Williams, R. L., \& Saecker, L. B. (2007). Effects of problem order on accuracy, preference, and choice of multiplication assignments. The Behavior Analyst Today, 8, 347-359. http://www.baojournal.com/BAT\%20Journal/BATissues.html

Johns, G. A., Skinner, C. H., \& Nail, G. L. (2000). Effects of interspersing briefer mathematics problems in assignment choice in students with learning disabilities. Journal of Behavioral Education, 10, 95-106. doi:10.1023/A:1016632012550 
Kangas, B. D., Berry, M. S., Cassidy, R. N., Dallery, J., Vaidya, M., \& Heckenberg, T., D. (2009). Concurrent performance in a three-alternative choice situation:

Response allocation in a Rock/Paper/Scissors game. Behavioral Processes, 82, 164-172. doi:10.1016/j.beproc.2009.06.004

Kern, L., Mantegna, M. E., Vorndran, C. M., Bailin, D., \& Hilt, A. (2001). Choice of task sequence to reduce problem behaviors. Journal of Positive Behavior Interventions, 3, 3-10. doi:10.1177/109830070100300102

Keselman, H.J., Algina, J., \& Kowalchuk, R.K. (2001). The analysis of repeated measures designs: A review. British Journal of Mathematical and Statistical Psychology, 54, 1-20. doi:10.1348/000711001159357

Kollins, S. H., Newland, M. C., \& Critchfield, T. S. (1997). Human sensitivity to reinforcement in operant choice: How much do consequences matter? Psychonomic Bulletin and Review, 4, 208-220. doi:10.3758/BF03209395

Lane, K. L., Smither, R., Huseman, R., Guffey, J., \& Fox, J. (2007). A function-based intervention to decrease disruptive behavior and increase academic engagement. Journal of Early and Intensive Behavior Intervention, 3-4, 348-364. http://www.baojournal.com/JEIBI/jeibi-index.html

Lee, D. L., Belfiore, P. J., Scheeler, M. C., Hua, Y., \& Smith, R. (2004). Behavioral momentum in academics: Using embedded high-p sequences to increase academic productivity. Psychology in the Schools, 41, 789-801. doi: 10.1002/pits. 20014

LeFevre, J. A., Kulak, A. G., \& Heymans, S. L. (1992). Factors influencing the selection of university majors varying in mathematical content. Canadian Journal of Behavioural Science, 24, 276-289. doi:10.1037/h0078742

Logan, P., \& Skinner, C. H. (1998). Improving students' perceptions of a mathematics assignment by increasing problem completion rates: Is problem completion a reinforcing event? School Psychology Quarterly, 13, 322-331. doi:10.1037/h0088988

MacDonall, J. S. (1988). Concurrent variable-ratio schedules: Implications for the generalized matching law. Journal of the Experimental Analysis of Behavior, 50, 55-64. doi:10.1901/jeab.1988.50-55

Mace, F. C., Hock, M. L., Lalli, J. S., West, B. J., Belfiore, P., Pinter, E., \& Brown, D. K. (1988). Behavioral momentum in the treatment of noncompliance. Journal of Applied Behavior Analysis, 21, 123-141. doi: 10.1901/jaba.1988.21-123

Mace, F. C., McCurdy, B., \& Quigley, E. A. (1990). A collateral effect of reward predicted by matching theory. Journal of Applied Behavior Analysis, 23, 197-205. doi:10.1901/jaba.1990.23-197

Mace, F. C., Neef, N. A., Shade, D., \& Mauro, B. C. (1994). Limited matching on concurrent-schedule reinforcement of academic behavior. Journal of Applied Behavior Analysis, 27, 585-596. doi:10.1901/jaba.1994.27-585

Mace, F. C., Neef, N. A., Shade, D., \& Mauro, B. C. (1996). Effects of problem difficulty and reinforcement quality on time allocated to concurrent arithmetic problems. Journal of Applied Behavior Analysis, 29, 11-24. doi:10.1901/jaba.1996.29-11

Martens, B. K., \& Houk, J. L. (1989). The application of Herrnstein's law of effect to disruptive and on-task behavior of a retarded adolescent girl. Journal of the 
Experimental Analysis of Behavior, 51, 17-27. doi:10.1901/jeab.1989.51-17

Martens, B. K., Lochner, D. G., \& Kelly, S. Q. (1992). The effects of variable-interval reinforcement on academic engagement: A demonstration of matching theory. Journal of Applied Behavior Analysis, 25, 143-151. doi:10.1901/jaba.1992.25-143

Matthews, L. R., \& Temple, W. (1979). Concurrent schedule assessment of preference in cows. Journal of the Experimental Analysis of Behavior, 32, 245-254. doi:10.1901/jeab.1979.32-245

McAdie, T. M., Foster, T. M., \& Temple, W. (1996). Concurrent schedules: Quantifying the aversiveness of noise. Journal of the Experimental Analysis of Behavior, 65, 37-55. doi:10.1901/jeab.1996.65-37

McCurdy, M., Skinner, C. H., Grantham, K., Watson, T. S. \& Hindman, P. M. (2001). Increasing on-task behavior in an elementary student during mathematics seatwork by interspersing additional brief problems. School Psychology Review, 30, 23-32. http://www.nasponline.org/publications/spr/index-list.aspx

McDonald, E., \& Ardoin, S. P. (2007). Interspersing easy math problems among challenging problems: Detection of interspersal effects in whole-class applications. Journal of Behavioral Education, 16, 342-354. doi:10.1007/s10864007-9046-X

McDowell, J. J. (1989). Two modern developments in matching theory. The Behavior Analyst, 12, 153-166. http://www.abainternational.org/journals/the-behavioranalyst.aspx

McSweeney, F. K., Farmer, V. A., Dougan, J. D., \& Whipple, J. E. (1986). The generalized matching law as a description of multiple-schedule responding. Journal of the Experimental Analysis of Behavior, 45, 83-101. doi:10.1901/jeab.1986.45-83

Mischel, W., Shoda, Y., \& Mendoza-Denton, R. (2002). Situation-behavior profiles as a locus of consistency in personality. Current Directions in Psychological Science, 11, 50-54. doi:10.1111/1467-8721.00166

Montarello, S., \& Martens, B. K. (2005). Effects of interspersed brief problems on students' endurance at completing math work. Journal of Behavioral Education, 14, 249-266. doi:10.1007/s10864-005-8649-3

Murray, L. K., \& Collins, S. H. (2000). Effects of methylphenidate on sensitivity to reinforcement in children diagnosed with attention deficit hyperactivity disorder: An application of the matching law. Journal of Applied Behavior Analysis, 33, 573-591. doi:10.1901/jaba.2000.33-573

Neef, N. A., Mace, F. C., Shea, M. C., \& Shade, D. (1992). Effects of reinforce rate and reinforce quality on time allocation: Extensions of matching theory to educational settings. Journal of Applied Behavior Analysis, 25, 691-699. doi:10.1901/jaba.1992.25-691

Neef, N. A., Mace, M. C., \& Shade, D. (1993). Impulsivity in students with serious emotional disturbance: The interactive effects of reinforce rate, delay, and quality. Journal of Applied Behavior Analysis, 26, 37-52. doi:10.1901/jaba.1993.26-37

Neef, N. A., Shade, D., \& Miller, M. S. (1994). Assessing influential dimensions of reinforcers on choice in students with serious emotional disturbance. Journal of Applied Behavior Analysis, 27, 575-583. doi:10.1901/jaba.1994.27-575 
Nevin, J. A. (1974). Response strength in multiple schedules. Journal of the Experimental Analysis of Behavior, 21, 389-408. doi: 10.1901/jeab.1974.21-389

Nevin, J. A. (1992). An integrative model for the study of behavioral momentum. Journal of the Experimental Analysis of Behavior, 57, 301-316. doi: 10.1901/jeab.1992.57-301

Nevin, J. A., Mendell, C., Atak, J. R. (1983). The analysis of behavioral momentum. Journal of the Experimental Analysis of Behavior, 39, 49-59. doi: 10.1901/jeab.1983.39-49

Patel, M., Reed, G. K., Piazza, C. C., Mueller, M., Bachmeyer, M. H., \& Layer, S. A. (2007). Use of a high-probability instructional sequence to increase compliance to feeding demands in the absence of escape extinction. Behavioral Interventions, 22, 305-310. doi: 10.1002/bin.251

Plaud, J. J. (1992). The prediction and control of behavior revisited: A review of the matching law. Journal of Behavioral Therapy and Experimental Psychiatry, 23, 25-31. doi:10.1016/0005-7916(92)90021-A

Poling, A., Edwards, T. L., Weeden, M., \& Foster, T. M. (2011). The matching law. The Psychological Record, 61, 313-322. http://opensiuc.lib.siu.edu/tpr/

Poncy, B. C., Skinner, C. H., \& Jaspers, K. E. (2007). Evaluating and comparing interventions designed to enhance math fact accuracy and fluency: Cover, copy, and compare versus taped problems. Journal of Behavioral Education, 16, 27-37. doi:10.1007/s10864-006-9025-7

Reed, D. D., Critchfield, T. S., \& Martens, B. K. (2006). The generalized matching law in elite sport competition: Football play calling as operant choice. Journal of Applied Behavior Analysis, 39, 281-297. doi:10.1901/jaba.2006.146-05

Reed, D. D., \& Martens, B. K. (2008). Sensitivity and bias under conditions of equal and unequal academic task difficulty. Journal of Applied Behavior Analysis, 41, 3952. doi:10.1901/jaba.2008.41-39

Reynolds, G. S. (1963). On some determinants of choice in pigeons. Journal of the Experimental Analysis of Behavior, 6, 53-59. doi:10.1901/jeab.1963.6-53

Rhymer, K. N., \& Cates, G. L. (2006). Student performance and preferences for mathematics word problems: An investigation of the effects of explicit timing and interspersing procedures. School Psychology Quarterly, 21, 34-45. doi:10.1521/scpq.2006.21.1.34

Rhymer, K. N., \& Morgan, S. K. (2005). Comparison of the explicit timing and interspersal interventions: Analysis of problem completion rates, student preference, and teacher acceptability. Journal of Behavioral Education, 14, 283 303. doi:10.1007/s10864-005-8651-9

Robinson, S. L., \& Skinner, C. H. (2002). Interspersing additional easier items to enhance mathematics performance on subtests requiring different task demands. School Psychology Quarterly, 17, 191-205. doi:10.1521/scpq.17.2.191.20858

Rock, M. L. (2005). Use of strategic self-monitoring to enhance academic engagement, productivity, and accuracy of students with and without exceptionalities. Journal of Positive Behavior Interventions, 7, 3-17. doi:10.1177/10983007050070010201

Schroeder, S. R., \& Holland, J. G. (1969). Reinforcement of eye movement with concurrent schedules. Journal of the Experimental Analysis of Behavior, 12, 897- 
903. doi:10.1901/jeab.1969.12-897

Shriver M. D., \& Kramer, J. J. (1997). Application of the generalized matching law for description of student behavior in the classroom. Journal of Behavioral Education, 7, 131-149. doi:10.1023/A:1022884823529

Skinner, C. H. (2002). An experimental analysis of interspersal research evidence, implications, and applications of the discrete task completion hypothesis. Journal of School Psychology, 40, 347-368. doi:10.1016/S0022-4405(02)00101-2

Skinner, C. H., Fletcher, P. A., Wildmon, M., \& Belfiore, P. J. (1996). Improving assignment preference through interspersing additional problems: Brief versus easy problems. Journal of Behavioral Education, 6, 427-436. doi:10.1007/BF02110515

Skinner, C. H., Hall-Johnson, K., Skinner, A. L., Cates, G., Weber, J., \& Johns, G. A. (1999). Enhancing perceptions of mathematics assignments by increasing relative problem completion rates through the interspersing technique. The Journal of Experimental Education, 68, 43-59. doi:10.1080/00220979909598493

Skinner, C. H., Hurst, K. L., Teeple, D. P., \& Meadows, S. O. (2002). Increasing on-task behavior during mathematics independent seat-work in students with emotional disturbance by interspersing additional brief problems. Psychology in the Schools, 19, 647-659. doi:10.1002/pits.10058

Skinner, C. H., Pappas, D. N., \& Davis, K. A. (2005). Enhancing academic engagement: Providing opportunities for responding and influencing students to choose to respond. Psychology in the Schools, 42, 389-403. doi:10.1002/pits.20065

Skinner, C. H., Robinson, S. L., Johns, G. A., Logan, P., \& Belfiore, P. J. (1996). Applying Herrnstein's matching law to influence students' choice to complete difficult academic tasks. The Journal of Experimental Education, 65, 5-17. doi:10.1080/00220973.1996.9943460

Stilling, S. T., \& Critchfield, T. S. (2010). The matching relation and situation-specific bias modulation in professional football play selection. Journal of the Experimental Analysis of Behavior, 93, 435-454. doi:10.1901/jeab.2010.93-435

Thorne, S., Kamps, D. (2008). The effects of a group contingency intervention on academic engagement and problem behavior of at-risk students. Behavior Analysis in Practice, 1, 12-18. http://www.abainternational.org/journals/behavioranalysis-in-practice.aspx

Todorov, J. C., Castro, J. M., Hanna, E. S., Bittencourt de Sa, M. C. N., \& Barreto, M. de Q. (1983). Choice, experience, and the generalized matching law. Journal of the Experimental Analysis of Behavior, 40, 99-111. doi:10.1901/jeab.1983.40-99

Vile Junod, R. E., DuPaul, G. J., Jitendra, A. K., Volpe, R. J., \& Cleary, K. S. (2006). Classroom observations of students with and without ADHD: Differences across types of engagement. Journal of School Psychology, 44, 87-104. doi:10.1016/j.jsp.2005.12.004

Vollmer, T. R., \& Bourret, J. (2000). An application of the matching law to evaluate the allocation of two- and three-point shots by college basketball players. Journal of Applied Behavior Analysis, 33, 137-150. doi:10.1901/jaba.2000.33-137

Von Mizener, B. H., \& Williams, R. L. (2009). The effects of student choices on academic performance. Journal of Positive Behavior Interventions, 11, 110-128. 
doi: $10.1177 / 1098300708323372$

Wallace, M. A., Cox, E. A., \& Skinner, C. H. (2003). Increasing independent seatwork: Breaking large assignments into smaller assignments and teaching a student with retardation to recruit reinforcement. School Psychology Review, 32, 132-142. http://www.nasponline.org/publications/spr/index-list.aspx

Wilber, A., \& Cushman, T. P. (2006). Selecting effective academic interventions: An example using brief experimental analysis for oral reading. Psychology in the Schools, 43, 79-84. doi: 10.1002/pits.20131

Wildmon, M. E., Skinner, C. H., McCurdy, M., \& Sims, S. (1999). Improving secondary students' perception of the "dreaded mathematics word problem assignment" by giving them more word problems. Psychology in the Schools, 36, 319-325. doi:10.1002/(SICI)1520-6807(199907)36:4<319::AID-PITS5>3.3.CO;2-K

Wildmon, M. E., Skinner, C. H., \& McDade, A. (1998). Interspersing additional brief, easy problems to increase assignment preference on mathematics reading problems. Journal of Behavioral Education, 8, 337-346. doi:10.1023/A:1022823314635

Wildmon, M. E., Skinner, C. H., Watson, T. S., \& Garrett, L. S. (2004). Enhancing assignment perceptions in students with mathematics learning disabilities by including more work: An extension of interspersal research. School Psychology Quarterly, 19, 106-120. doi:10.1521/scpq.19.2.106.33310

Woolverton, W. L., \& Alling, K. (1999). Choice under concurrent VI schedules: Comparison of behavior maintained by cocaine or food. Psychopharmacology, 141, 47-56. doi:10.1007/s002130050805 
APPENDIX A

INFORMED CONSENT 
This letter is to obtain your consent to participate in a research study in mathematics.

From this study we expect to gain information about how mathematics assignments affect students' performance and how to match up assignments with students choices.

Participation in this study is unlikely to result in any risk to you beyond that of working on several mathematics worksheets. You are free to withdraw from participation at any time. The Institutional Review Board at Illinois State University has already approved this study before asking you to participate.

You will be asked to work on mathematics assignments and answer questions about what you thought of the assignments. Your performance and answers will be kept strictly confidential. To ensure this, your name will not be asked, and there will be no way to associate your name with your performance.

We will also be video recording as you work on these mathematics assignments. Although your full facial features will be visible and recorded, we will not identify you on the video recording with your name. Although you might be identifiable by having your full facial features recorded, this recording will be used solely by the researchers for data analysis and will be kept as a data file on a password-protected computer. The video recording will not be available to the public for viewing.

The study will require about 60 minutes of your time. You are free to withdraw from participation at any time without any kind of penalty. For your participation in the study you will receive one half extra credit point for every 30 minutes of your participation time (a total of one extra credit point).

If you have questions regarding this study, please contact Gary L. Cates, Ph.D. at (309) 483-3123 or glcates@ilstu.edu. You may also contact the Research Ethics \& Compliance Office via phone (309) 438-2529 or email rec@ilstu.edu to learn about the protection of human participants in university research. (You are entitled to receive a copy of this consent form if you wish. Please ask the experimenter.)

I verify that I am at least 18 years of age and voluntarily consent to participate in the research described above.

Yes No 
APPENDIX B

\section{PSYCHOLOGY DEPARTMENT RESEARCH}

PARTICIPATION FORM 
RESEARCH PARTICIPATION OPPORTUNITY

ILLINOIS STATE UNIVERSITY DEPARTMENT OF PSYCHOLOGY

\begin{tabular}{|c|c|}
\hline \multirow[t]{2}{*}{$\begin{array}{l}\text { STUDY } \\
\text { CODE }\end{array}$} & \begin{tabular}{|l|l|} 
SUPERVISING & Cates \\
FACULTY & \\
MEMBER &
\end{tabular} \\
\hline & $\begin{array}{ll}\text { SUPERVISOR'S } & 309-438-3123 \\
\text { PHONE } & \\
\text { NUMBER } & \end{array}$ \\
\hline LOCATION OF STUDY & \begin{tabular}{|l} 
RRB \\
REGISTRATION \\
NUMBER
\end{tabular} \\
\hline & $\mid \begin{array}{l}\text { IRB } \\
\text { APPROVAL } \\
\text { EXPIRES }\end{array}$ \\
\hline $\begin{array}{l}\text { Amount of Volunteer's Time } \\
\text { Required } \\
\qquad 1.5 \text { hours } \\
\square \\
\square 2 \text { hour } \\
\square \text { Other: }\end{array}$ & $\begin{array}{l}\text { If you have questions about this } \\
\text { study, please call } \\
\text { Dr. Cates } 309-438-3123\end{array}$ \\
\hline
\end{tabular}

\section{Instructions to Volunteers}

1. Read the Special Instructions and Requirements below to make sure you qualify for this study.

2. If you qualify, fill in the information requested on the sign-up sheet(s) below.

3. Make a note of the date, time, and location of your appointment. If a Reminder Stub is provided, tear it off and bring it with you to your appointment. 4. Please arrive promptly to your appointment. Please contact the researcher 24 hours in advance if you cannot keep your appointment.

5 . The researcher is required to meet you promptly at the time scheduled. If no researcher arrives within 15 minutes of your appointment time, you are entitled to participation credit. Contact the study's Supervising Faculty Member (above).

6. The study's Supervising Faculty Member can answer any questions you may have about the study.

SPECIAL RULES AND REQUIREMENTS: 


\section{APPENDIX C \\ RESEARCH PARTICIPATION}

SIGN-UP SHEET 


\begin{tabular}{|l|l|}
\hline Study & Supervising \\
Code & Faculty Member \\
& $\begin{array}{l}\text { Supervisor's } \\
\text { Telephone } \\
\text { Number }\end{array}$ \\
\hline Location & \\
\hline & IRB registration \\
\hline
\end{tabular}

\section{Illinois State University Department of Psychology Research Sign-Up Form}

Day Date Time PRINT Your Name Phone Instructor Course $\begin{gathered}\text { Course } \\ \text { Days/time }\end{gathered}$

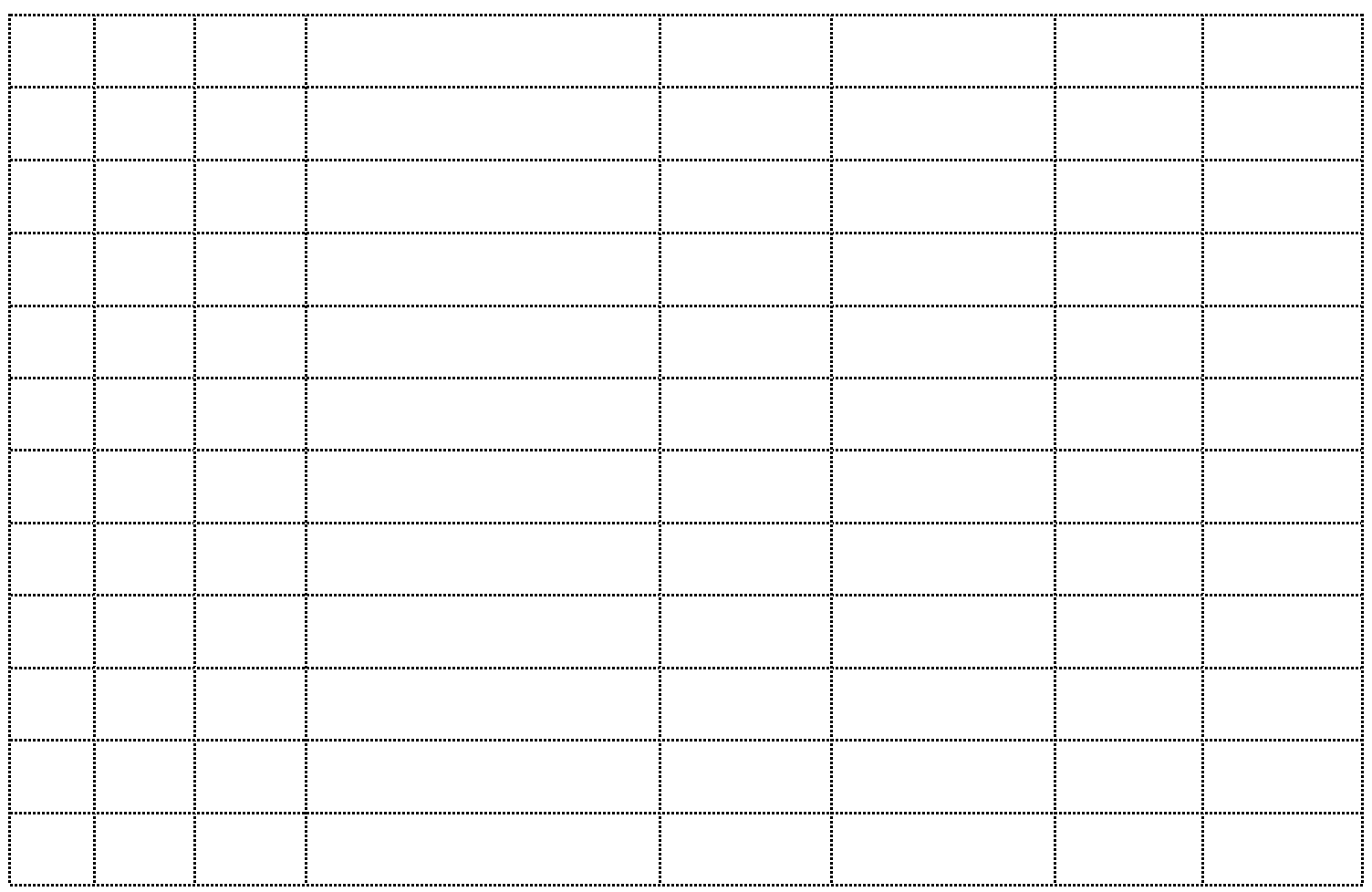


APPENDIX D

DEMOGRAPHIC FORM 


\section{Please provide the following information}

Age:

Sex:

Academic year

(e.g., Freshman):

Major:

**Do not turn to the next page until instructed**
Race/Ethnicity (please check one):

$\square$ American Indian or Alaska Native

$\square$ Asian

$\square$ Black or African American

$\square$ Hispanic-Latino

$\square$ Native Hawaiian - Other

Pacific Islander

$\square$ White 
APPENDIX E

\section{MATH ASSIGNMENT PREFERENCE \\ QUESTIONNAIRE}


1. Which assignment would require more time to complete from start to finish? L M

2. Which assignment would require more effort to complete from start to finish? L M

$\begin{array}{lll}\text { 3. Which assignment was more difficult? } & \text { L } & \text { M }\end{array}$

$\begin{array}{lll}\text { 4. Which assignment would you choose for homework? } & \text { L } & \text { M }\end{array}$ 
APPENDIX F

\section{DEBRIEFING STATEMENT}


As you have been made aware before the study, the purpose was to look at student choices for mathematics assignments. To tell you a bit more, we were really examining whether completing assignments with differing amounts of brief problems mixed among longer problems changed your choices across assignment pairs. We will also be examining whether completing these assignments accounts for different levels of academic on-task performance. Anonymous results for all participants as a group can be obtained from Gary L. Cates, PhD. In no way will your performance be made public in a manner that will jeopardize anonymity. Data will be kept for 5 years and then shredded. For further information please contact Dr. Cates by calling (309) 438-3123 or e-mail glcates@ilstu.edu.

Thank you for your participation,

Gary L. Cates, Ph.D., NCSP

Associate Professor of Psychology

School Psychology

Illinois State University

Kiley Bliss, B.A.

Advanced Doctoral Student

School Psychology

Illinois State University 
APPENDIX G

\section{REINFORCEMENT HISTORY QUESTIONNAIRE}


Out of the math assignments you recall completing, what percent of the time did each of the following occur (Please provide a percent number):

Time away from working on math (e.g., early dismissal from a class or assignment, a day without homework, etc.)

An undesirable outcome (e.g., a bad grade, reprimand, or extra homework)

Loss of privileges (e.g., "grounding," forced time away from friends, detention, being sent to the principal's office)

A desirable outcome (e.g., a good grade, praise, permission to do a special activity, etc.)

[TOTAL SHOULD ADD UP TO 100\%] 
APPENDIX H

MATH ASSIGNMENT: 0:1 RATIO EXPERIMENTAL

WORKSHEET 
67

$\underline{\times 78}$

76

X95

98

X56

67

X56

$77 \quad 99$

X89 $\quad \underline{X 85}$
59

X87

69

X86

56

X 87

X99

\begin{tabular}{rr}
68 & 98 \\
$\times 58$ & $\times 67$ \\
\hline
\end{tabular}

59

$\mathrm{X} 76$ 
APPENDIX I

MATH ASSIGNMENT: 0:1 RATIO CONTROL

WORKSHEET 
86

X 77

56

X79

88

X65

76

X65

89

X59
89

96

X75

X68

75

X 86

76

X89

67

X95

98

X77
68

X59

69

X95 
APPENDIX J

MATH ASSIGNMENT: 1:3 RATIO EXPERIMENTAL

WORKSHEET 


$\underline{\times 75} \quad \underline{x 68} \quad \underline{\mathrm{x}}$

\begin{tabular}{rr}
57 & 2 \\
$\times 85$ & $\times 2$ \\
\hline
\end{tabular}

\begin{tabular}{rrr}
58 & 76 & 1 \\
$\times 77$ & $\times 95$ & $\times 1$ \\
\hline
\end{tabular}

\begin{tabular}{rrr}
97 & 68 & 3 \\
$\times 55$ & $\underline{999}$ & $\underline{2}$ \\
\hline
\end{tabular}


APPENDIX K

MATH ASSIGNMENT: 1:3 RATIO CONTROL

WORKSHEET 


\begin{tabular}{rrr}
59 & 57 & 78 \\
$\times 98$ & $\times 78$ & $\times 66$ \\
\hline
\end{tabular}

58

x95

98

$\underline{\mathrm{x} 67}$

75

$\times 87$
69

$\times 57$
55

×69

57

x99 
APPENDIX L

MATH ASSIGNMENT: 2:1 RATIO EXPERIMENTAL

WORKSHEET 


\begin{tabular}{|c|c|c|c|c|c|}
\hline & 1 & 3 & 97 & & 2 \\
\hline & $\underline{\mathrm{x} 1}$ & $\underline{\times 3}$ & $\underline{\times 55}$ & & $\underline{x 1}$ \\
\hline 2 & & & 58 & 1 & \\
\hline$\underline{x 2}$ & & & $\underline{\times 77}$ & $\underline{\mathrm{x} 4}$ & \\
\hline & 2 & 66 & 3 & 1 & \\
\hline & $\underline{\times 3}$ & $\times 57$ & $\underline{x 4}$ & $\underline{x 2}$ & \\
\hline 68 & & & 4 & 3 & 76 \\
\hline$\times 99$ & & & $\underline{x 1}$ & $\underline{\mathrm{x} 1}$ & $\underline{\times 95}$ \\
\hline & 2 & & 3 & 57 & 3 \\
\hline & $\underline{x 2}$ & & $\underline{x} 2$ & $\times 85$ & $\underline{\times 4}$ \\
\hline 3 & & 97 & 4 & 1 & \\
\hline$\underline{\times 3}$ & & $\underline{\mathrm{x} 88}$ & $\underline{\mathrm{x} 1}$ & $\underline{x 1}$ & \\
\hline & 97 & 1 & & 2 & 79 \\
\hline & $\begin{array}{r}\times 59 \\
\end{array}$ & $\mathrm{x} 3$ & & $\mathrm{x} 2$ & $\underline{x 86}$ \\
\hline & 4 & 2 & 65 & 4 & 2 \\
\hline & $\underline{x}$ & $\times 3$ & $\times 95$ & x3 & $\underline{x} 1$ \\
\hline
\end{tabular}




\begin{tabular}{|c|c|c|c|c|c|}
\hline 89 & 3 & 2 & & 55 & \\
\hline$\times 66$ & $\underline{x 2}$ & $\underline{x 4}$ & & x89 & \\
\hline 1 & & & 3 & 87 & 3 \\
\hline$\underline{x 1}$ & & & $\mathrm{x} 4$ & $\mathrm{x} 75$ & $\underline{x 1}$ \\
\hline & & 1 & 67 & 2 & \\
\hline & & $\mathrm{x} 2$ & x68 & $\underline{x} 2$ & \\
\hline
\end{tabular}

$\begin{array}{r}2 \\ \times 3 \\ \hline\end{array}$

$\times 58$ 
APPENDIX M

MATH ASSIGNMENT: 2:1 RATIO CONTROL

WORKSHEET 


\begin{tabular}{rr}
89 & 57 \\
$\times 78$ \\
$\times 999$ \\
\hline
\end{tabular}

$98 \quad 55$

$\underline{x 67} \quad \underline{x 69}$ 
APPENDIX N

PROCEDURAL PROTOCOL 


\section{Materials needed:}

\section{- Camera}

\section{- Timer/stopwatch}

\section{- Blue cards}

- Pencils

- Informed consent forms

- Packets for study 1

- A debriefing statement form

\section{Procedures}

1. Set up camera

2. Pass out pencils and informed consent and have participants sign

3. Pass out packets to those who choose to participate (as indicated by informed consent form)

4. Have participants complete demographics form

5. Have participants complete math questionnaire (instruct participants not to turn pages ahead in packet until instructed)

6. Read and demonstrate instructions (use random copy of assignment) for math worksheet

7. Ask if any questions; begin recording with camera

8. Instruct participants to turn page and begin working; begin timing for $4 \mathrm{~min}$.

9. At the end of four minutes instruct participants to stop, put pencils down; stop camera recording

10. Repeat instructions for next assignment 
11. Ask if any questions; begin recording with camera

12. Instruct participants to turn page and begin working; begin timing for 4 min.

13. At the end of four minutes instruct participants to stop, put pencils down; stop camera recording

14. Instruct participants to turn page and have them complete the 4 questions regarding the worksheets they just completed by circling L or M

a. Tell participants that they may glance at the assignments again to determine the order in which they completed assignments (i.e., $\mathrm{L}$ or $\mathrm{M}$ first)

15. Repeat steps $6-14$ for the next 2 assignment pairs

16. After participants have completed the questions for the last assignment pair, read debriefing statement.

17. Ask if any questions or clarification needed; hand out blue cards/dismiss participants. 
APPENDIX O

PROCEDURAL SCRIPT 


\section{Script}

As you hand out a consent form and pencil to each participant upon entering "Please read carefully the consent form and indicate your willingness to participate by checking either 'Yes' or 'No' at the bottom of the form, followed by your signature and today's date."

\section{After all participants completed consent forms and received a packet}

"Please begin by filling out the front page of your packet. Do not turn the page until we tell you."

\section{When all participants have filled out the demographics form}

"Please turn to the next page in your packet. We would like you to fill out a form regarding your recent experiences with completing math assignments. Please indicate the number of times within the last 100 math assignments each of the listed instances have occurred. Provide the number on the line next to each response item."

\section{When all participants have completed the reinforcement history questionnaire}

"Please put your pencils down and listen and watch as we explain today's procedures. We will ask you to complete as many problems as you can on some math assignments. Please work all of the problems on each page in order from left to right as quickly as possible, without skipping problems or making errors, starting with the first problem on the top left. When you have finished all of the problems on the first line, begin working on the next problem on the next line. If you finish the assignment before we tell you to stop, please put your pencil down and sit quietly without looking ahead in your packet. Any questions? Ready, begin.”

\section{When 4 min. is up}


"Stop and please put your pencils down. When we tell you to turn to the next page, please work all of the problems in order from left to right as quickly as possible, without skipping problems or making errors, starting with the first problem on the top left. When you finish all of the problems on the first line, begin working on the next problem on the next line. If you finish the assignment before we tell you to stop, please put your pencil down and sit quietly without looking ahead in your packet. Any questions? Ready, begin."

\section{When 4 min. is up}

"Stop and please put your pencils down. Turn to the next page in your packet. You will see four questions regarding the two assignments you just completed. Please read each question carefully and answer by circling either L or M. If needed you may glance back at the top right-hand corner of both assignments (demonstrate) to help you remember the order in which you completed the assignments."

\section{Repeat the above instructions for both of the remaining assignment pairs}

\section{When participants have completed the questionnaire for the last assignment pair}

"Please put your pencils down and listen as we tell you a little bit more about the experiment (read debriefing statement aloud).”

"Are there any questions? Thank you for participating." 
APPENDIX P

TRAINING FIDELITY CHECKLIST 


\section{Training Fidelity Checklist}

Researcher:

Observer:

Study \#:

Date:

Session number Integrity observer:

Steps Observed

1. Researcher is prepared with necessary materials (e.g., correct packets, pencils, blue cards, etc.)

2. Set up camera

3. Present consent form and pencil to each participant

4. Participants instructed to complete demographics form and math questionnaire

5. Researcher reads aloud and demonstrates instructions prior to each math assignment

6. Researcher begins camera recording for each assignment prior to instructing participants to begin working

7. Instruct participants to begin each assignment and start timing 4 min.

8. At the end of $4 \mathrm{~min}$., for each assignment, stop timer, instruct participants to put pencils down, and stop camera recording

9. Instruct participants to turn page and complete 4 questions; mention they can look back to recall letters on assignments

10. After questions for last assignment, read debriefing statement aloud

11. Hand out blue cards and dismiss participants

\begin{tabular}{|l|l|l|}
\hline Yes & \multicolumn{1}{l}{ No } & N/A \\
\hline & & \\
\hline & & \\
\hline & & \\
\hline & & \\
\hline & & \\
\hline & & \\
\hline & & \\
\hline & & \\
\hline & & \\
\hline & & \\
\hline
\end{tabular}

